\title{
Geothermal Heat Flux at the COST B-2 and B-3 Wells, U. S. Atlantic Continental Margin
}

by

B. Della Vedova

R. P. Von Herzen

Woods Hole Oceanographic Institution
Woods Hole, Massachusetts 02543

July 1987

\section{Technical Report}

Reproduction in whole or in part is permitted for any purpose of the United States Government. This report should be cited as:

Woods Hole Oceanog. Inst. Tech. Rept., WHOI-87-27.

Approved for publication; distribution unlimited.

Approved for Distribution:

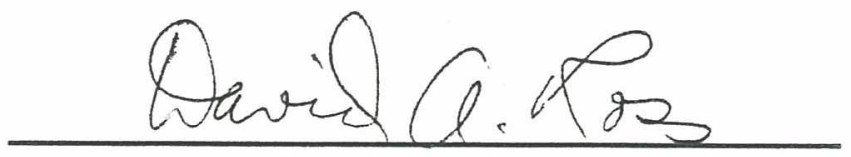

David A. Ross, Chairman

Department of Geology \& Geophysics 



\section{Geothermal Heat Flux at the COST B-2 and B-3 Wells, U.S. Atlantic Continental Margin \\ by}

B. De11a Vedova*

R. P. Von Herzen

Woods Hole Oceanographic Institution Woods Hole, MA 02543

* Permanent address:

Istituto di Miniere e Geofisica Applicata Università degli Studi di Trieste

34123 Trieste, Italy 

TABLE OF CONTENTS

Page No.

LIST OF FIGURES

LIST OF TABLES $\quad 4$

ABSTRACT

$\begin{array}{ll}\text { 1. INTRODUCTION } & 7\end{array}$

2. GEOLOGICAL SETTING 9

3. COST B-2 AND COST B-3 DATA SET 14

4. LABORATORY MEASUREMENTS AND DATA PROCESSING 14

4.1 SAMPLE PREPARATION 17

4.2 SAMPLES POROSITY AND DENSITY COMPUTATION 18

4.3 THERMAL CONDUCTIVITY MEASUREMENTS 18

4.4 QUARTZ CONTENT EVALUATION 22

4.5 LITHOLOGY DISTRIBUTION AND IN SITU POROSITY ESTIMATE 27

4.6 MEAN IN SITU THERMAL CONDUCTIVITY AND ANISOTROPY
CORRECTION

4.7 ESTIMATION OF THERMAL CONDUCTIVITY FROM WELL LOGS 36

4.8 EQUILIBRIUM TEMPERATURES AND- THERMAL GRADIENTS 36

5. CALCULATION OF HEAT FLUX 38

5.1 RADIOACTIVE HEAT PRODUCTION IN SEDIMENTS 38

a) U, Th Determinations By Neutron Activation 46

b) Potassium Analysis Through Atomic Absorption Spectrophotometry $\quad 46$

c) ${ }^{40} \mathrm{~K} \gamma$-Ray Spectrometer Analysis 49

d) Heat Production Evaluation 52

5.2 CORRECTION FOR THERMAL BLANKETING AND HEAT FLUX FROM
THE LITHOSPHERE

6. DISCUSSION AND CONCLUSIONS 58

6.1 SAMPLES TREATMENT AND LABORATORY MEASUREMENTS 60

6.2 WELL LOG ANALYSES $\quad 61$

6.3 HEAT FLOW ESTIMATE $\quad 62$

6.4 INTERNAL HEAT PRODUCTION AND THERMAL BLANKETING EFFECT 62

$\begin{array}{ll}\text { REFERENCES } & 65\end{array}$

$\begin{array}{ll}\text { ACKNOWLEDGMENTS } & 72\end{array}$

APPENDIX A. ANALYSIS OF SAMPLES QUARTZ CONTENT

B. ANALYSIS OF SAMPLES POTASSIUM CONTENT 78 


\section{LIST OF FIGURES}

Page No.

Fig. 1. Map of COST B-2 and B-3 sites 8

Fig. 2. Block diagram of procedures to evaluate heat flow 10

Fig. 3. Cross section of U.S. Atlantic margin. 11

Fig. 4. Geoid and gravity observed and computed for simplified structure of margin off New Jersey.

Fig. 5. Block diagram of procedures to determine in situ thermal conductivity from drill chip samples.

Fig. 6. Quartz content, paleobathymetry, and sedimentation rate vs. depth for $\operatorname{COST} B-2 / B-3$ wells.

Fig. 7. Correlation of quartz content with solid fraction thermal conductivity $\mathrm{K}_{\mathrm{s}}$ of samples.

Fig. 8. Comparison of measured and calculated thermal conductivity of samples.

Fig. 9. Lithologies vs. depth at COST B-2 well.

Fig. 10. Porosity vs. depth for various lithologies of COST B-2 we11.

Fig. 11. Acoustic velocities, estimated and calculated thermal conductivity vs. depth at COST B-2 we11.

Fig. 12. Plot to estimate equilibrium temperatures from measured bottom hole temperatures, COST B-2 we11.

Fig. 13. Plot to estimate equilibrium temperatures from measured bottom hole temperatures, COST B-3 well.

Fig. 14. Temperatures, thermal gradients, thermal conductivity, and heat flow vs. depth, COST B-2 we11.

Fig. 15. Temperatures, thermal gradients, thermal conductivity, and heat flow vs. depth, COST B-3 we11.

Fig. 16. Correlation of potassium content and thermal conductivity of the solid fraction $K_{s}$ of samples.

Fig. 17. Comparison of potassium content of samples

Fig. 18. Cross plots of Uranium Thorium, and Potassium measured on samples.

Fig. 19. Correlation of heat production and thermal conductivity of the solid fractions sorted from samples. 
Fig. 20. Sediment accumulation and calculated effect on heat flow with time at $\operatorname{COST} \mathrm{B}-2 / \mathrm{B}-3$ we11s.

List of Figures for the Appendices

Fig. A-1. Calibration of quartz standard from height of diffraction peak.

Fig. A-2. Calibration of quartz standard from area under diffraction peak.

Fig. A-3. X-ray diffractograms of various 1ithologies

Fig. B-1. Calibration of atomic absorption instrumentation with potassium standards. 


\section{LIST OF TABLES}

Page No.

Table 1. List of depth intervals of original drill cuttings

samples for COST B-2 well.

Table 2. List of depth intervals of original drill cuttings

samples for COST B-3 well.

Table 3. Summary of drill cuttings samples used for thermal conductivity measurements.

Table 4. List of COST B-2 and COST B-3 sample measurements.

Table 5. Summary of thermal conductivity of various 1ithologies at zero porosity $\left(\mathrm{K}_{\mathrm{s}}\right)$.

Table 6. COST B-3 1ithology in $1000 \mathrm{ft.}(304.8 \mathrm{~m})$ intervals.

Table 7. Mean porosities of COST B-2 1ithologies at $1000 \mathrm{ft}$. (304.8m) depth intervals.

Table 8. COST B-2 Calculated mean thermal conductivity for various lithologies at $1000 \mathrm{ft} .(304.8 \mathrm{~m})$ depth intervals.

Table 9. COST B-3 Calculated mean thermal conductivity for various lithologies at $1000 \mathrm{ft} .(304.8 \mathrm{~m})$ depth intervals.

Table 10. Summary of temperature measurements, COST B-2.

Table 11. Summary of temperature measurements, COST B-3.

Table 12. Summary of geothermal data averaged over vertical intervals.

Table 13. Ranges of matrix thermal conductivity $\left(\mathrm{K}_{\mathrm{s}}\right)$, quartz content, and potassium content for COST B-2/B-3 lithologies.

Table 14. U, Th, Potassium content and heat production of primary lithologies.

Table 15. Calculated radiogenic heat production over vertical

intervals.

Table 16. Heat flow summary. 


\section{ABSTRACT}

Heat flow estimates at two sites on the U.S. Atlantic continental margin are presented. An estimate of the heat flowing from the basement also has been obtained. About $4.8 \mathrm{~km}$ of sediments penetrated at the COST B-2 and 4.0 $\mathrm{km}$ at the COST B-3 were deposited since the Upper Jurassic. Wel1 logs were used to evaluate thermal gradients and sedimentation rates, whereas thermal conductivities and radiogenic heat productions were measured on drill cuttings samples.

A procedure to estimate in-situ thermal conductivity from drill cuttings and well logs is described. A substantial set of samples, in the form of drill cuttings, were sorted in four major lithologies: sandstones, siltstones, shales and limestones. Laboratory measurements of density, porosity, thermal conductivity, quartz (\%), potassium (\%), uranium (ppm) and thorium (ppm) were performed on 128 reorganized and pulverized samples. A significant correlation of the matrix thermal conductivity to quartz and potassium content was found. In situ porosity and volume fraction of each lithology, determined mainly from well logs, were used to calculate in situ mean thermal conductivity. Finally the mean in situ vertical component of the thermal conductivity, as required for heat flow values, has been estimated from a correction factor for the anisotropy of each lithology. The in-situ temperature and anisotropy effects substantially decrease estimates of thermal conductivity at depth.

Below the uppermost $1 \mathrm{~km}$ in both wells the best estimate of the therma1

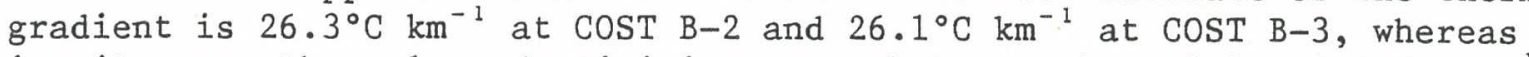
in situ mean thermal conductivities range between about 1.8 and $1.9 \mathrm{~W} \mathrm{~m}^{-1}$ $\mathrm{K}^{-1}\left(4.3-4.5\right.$ T.C.U.). The average heat flow is estimated as about $45 \mathrm{mWm}^{-2}$ (1.07 H.F.U.) at COST B-2 and $44 \mathrm{mWm}^{-2}$ (1.06 H.F.U.) at COST B-3, with an uncertainty of about $20-25 \%$. The mean radiogenic production in sediments at the two sites has been estimated as 1.83 (COST B-2) and 1.44 (COST B-3) $10^{-6} \mathrm{Wm}^{-3}$. With a $12-14 \mathrm{~km}$ thick sedimentary sequence a radioactive contribution of $20-25 \mathrm{mWm}^{-2}$ can be expected.

The effects of sediment deposition, compaction, pore water advection and radiogenic heat production have been combined in a numerical mode1 (Hutchison, 1985) to estimate the undisturbed basement heat flux. Although the sedimentation depresses the basement heat flux by $15-20 \%$, this effect is more than compensated by radioactive heat production in the sediments, so that the surface flux is estimated to be higher than that from the basement. The latter is calculated at about $33-39 \mathrm{mWm}^{-2}(0.8-0.9$ H.F.U. ), a relatively low value. The overall uncertainity is about $\pm 20-25 \%$, and other estimates on continental margins with thick sediments (e.g. Reiter and Jessop, 1985) probably have at least a similar uncertainty. 


\section{INTRODUCTION}

The evaluation of heat flow at the earth's surface is a complex problem which requires data on thermal conditions at depth through time. Important information about the nature, age and evolution of the crust can be obtained if a reliable estimate of the two main components of surface heat flow, i.e. radiogenic heat production in the lithosphere and heat flow transferred from the asthenosphere, is available (Keen and Lewis, 1982). The geological, geophysical and deep exploratory drilling data existing along the U.S. Atlantic continental margin give us an opportunity both for evaluation of these heat flow components through this province, and to propose a general procedure for the determination of heat flow starting from the usually available data from deep exploratory and/or oil wells.

An extensive regional study on terrestrial heat flow across the Canadian Atlantic continental margin has been recently published by Reiter and Jessop (1985) starting from bottom-hole-temperatures and thermal conductivities, estimated from lithologic descriptions, of 72 sites on the eastern Canadian shelf. This paper will analyse in detail only 2 deep wells drilled offshore New Jersey on the same north Atlantic margin of the U.S.A. Data from the COST B-2 and COST B-3 wells, drilled in the Baltimore Canyon Trough (Fig. 1), have been analyzed.

The evaluation of heat flow and thermal structure of the COST we11s will contribute to a better understanding of the thermal history following continental margin formation. In particular, accurate measurements of heat flow in deep wells could be extremely useful in testing some of the thermal models (McKenzie, 1978; Royden et a1., 1980; Hellinger and Sclater, 1983; and others) developed to explain thermally driven subsidence.

Continental rifting and crustal thinning are accompanied by extensive heating and vertical movements (uplift and initial subsidence) of the margins, evidenced most directly by listric faulting and volcanic intrusions; the rifting process is completed when a mid-ocean ridge is created. Following the onset of sea floor spreading, heat is lost from the margin both vertically and horizontally (Steckler, 1981) making the long term thermal subsidence (McKenzie, 1978; Hellinger and Sclater, 1983) more rapid and variable.

The amount of heating has important implications for the sediments that accumulate on the subsiding continental margin (Steckler and Watts, 1982); they will be heated during and after rifting, possibly creating the conditions for, or accelerating the process of, oil and gas maturation. Thermal models can predict, within restricted assumptions (initial lithosphere in isostatic and thermal equilibrium, heat transfer by conduction only, uniqueness of rifting event, etc.), the temperatures and heat flowing out of the cooling lithosphere for different times during continental margin formation. More accurate heat flow estimates in deep wells will better constrain such models, verifying the reliability of the initial assumptions.

In dealing with the heat flow determinations from well data, a major problem is the estimate of the thermal conductivity of the sedimentary formations penetrated, particularly when core sampling is inadequate or nonexistent. Many different approaches have been proposed to evaluate the thermal conductivity of sediments based only on standard logs (Goss et a1., 1975; 


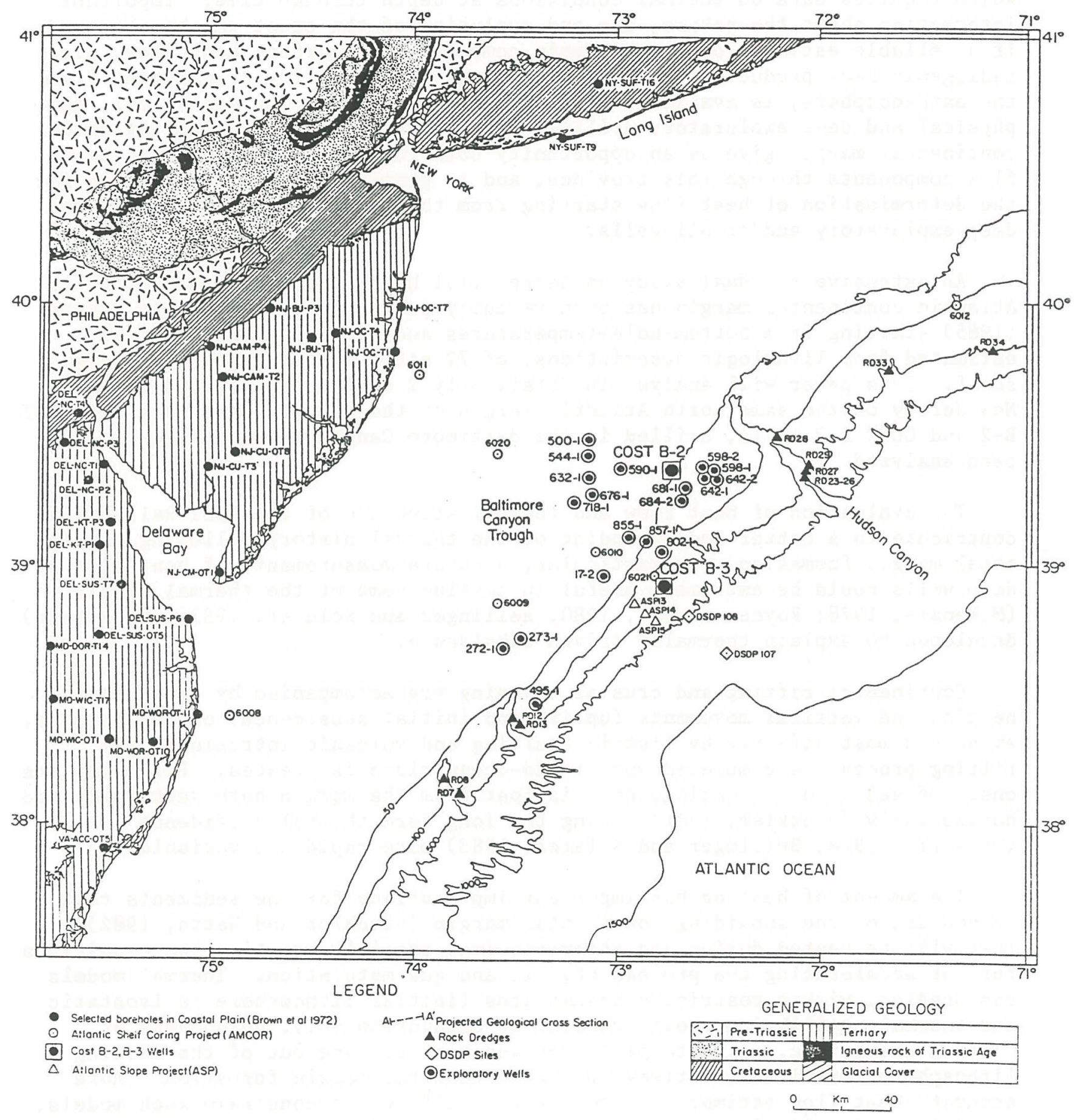

Fig. 1. Geological map showing location of COST B-2 and B-3 wells and other exploratory wells off New Jersey (from Watts, 1981). 
Evans, 1977; Houbo1t and We11s, 1980; Drury and Jessop, 1983), a1though a general empirical and simple relation has not yet been determined. Radioactivity in sediments may contribute significantly to surface heat flux wherever the sediments are more than a few $\mathrm{km}$ thick. Radiogenic heat production has been approached by measuring directly the $U$, Th and ${ }^{40} \mathrm{~K}$ concentrations in 122 samples of various sediment lithologies sorted from the drill cuttings originally available. In the opposite sense, the rapid accumulation of sediments at a margin suppresses the heat flux from the subsiding basement, depending primarily the sedimentation rate (Von Herzen and Uyeda, 1963; Hutchison, 1985).

The general approach followed in analyzing the COST B-2 and COST B-3 data is summarized in Fig. 2. Basically, a few hundred drill cuttings samples are separated into various lithologies, ground up, and the porosity, density, and thermal conductivity are measured in the saturated samples. The in situ thermal conductivity is estimated from well $10 \mathrm{~g}$ parameters taking into account the anisotropy correction.

The surface heat flow is then computed by combining these data with the thermal gradients obtained from temperature logs. The thermal blanketing effect induced by the sedimentation is also considered, and radiogenic heat production in the sediments is estimated from $U$, Th and ${ }^{40} \mathrm{~K}$ concentration measurements.

\section{GEOLOGICAL SETTING}

The U.S. Atlantic passive continental margin with its substantial thickness of sedimentary rocks contains a well preserved record of the evolutionary history of the area since the early opening of the Atlantic Ocean. During the past two decades it has been the site of extensive geological and geophysical investigation by academic, government and industry groups both for scientific and economic interest.

Gravity, magnetic, seismic and deep exploratory drilling data are available in many areas along the margin from Nova Scotia to Florida (Rabinowitz, 1974; Taylor et al., 1968; Schouten and K1itgord, 1977; Klitgord and Behrendt, 1979; Schlee et a1., 1976; Sheridan, 1976; Grow and Mark1, 1977; Grow et a1., 1979; Buffler et al., 1979; Grow, 1980, 1981; Schlee, 1981; Scholle et a1., 1977, 1980; Amato and Bebout, 1978). Based on these data, the general understanding of the origin and evolution of the Atlantic-type continental margin has been significantly improved (Grow and K1itgord, 1980; Watts, 1981; Watts and Thorne, 1984 ).

The multichannel seismic reflection profiles have shown considerable thicknesses of sediments beneath the shelf (up to $14 \mathrm{~km}$ ) and slope (up to $8 \mathrm{~km}$ ) regions in a sequence of basins separated by structural highs (Fig. 3 ). The COST test wells and more than 20 exploratory drillings (Fig. 1) provide information on stratigraphy, age and physical parameters of the seismic reflectors to depths of $5 \mathrm{~km}$ underlying the outer part of the shelf. These wells show a sedimentary section composed mainly of sandstones and shales with lesser amounts of limestone and subordinate amounts of coal and lignite (Scholle et a1., 1977, 1980). Biostratigraphic studies indicate that these sediments are Jurassic to Quarternary in age and were deposited in continental or shallow marine environments. 


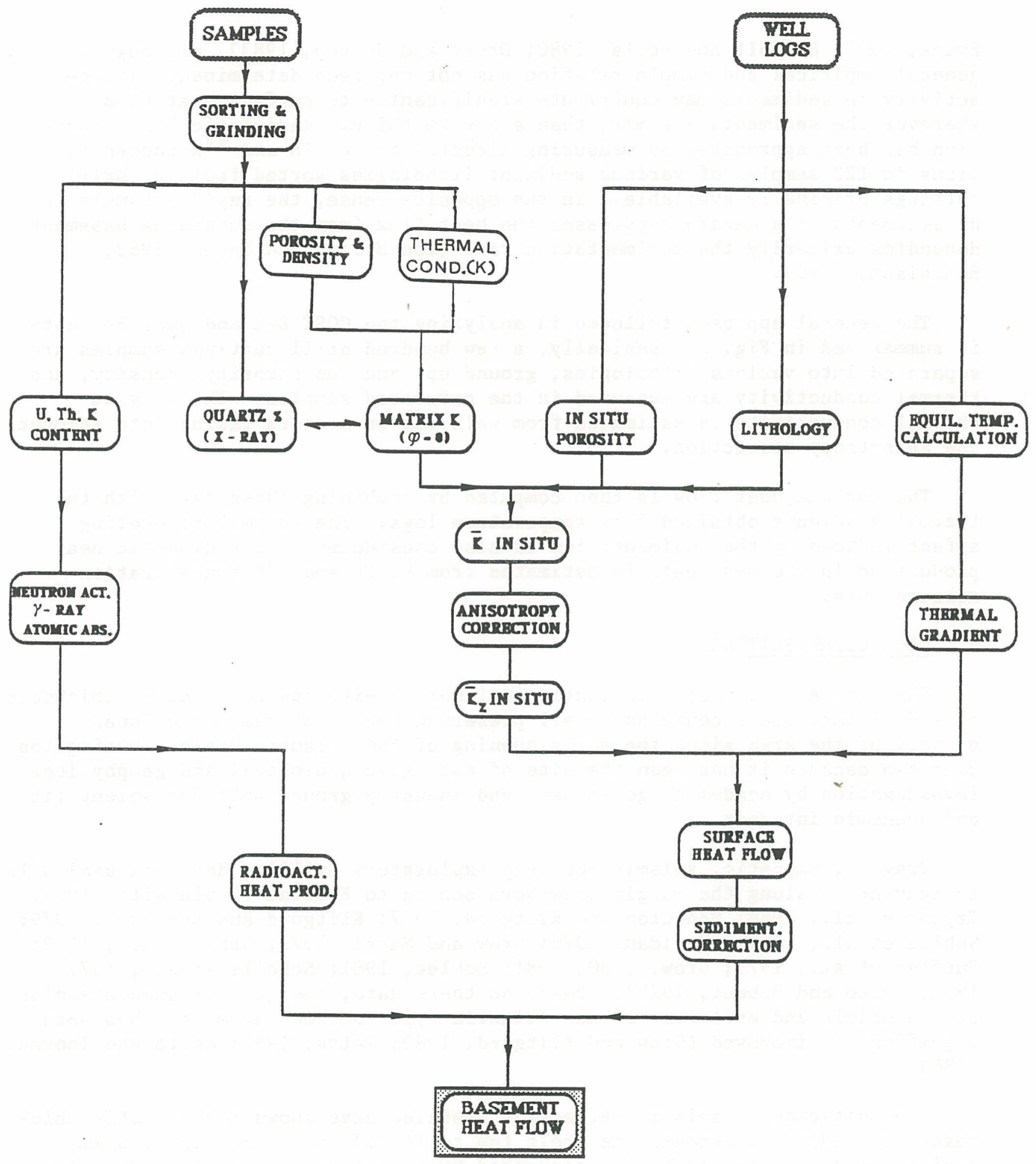

Fig. 2. Block diagram of the sequence of procedures followed in the COST $B-2$ and $B-3$ data analysis for evaluation of the heat flow. 


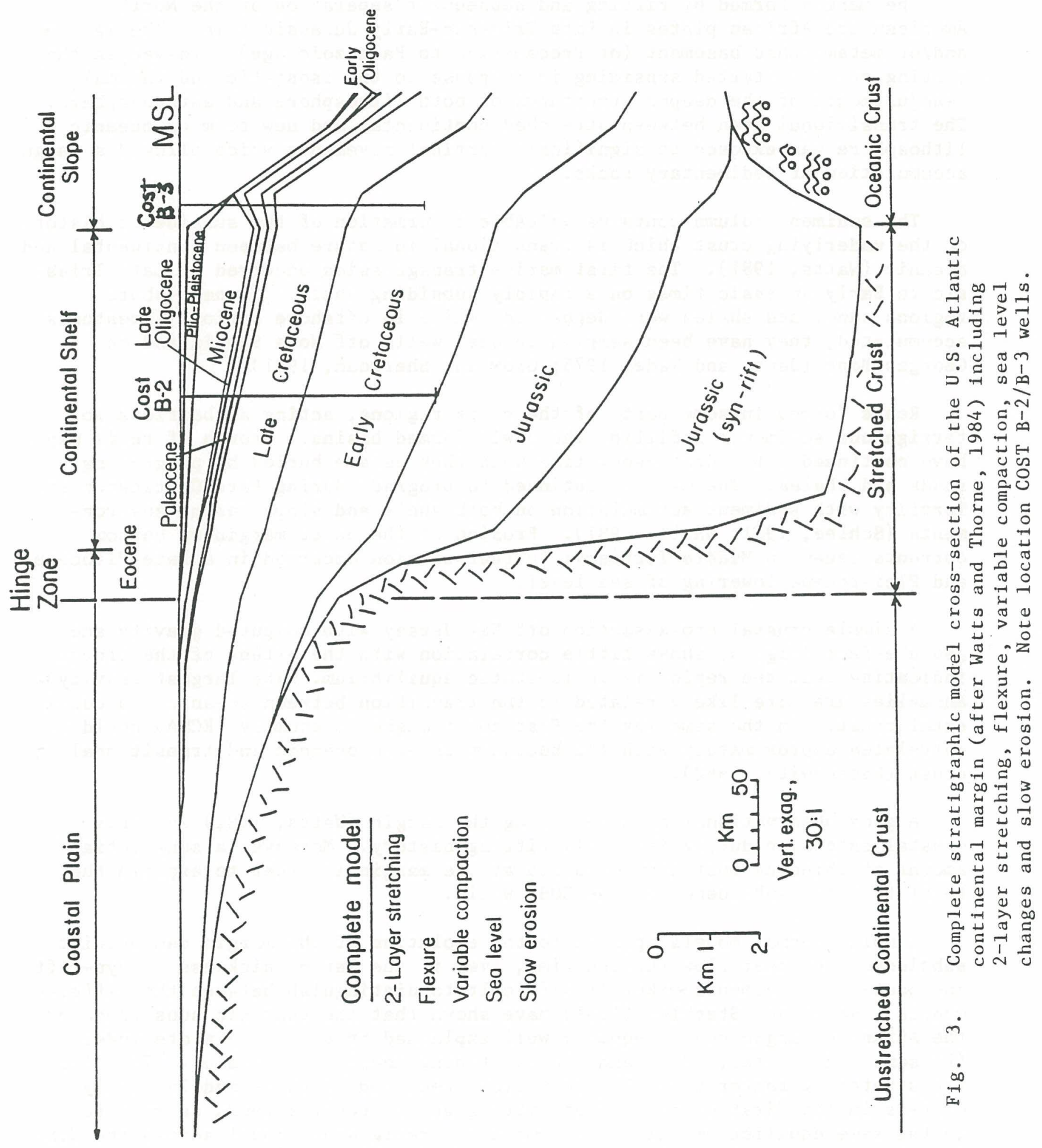


The margin formed by rifting and subsequent separation of the North American and African plates in Late Triassic-Early Jurassic time. The igneous and/or metamorphic basement (of Precambrian to Paleozoic age) involved in the rifting process started subsiding in response to the isostatic and thermal readjustments of the deeper structures of both lithosphere and asthenosphere. The transitional area between stretched continental and new forming oceanic lithosphere was exposed to significant vertical movements which allowed a large accumulation of sedimentary rocks.

The sediment column contains valuable information of the subsidence history of the underlying crust which is transitional in nature between continental and oceanic (Watts, 1981). The first marine transgression occurred in Late Triassic to Early Jurassic times on a rapidly subsiding shelf. In near-shore regions sands and shales were deposited, while in offshore regions limestones accumulated; they have been sampled in deep wells off Nova Scotia and on Georges Bank (Jansa and Wade, 1975; Grow and Sheridan, 1981).

Reefs formed in some parts of the slope regions, acting as barriers to terrigenous sediments infilling the newly formed basins. Growth of reefs may have continued until Cretaceous time when they became buried by prograding sands and shales. The margin continued to prograde during Late Cretaceous and Tertiary with sediment accumulation on both shelf and slope marine environments (Schlee, 1981; Watts, 1981). Erosion of the outer margin by bottom currents began in Middle Tertiary; further erosion occurred in a Late Pliocene and Pleistocene lowering of sea level.

A simple crustal cross-section off New Jersey with computed gravity and geoid effect (Fig. 4) shows little correlation with the extent of the trough indicating that the region is in isostatic equilibrium. The largest gravity anomalies are more likely related to the transition between oceanic and continental crust. In the same way the East coast magnetic anomaly (ECMA) could be correlated approximately with the boundary between oceanic and transitional crust (Rabinowitz, 1982).

A good observational data set along the margin (Watts, 1981) supports crustal extension during the early rifting history. Moreover a substantial amount of thinning must have occurred at the margin in order to explain the total tectonic subsidence at the COST we1ls.

Simple thermal models applied to the evolution of the margin can predict subsidence and heat flow through time, even if the large thickness of syn-rift and post-rift sediments makes it difficult to distinguish between the different models. Watts and Steckler (1981) have shown that the tectonic subsidence of the Atlantic margin can be equally well explained by a cooling plate model (Parsons and Sclater, 1977) and the stretching model of McKenzie (1978) with the stretching factor $\beta=6$. The heat flow predicted by these models mainly differs in the first $60 \mathrm{M} . \mathrm{y}$. after rifting and thereafter tends asymptotically to the same equilibrium value. A complete stratigraphic model across the U.S. Atlantic continental margin (close to the COST wells) was proposed by Watts and Thorne (1984) (Fig. 3). This model includes: 2-layer stretching, flexure, variable compaction, sea level changes and slow erosion. 


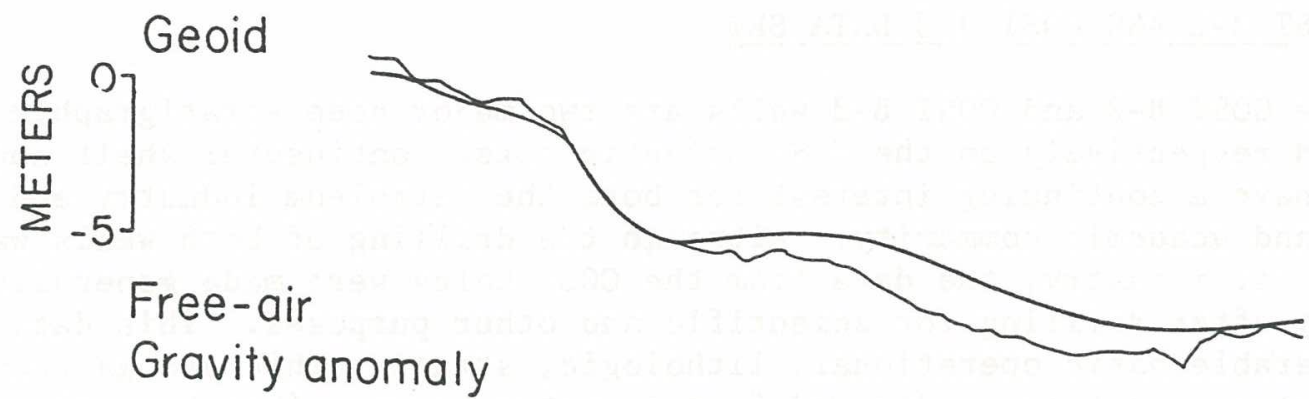

$\left.\sum_{\sum}^{1} \begin{array}{r}50 \\ -50\end{array}\right]$
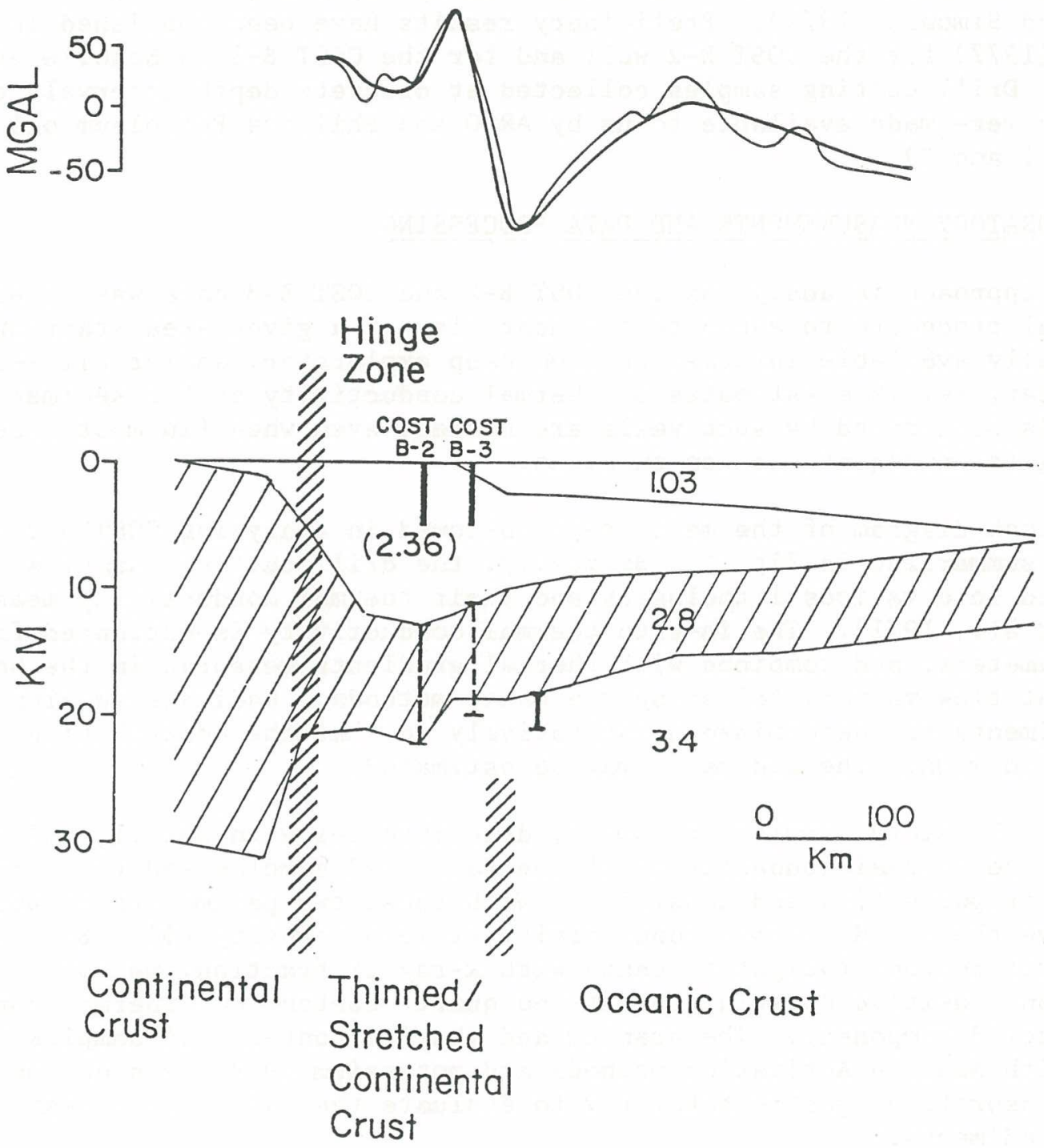

Fig. 4. Computed gravity and geoid effect (heavy curve) of a simple model for the crustal structure off New Jersey compared to observed (thin curve) free-air gravity anomaly and GEOS-3 satellite altimeter data. The numbers on the section are densities, and the dashed lines indicate the estimate of crustal thickness at the COST wells based on thermal models (from Watts, 1981, Fig. 29). 


\section{COST B-2 AND COST B-3 DATA SET}

The COST B-2 and COST B-3 wells are two major deep stratigraphic tests located respectively on the U.S. Atlantic outer continental shelf and slope which have a continuing interest for both the petroleum industry and the scientific and academic community. Although the drilling of both wells was financed by the oil industry, the data from the COST holes were made generally available shortly after drilling for scientific and other purposes. This data includes considerable basic operational, 1ithologic, stratigraphic and geochemical information, most of it derived from industry reports (Smith et a1., 1976; Amato and Simonis, 1979). Preliminary results have been published in Scholle et a1. (1977) for the COST B-2 well and for the COST B-3 in Scholle et al. (1980). Drill cutting samples collected at discrete depth intervals during drilling were made available to us by ARCO and Phillips Petroleum oil companies (Tables 1 and 2).

\section{LABORATORY MEASUREMENTS AND DATA PROCESSING}

Our approach in analyzing the COST B-2 and COST B-3 data was to establish a general procedure to evaluate the heat flow of a given area starting from the usually available information from deep exploratory and/or oil wells. In particular, reliable estimates of thermal conductivity of the sedimentary materials penetrated by such wells are needed, even when (in most cases) core sampling is inadequate or non-existent.

A block diagram of the main steps followed in analyzing COST B-2 and B-3 data is summarized in Fig. 2. Basically, the drill cuttings samples are separated into various lithologies and their thermal conductivity measured (Sass et al., 1971). The in-situ thermal conductivity is estimated from well log parameters, and combined with thermal gradients measured in the hole to give heat flow values, following the usual methods. Radioactive elements in the sediments are determined quantitatively so that the contribution of heat generation within the sediments may be estimated.

The laboratory samples treatment, described below in detail, allowed us to measure the thermal conductivity of the saturated samples and to calculate their porosities and densities. With these two parameters it was possible to derive the solid thermal conductivity at zero porosity $(\Phi)$. By measuring the quartz content (weight percent) with $x$-ray diffraction, we could verify the strong positive correlation between quartz content and thermal conductivity of the solid component. The uranium and thorium contents of samples were measured with Neutron Activation methods and potassium by X-ray spectrometry and atomic absorption spectrophotometry to evaluate the radioactive heat production in the sediments.

The geophysical well logs were used to calculate the in situ porosity and the equilibrium temperature at discrete points. From these data the temperature gradients and the vertical component of in situ thermal conductivity $\mathrm{K}_{\mathrm{z}}$ were estimated, assuming an anisotropy correction factor of conductivity for the primary lithologies from the literature. The surface heat flow was computed and the heat flow from the lithosphere was estimated taking into account the thermal blanketing effect of the sedimentation and the radiogenic heat production, which have overall contributions of opposite sign. 
Table 1. Depth Intervals of COST B-2 Drill Cuttings Samples (ft. below K.B.)

\begin{tabular}{|c|c|c|}
\hline $4110-4140$ & $7980-7990$ & $12960-12970$ \\
\hline $4140-4170$ & $8000-8010$ & $13160-13170$ \\
\hline $4170-4200$ & $8220-8240$ & $13200-13210$ \\
\hline $4200-4230$ & $8250-8260$ & $13220-13230$ \\
\hline $4230-4260$ & $8450-8460$ & $13240-13250$ \\
\hline $4620-4630$ & $8470-8480$ & $13260-13270$ \\
\hline $4640-4650$ & $8530-8540$ & $13300-13310$ \\
\hline $4660-4670$ & $8550-8560$ & $13340-13350$ \\
\hline $4880-4890$ & $9290-9300$ & $13380-13390$ \\
\hline $4900-4910$ & $9310-9320$ & $13410-13420$ \\
\hline $4920-4930$ & $9370-9380$ & $13630-13640$ \\
\hline $5090-5100$ & $9390-9400$ & $13690-13700$ \\
\hline $5110-5140$ & $9620-9630$ & $13710-13720$ \\
\hline $5140-5170$ & $9640-9650$ & $13870-13880$ \\
\hline $5200-5230$ & $9660-9670$ & $14010-14020$ \\
\hline $6280-6290$ & $9680-9690$ & $14030-14040$ \\
\hline $6300-6310$ & $9700-9710$ & $15260-15270$ \\
\hline $6320-6330$ & $10060-10070$ & $15280-15290$ \\
\hline $6530-6540$ & $10080-10090$ & $15300-15310$ \\
\hline $6560-6560$ & 10100-10110 & $15320-15330$ \\
\hline $6770-6780$ & $10270-10300$ & $15340-15350$ \\
\hline $6790-6800$ & $11050-11080$ & $15530-15540$ \\
\hline $6850-6860$ & $11260-11290$ & $15770-15780$ \\
\hline $6870-6880$ & $11350-11380$ & $15780-15790$ \\
\hline $6890-6900$ & $11380-11410$ & $15790-15800$ \\
\hline 7070-7080 & $11530-11560$ & $15820-15830$ \\
\hline $7140-7150$ & $11650-11680$ & $15840-15850$ \\
\hline $7160-7170$ & $11710-11740$ & $15910-15920$ \\
\hline $7180-7190$ & $11740-11770$ & \\
\hline $7220-7230$ & $11770-11800$ & \\
\hline $7280-7290$ & $11800-11830$ & \\
\hline $7320-7330$ & $11980-12000$ & \\
\hline $7400-7410$ & $12000-12020$ & \\
\hline $7540-7550$ & $12370-12400$ & \\
\hline $7580-7590$ & $12460-12490$ & \\
\hline $7720-7730$ & $12550-12580$ & \\
\hline $7740-7750$ & $12640-12650$ & \\
\hline $7760-7770$ & $12680-12690$ & \\
\hline $7920-7930$ & $12720-12730$ & \\
\hline $7940-7950$ & $12740-12750$ & \\
\hline \multirow[t]{2}{*}{$7960-7970$} & $12860-12870$ & \\
\hline & $12940-12950$ & \\
\hline
\end{tabular}


Table 2. Depth Intervals of COST B-3 Drill Cuttings Samples (feet below K.B.)

$3810-3840$
$3840-3870$
$3930-3960$
$3960-3990$
$4020-4050$
$4080-4110$
$4290-4320$
$4380-4310$
$4440-4470$
$4560-4590$
$4590-4620$
$4650-4680$
$4800-4830$
$4890-4920$
$4950-4980$
$5010-5040$
$5100-5130$
$5130-5160$
$5220-5250$
$5310-5340$
$5400-5430$
$5490-5520$
$5610-5640$
$5730-5760$
$5790-5800$
$5830-5840$
$5870-5880$
$5900-5910$
$5940-5950$
$5980-5990$
$6020-6030$
$6050-6060$
$6180-6190$
$6260-6270$

$$
\begin{aligned}
& 6300-6360 \\
& 6400-6430 \\
& 6430-6460 \\
& 6500-6520 \\
& 6520-6550 \\
& 6600-6630 \\
& 6630-6650 \\
& 6700-6720 \\
& 6730-6750 \\
& 6760-6770 \\
& 6800-6820 \\
& 6830-6840 \\
& 6900-6930 \\
& 7000-7020 \\
& 7030-7040 \\
& 7100-7140 \\
& 7200-7220 \\
& 7230-7250 \\
& 7300-7330 \\
& 7330-7350 \\
& 7400-7430 \\
& 7500-7540 \\
& 7600-7640 \\
& 7700-7720 \\
& 7720-7760 \\
& 7810-7840 \\
& 7900-7930 \\
& 8000-8030 \\
& 9000-9030 \\
& 9100-9130 \\
& 9200-9230 \\
& 9300-9330 \\
& 9400-9430 \\
& 9500-9530
\end{aligned}
$$

$9700-9720$
$9800-9850$
$9870-9890$
$9900-9930$
$9930-9950$
$10000-10030$
$10100-10130$
$10130-10160$
$10200-10240$
$10300-10330$
$10400-10450$
$10450-10480$
$10600-10640$
$10700-10720$
$10720-10750$
$10790-10820$
$10920-10950$
$11030-11050$
$11060-11070$
$11120-11150$
$11170-11200$
$11210-11220$
$11220-11230$
$11250-11260$
$11310-11320$
$11320-11330$
$11390-11400$
$11490-11500$
$11560-11570$
$11650-11660$
$11700-11710$
$11800-11810$
$11910-11920$
$12000-12010$

$12090-12100$

$12210-12220$

$12300-12310$

$12310-12320$

$12390-12400$

$12420-12430$

$12490-12500$

$12580-12590$

$12620-12630$

$12660-12670$

12690-12700

12750-12760

12780-12790

12820-12830

12900-12910

13040-13050

13190-13200

13240-13250

13350-13360

13440-13450

13550-13560

13680-13690

13750-13760

13870-13880

13970-13980

14020-14030

14080-14090

14200-14210

14310-14320

14380-14390

14440-14450

14550-14560

14620-14630

14710-14720 


\subsection{SAMPLE PREPARATION}

The sample preparation and the measurements of porosity, density and thermal conductivity consumed most of the time and effort of this project; for the most part they were completed by four summer students between 1979 and 1982. A summary of the data distribution is presented in Table 3.

\begin{tabular}{|c|c|c|c|c|c|}
\hline & Table 3 & $\begin{array}{r}\text { - Summary of Cut } \\
\text { Conductiv }\end{array}$ & $\begin{array}{l}\text { S Samples } \\
\text { Measurement }\end{array}$ & d for Therm & \\
\hline & $\begin{array}{l}\text { Original no. } \\
\text { of samples }\end{array}$ & $\begin{array}{c}\text { Depth } \\
\text { Interva1 } \\
\text { (ft. below K.B.) }\end{array}$ & Operator & $\begin{array}{l}\text { No. } \\
\text { Recombined } \\
\text { samples }\end{array}$ & $\begin{array}{c}\text { No. } \\
\text { Reliable } \\
\text { measurements }\end{array}$ \\
\hline $\cos \mathrm{B}^{\mathrm{B}-2}$ & 116 & $\begin{array}{r}4,110-12,970 \\
11,980-15,930\end{array}$ & $\begin{array}{l}\text { G. Moritz } \\
\text { L. Hobbie }\end{array}$ & $\begin{array}{l}38(?) \\
47(?)\end{array}$ & $\begin{array}{l}38 \\
47\end{array}$ \\
\hline $\operatorname{cosT} B-3$ & 151 & $\begin{array}{r}3,810-11,200 \\
11,210-14,630\end{array}$ & $\begin{array}{l}\text { P. Borga } \\
\text { K. Lange }\end{array}$ & $\begin{array}{l}29 \\
16\end{array}$ & $\begin{array}{l}24 \\
16\end{array}$ \\
\hline
\end{tabular}

*NB: the difference between the number of recombined samples and the number of final reliable values is due to the loss of 3 samples in the centrifuge and to an insufficient amount of material in another 2 samples.

Each operator used slightly different procedures in the treatment of samples mainly because the sorting of the samples by lithology and the accuracy of procedures (grinding, saturation, weighing) are somewhat subjective and therefore operator dependent. For the detailed description of the procedures used, refer to the original reports (Moritz, 1979; Hobbie, 1980; Borga, 1981; Lange, 1982). In any case, the main steps generally followed can be briefly described as follows:

a) Washing: the rock chips were washed through a seive with a $1 \mathrm{~mm}$ opening size to remove drilling mud and miscellaneous fine particles.

b) Drying: they were dried in an oven at $50-60^{\circ} \mathrm{C}$ for a few hours.

c) Sorting: the rock fragments were sorted in 5 1ithology groups. Sandstones, siltstones, shales, limestones and coal. The criteria used were mainly based on visible characteristics such as: grain size, texture, habit, shape of breaking surface, hardness, color, hydrochloric acid fizzing test.

d) Recombining and labeling: a minimum amount of 40-45g of each lithotype from each depth interval is required for a thermal conductivity measurement and for a $\gamma$-ray spectrometry analysis. When insufficient material was available from a sample (depth interval), identical lithologies from nearby depth intervals had to be combined to obtain the minimum weight. These sorted and recombined samples were properly labelled. 
e) Grinding: The material must be reduced to a uniform grain size to correctly measure the thermal conductivity. This was accomplished by hand-grinding the rock chips with mortar and pestle. For the quartz analysis on the x-ray diffraction machine all the samples were reground again to a grain size of approximately 62 microns $\left(\mu=10^{-6} \mathrm{~m}\right)$.

f) Drying: The pulverized samples were dried for at least 12 hours in an oven.

\subsection{SAMPLES POROSITY AND DENSITY COMPUTATION}

A11 the powdered samples weighed to an accuracy of $\pm 0.01 \mathrm{~g}$ are saturated with water in a moderate vacuum ( $\sim 20$ torr) and agitatéd to eliminate air bubbles. The samples are generally left for 12-36 hrs. to settle. A few COST B-3 samples (Borga, 1981) were run in a centrifuge for 3-5 hrs. at 200-500 rpm to enhance settling, but no significant effect was noticed. A complete settling is almost impossible to reach and the quality of the results is directly related to the grain size of the samples. The excess water above the upper sample interface is then removed either by a filter paper or a dropper and the amount of suspended sediment lost in this operation is measured after evaporation of the water in a drying oven.

The calculation of porosity $(\Phi)$ and the density $(\rho)$ of the samples is simply calculated from the measured weights and volumes, e.g., Goldberg et al. (1980). The final relations are:

$$
\begin{aligned}
& \Phi=\frac{V_{W}}{V_{W}+V_{s}} \\
& \rho=\frac{W_{s}}{V_{s}}
\end{aligned}
$$

where

$$
\begin{aligned}
V_{W}= & W_{W}=\text { volume or weight of interstitial water (assuming } \rho_{W}=1 \text { ) } \\
W_{s}= & \text { weight of the sediment } \\
V_{S}= & W_{W}^{1}-W_{W}=\text { volume of sediment, where } W_{W}^{1}=\text { weight of equivalent } \\
& \text { volume of water }
\end{aligned}
$$

\subsection{THERMAL CONDUCTIVITY MEASUREMENTS}

The thermal conductivity of the pulverized and saturated samples was measured with the needle-probe technique (Von Herzen and Maxwe11, 1959) following the procedure illustrated in Goldberg et al. (1980). The results are presented in Table 4.

Among the models proposed to calculate the thermal conductivity of a two-phase aggregate knowing the conductivities and volume fractions of the components (Zierfuss and Van der V1iet, 1956; Woodside and Messmer, 1961a, 1961b; Brailsford and Major, 1964, Budiansky, 1970, Adler et a1., 1973; 


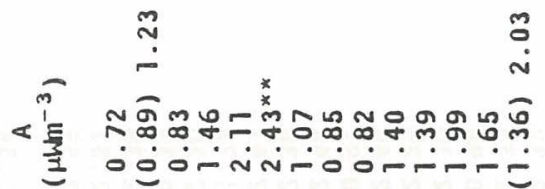

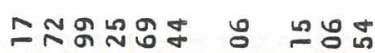

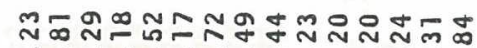

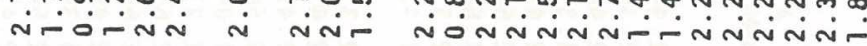

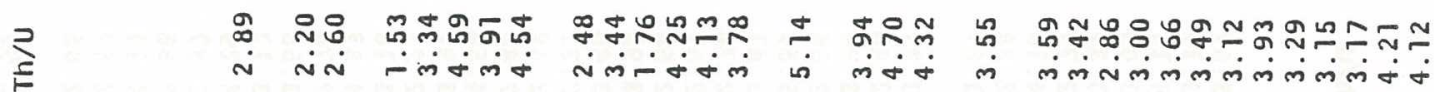

ह

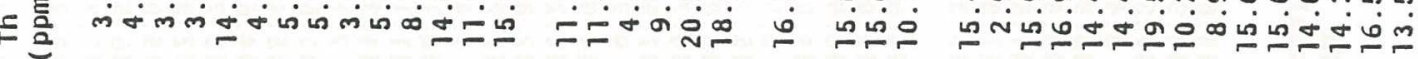

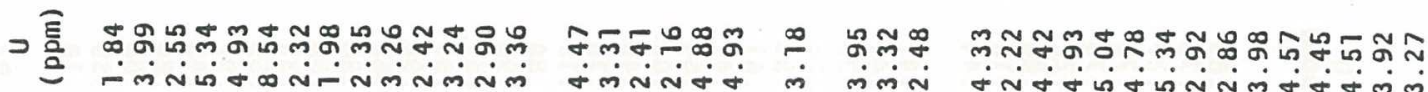

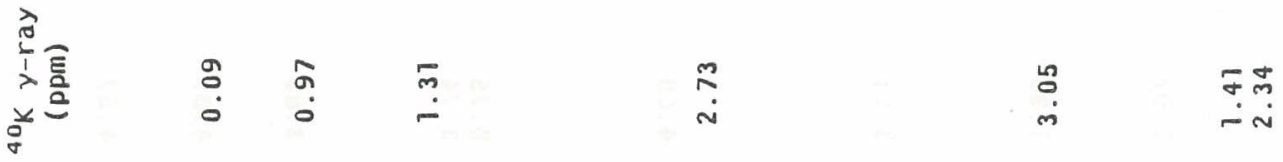

皇

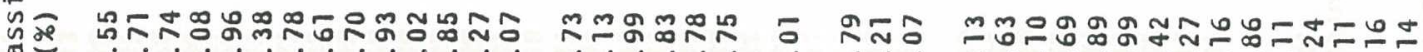

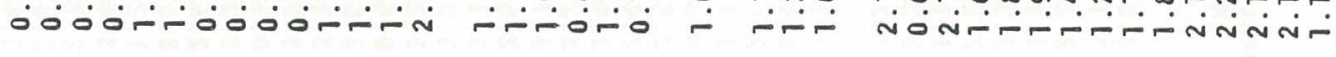

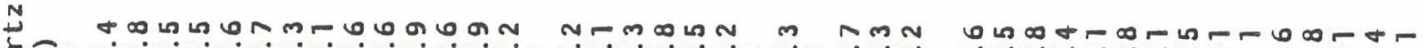
氙

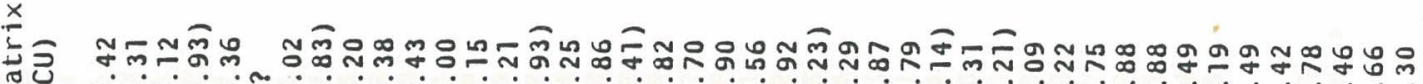

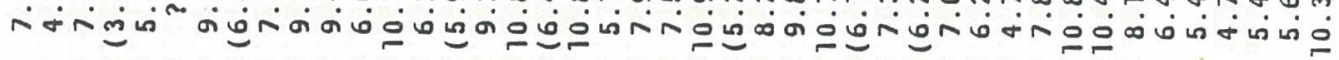

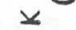

综

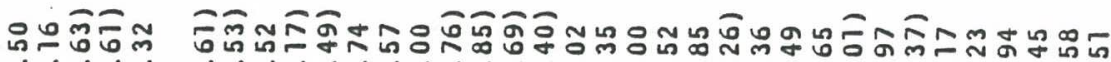

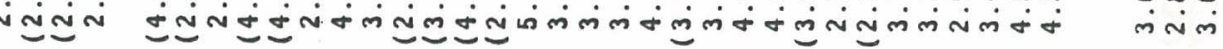

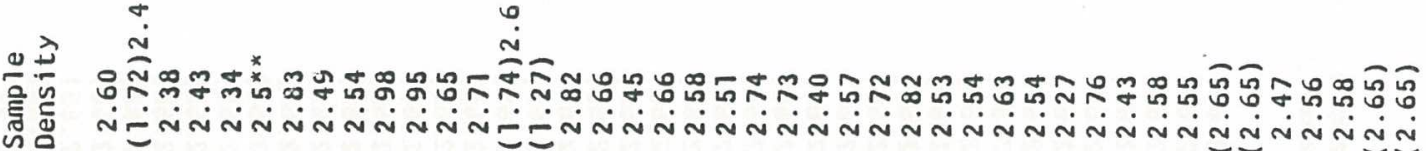

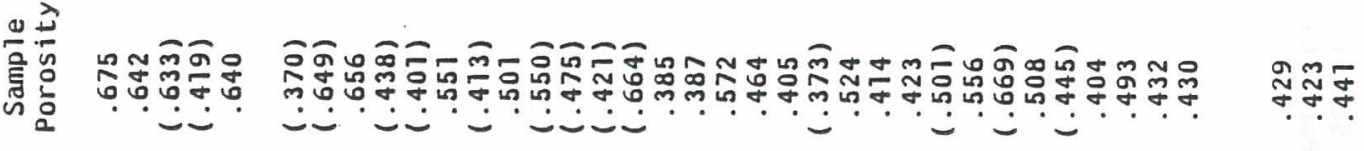

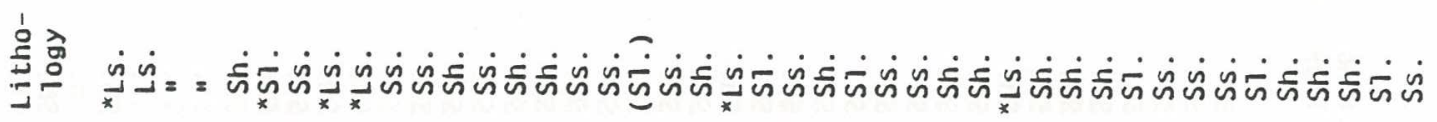

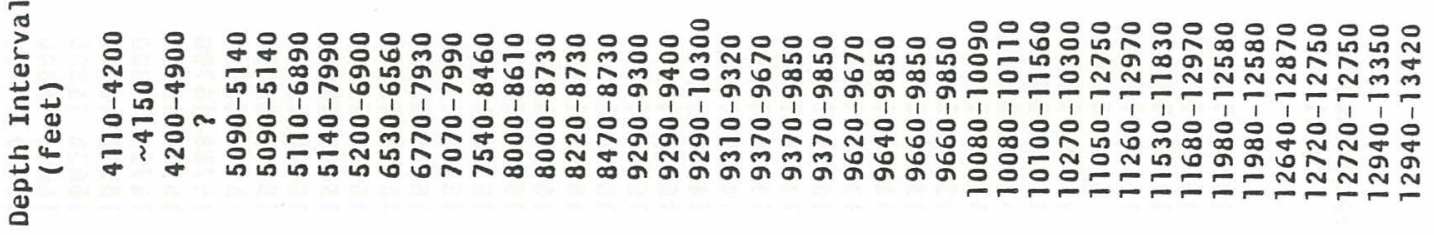

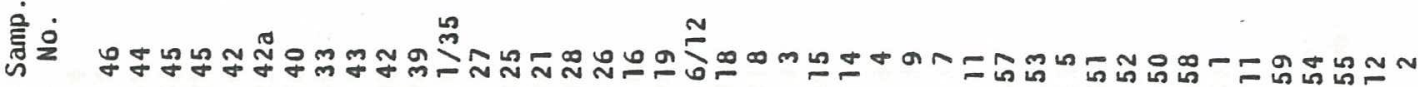


$<\frac{m}{3}$

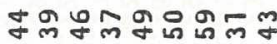

ini-niñ

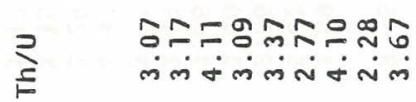

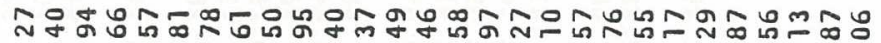

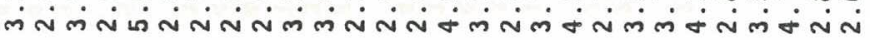

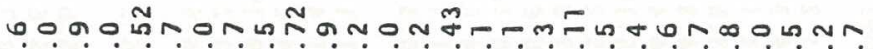

E 틀

0 o

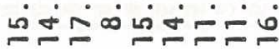

பேம்

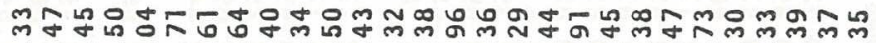

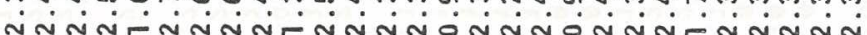

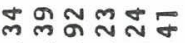
nininin

$\checkmark \widehat{\overline{\mathrm{a}}}$

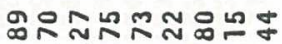

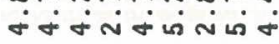

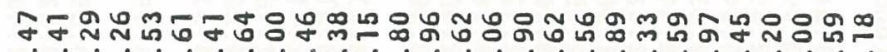

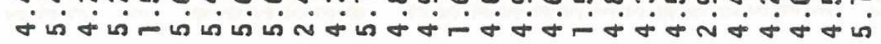

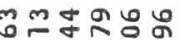

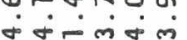

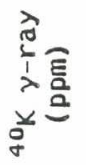

艺

点

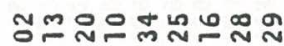

inimininin

เo

$\stackrel{0}{0}$

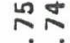

$\dot{0} \dot{m}$

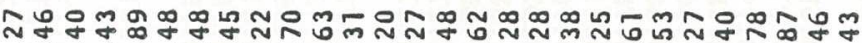

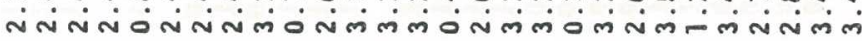

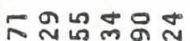
तांविंत्रां

$0,00 \pi n+n+n$

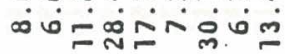

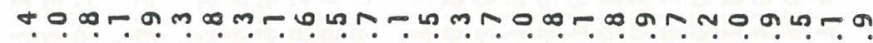
స̃กั

- on on $\infty \min \dot{0}$

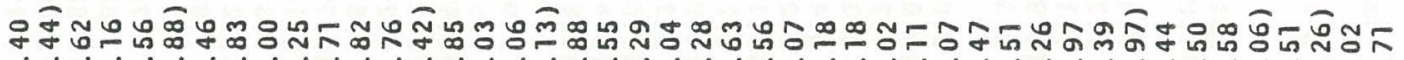
ம ف

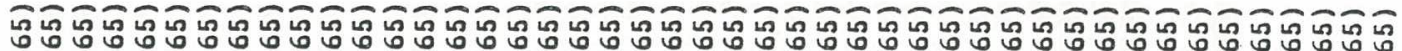
સิ

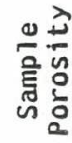

$\stackrel{1}{ \pm}$

ผ

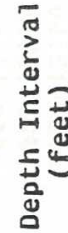

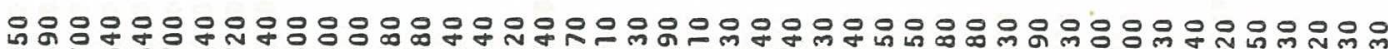

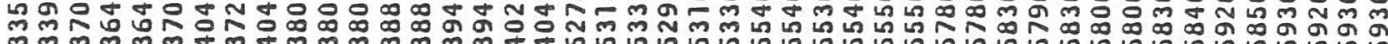

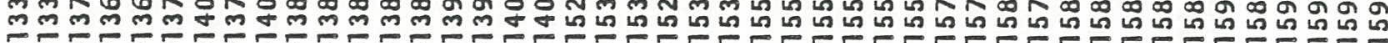

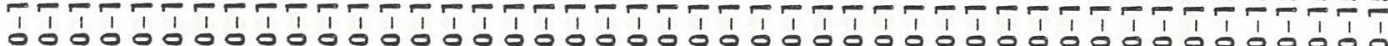

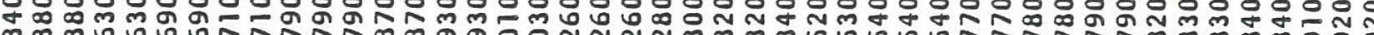

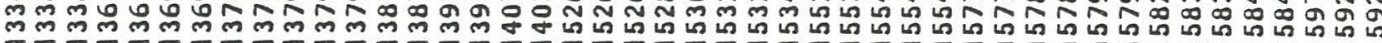

惫完

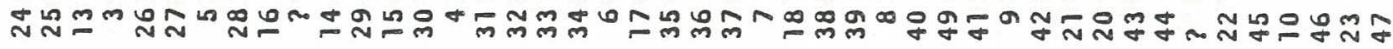




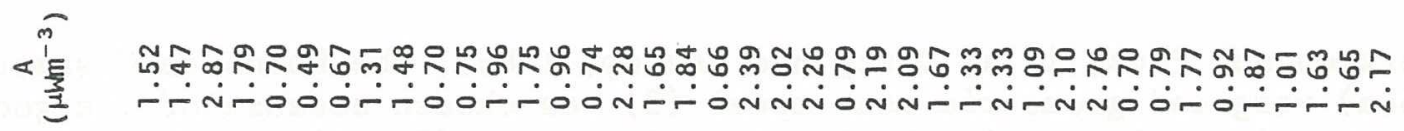

? ํํ, |

I $\quad$ Nm

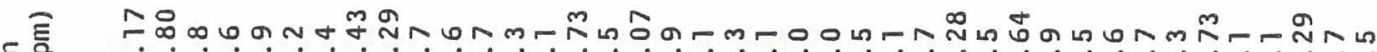

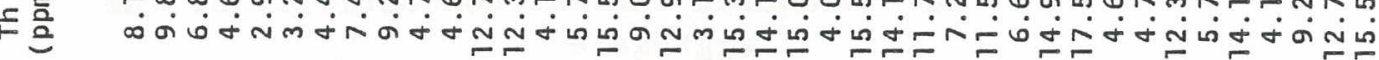

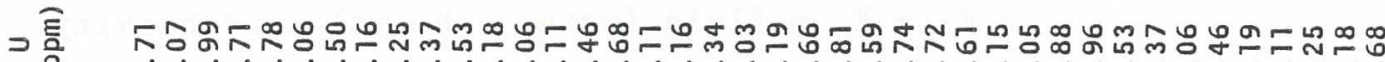

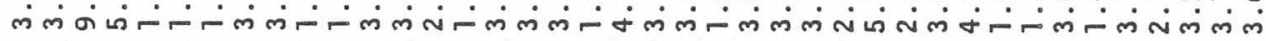

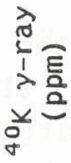

$$
\begin{array}{llll}
\infty & \multirow{2}{*}{} & \circ & \text { กे } \\
0 & \dot{0} & 0 & \text { मे }
\end{array}
$$

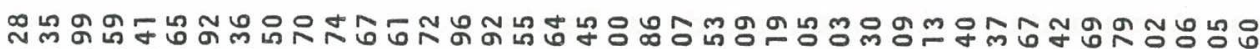

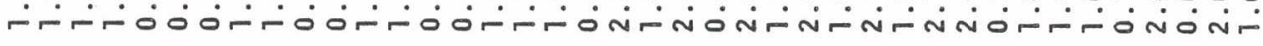

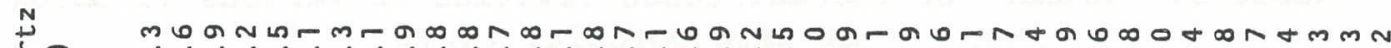
范

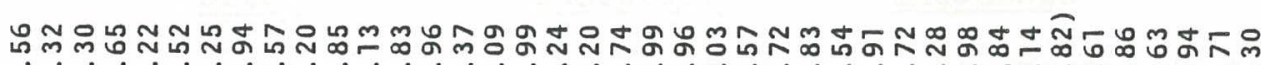

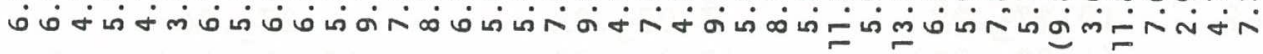

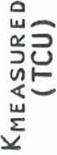

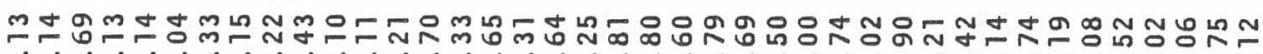

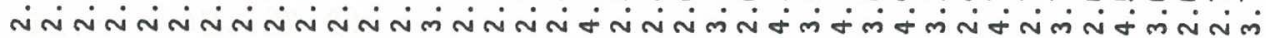

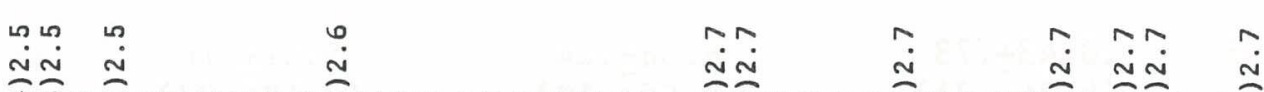

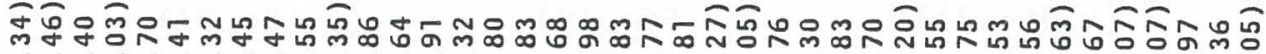

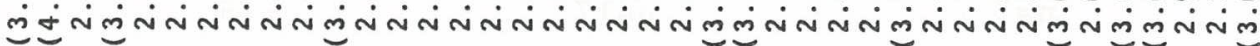

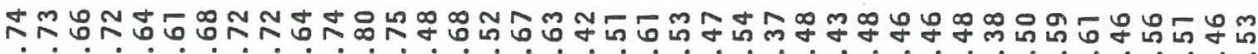

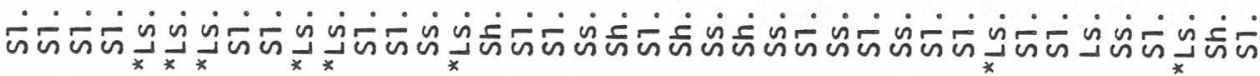


Robertson and Peck, 1974; Drury and Jessop, 1983), the Woodside-Messmer (1961a) weighted geometric mean mode1 (3) was chosen because of its good fit with experimental data in the low porosity range (0-0.5), as shown by Drury and Jessop (1983), and Sekiguchi (1984):

$$
\mathrm{K}_{\mathrm{m}}=\mathrm{K}_{f}^{(\Phi)} \cdot \mathrm{K}_{\mathrm{s}}^{(1-\Phi)}
$$

$$
\begin{aligned}
& \mathrm{K}_{\mathrm{m}}=\begin{array}{r}
\text { measured thermal conductivity of the } \\
\text { aggregate }
\end{array} \\
& \mathrm{K}_{\mathrm{f}}=\mathrm{K}_{\mathrm{w}}=\text { fluid (water) thermal conductivity } \\
& \mathrm{K}_{\mathrm{s}}=\text { solid fraction thermal conductivity }
\end{aligned}
$$

The procedures to calculate the solid conductivity $\mathrm{K}_{\mathrm{s}}$ from the measured sample conductivity $\mathrm{K}_{\mathrm{m}}$ and finally the in situ aggregate mean thermal conductivity $\mathrm{K}$ is shown in the block diagram of Fig. 5. The calculated values of $\mathrm{K}_{\mathrm{s}}$ at room temperature assuming $\mathrm{K}_{\mathrm{w}}=1.45$ T.C.U. (Clark, 1966) are

\begin{tabular}{|c|c|c|c|c|}
\hline We11 & Sands tone & Siltstone & Shale & Limes tone \\
\hline $\operatorname{cosT} \quad B-2$ & $\begin{array}{l}10.27 \pm .22 \\
(4.30 \pm .09) \\
n=23\end{array}$ & $\begin{array}{c}7.03 \pm .22 \\
(2.94 \pm .09) \\
n=16\end{array}$ & $\begin{array}{l}6.27 \pm .26 \\
(2.62 \pm .11), \mathrm{n}=7 \\
\text { (upper interva1) } \\
5.26 \pm .09 \\
(2.20 \pm .04), \mathrm{n}=22 \\
\text { (1ower interval) }\end{array}$ & $\begin{array}{c}6.57 \pm .45 \\
(2.75 \pm .19) \\
n=8\end{array}$ \\
\hline $\operatorname{cosT} B-3$ & $\begin{array}{l}10 \cdot 43 \pm .73 \\
(4 \cdot 36 \pm .31) \\
n=7\end{array}$ & $\begin{array}{c}6.36 \pm .24 \\
(2.66 \pm .10) \\
n=17\end{array}$ & $\begin{array}{c}5.01 \pm .16 \\
(2.10 \pm .07) \\
n=5\end{array}$ & $\begin{array}{c}5.53 \pm .56 \\
(2.31 \pm .23) \\
n=9\end{array}$ \\
\hline \multicolumn{5}{|c|}{$\begin{array}{l}\text { Values given are mean }+ \text { standard error, } \\
\text { Units in TCU, }\left(\mathrm{Wm}^{-1} \mathrm{~K}^{-\mathrm{I}}\right) \text {. } \\
\text { Measurements at room temperature }\left(25 \pm 2^{\circ}\right.\end{array}$} \\
\hline
\end{tabular}
reported in Table 4. The mean thermal conductivity of each 1ithology $\left(\mathrm{K}_{\mathrm{s}}\right)$ at room temperature is presented in Table 5.

Table 5. Summary of thermal conductivities of various 1ithologies at zero porosity $\left(\mathrm{K}_{\mathrm{s}}\right)$.

\subsection{QUARTZ CONTENT EVALUATION}

The weight percent of quartz in the samples has been determined by the $x$-ray powder diffraction technique. A description of the analytical methods used in defining the mineralogy of the DSDP cores is reported in Bader et al. (1970). An important part of determining accurate quartz content values is having a good standard; our technique for standard preparation and evaluation of quartz content in the samples is given in Appendix A. In general, the results we obtained show a reasonable estimate of the quartz content with an accuracy of about $\pm 5 \%$. 


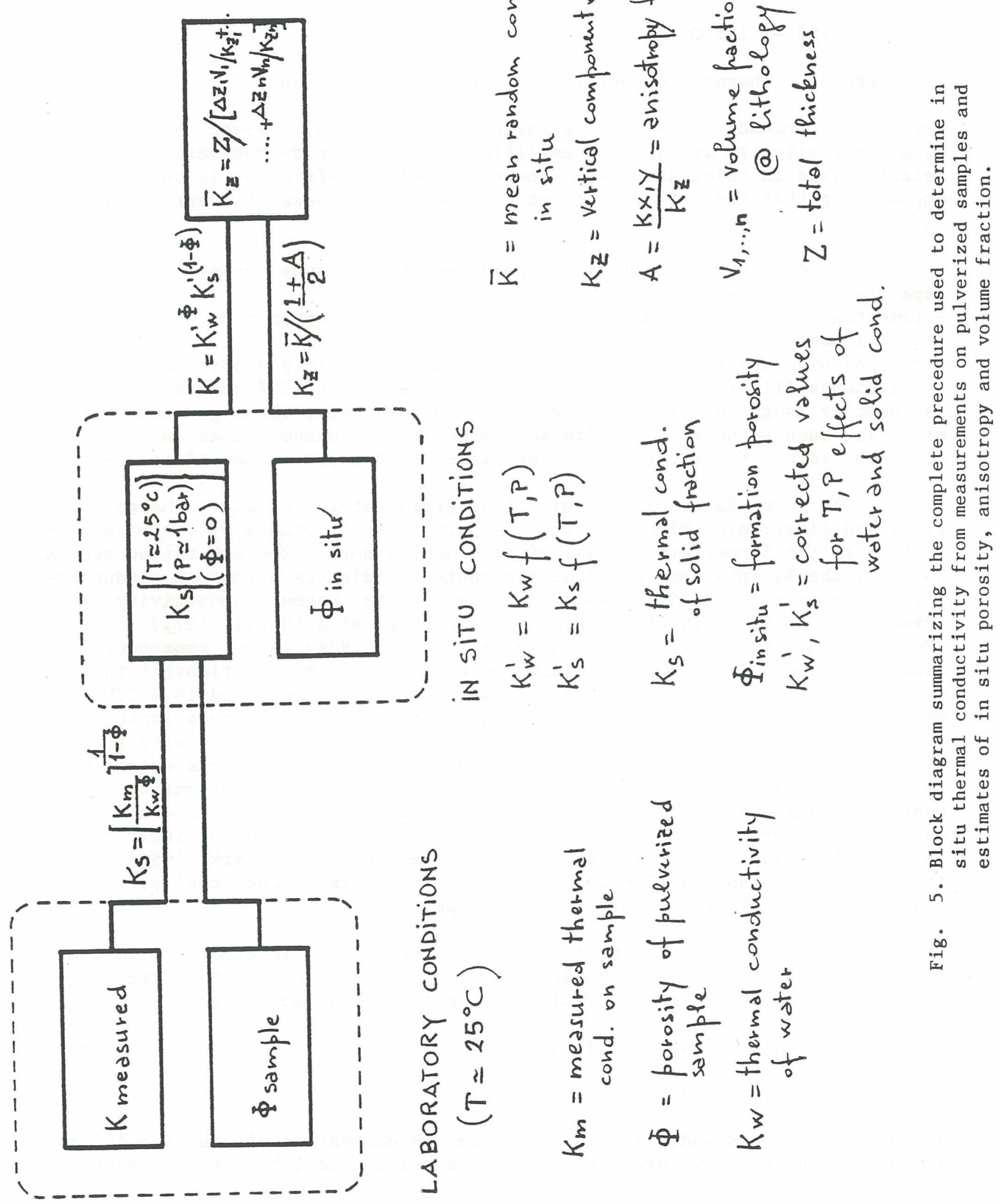


The quartz content data are reported in Table' 4 and the plots of sample quartz content vs. depth in COST B-2 and COST B-3 are shown in Fig. 6. The quartz content versus the solid thermal conductivity (Fig. 7) shows a strong positive correlation which can be represented by:

$$
\mathrm{K}_{\mathrm{s}}=4.53+.151 \mathrm{Qtz} \%
$$

where $\mathrm{K}_{\mathrm{s}}=$ thermal conductivity of the solid fraction.

The scatter around the best fit straight line is large; however, errors in $\mathrm{K}_{\mathrm{m}}$ and porosity $(\Phi)$ are greatly amplified by the Woodside-Messmer (1961) relation used in calculating $\mathrm{K}_{\mathrm{s}}$. The correlation coefficient is only 0.71 , emphasizing that (eqn. 4) should not be used for purposes of accurate calculations.

The different lithologies considered in our study are reasonably well separated on such a plot:

- Limestones, clays and shales primarily occupy the region from 0 to $15 \%$ quartz content;

- samples with quartz contents higher than $25 \%$ are mainly sandstones;

- siltstones fill the intermediate range between 10 and $30 \%$ quartz content. As shown by Langseth (1984) for Arctic Ocean sediments, the high conductivity minerals, such as quartz, calcite and dolomite, are concentrated in the coarser fraction $(>62 \mu) ; K_{m}$ is positively correlated to the percentage of coarse fraction.

The lower $\mathrm{K}_{\mathrm{m}}$ associated with fine grain materials, e.g., shales, clays and limestones, might be affected more than the others by larger errors related to the incomplete removal of air bubbles during the saturation process. However, the $\mathrm{K}_{\mathrm{s}}$ intercept at $0 \%$ quartz content indicates a thermal conductivity of the matrix of 4.5 TCU which is close to the thermal conductivity of several common minerals: K-feldspar, plagioclase, mica (Horai, 1971), clay (Morin and Silva, 1984), common shale (Sekiguchi, 1984) and/or amorphous material (Fry, 1982). If we extrapolate the best fit linear relationship to $100 \%$ quartz, a value of 19.6 TCU is obtained. Horai (1971) measured 18.4 TCU (7.7 $\mathrm{Wm}^{-1} \mathrm{~K}^{-1}$ ) on pulverized quartz. Sekiguchi (1984) studied the relationship of conductivity of pure quartzose sandstone as a function of porosity applying different models; at zero porosity the thermal conductivity turns out to be 19.0 TCU. Thus it is reasonably clear that the conductivity of marine sediments and sedimentary rocks is strongly influenced by the abundance of quartz, as would be expected. Calcite and dolomite also have a high intrinsic contrast in therma1 conductivity ( 8.5 and 13 T.C.U., respectively; Clark, 1966). Thus their abundances should also be correlated with thermal conductivity, but we did not analyze these possible relationships.

The relationship of $\mathrm{K}_{\mathrm{s}}$ to quartz content can be incorporated in the simple geometric mean model (Woodside and Messmer, 1961a) to check the agreement between measured conductivities and calculated values using:

$$
\begin{aligned}
& \mathrm{K}_{\mathrm{calc} .}=\mathrm{K}_{\mathrm{w}}^{(\Phi)} \cdot(4.53+.151 \mathrm{Qtz} \%)(1-\Phi) \\
& \text { where } \mathrm{K}_{\mathrm{w}}=\text { water conductivity }
\end{aligned}
$$

The utility of this model is limited since the derivation of equation (5) is in part circular. However this analysis is still useful because the mean 

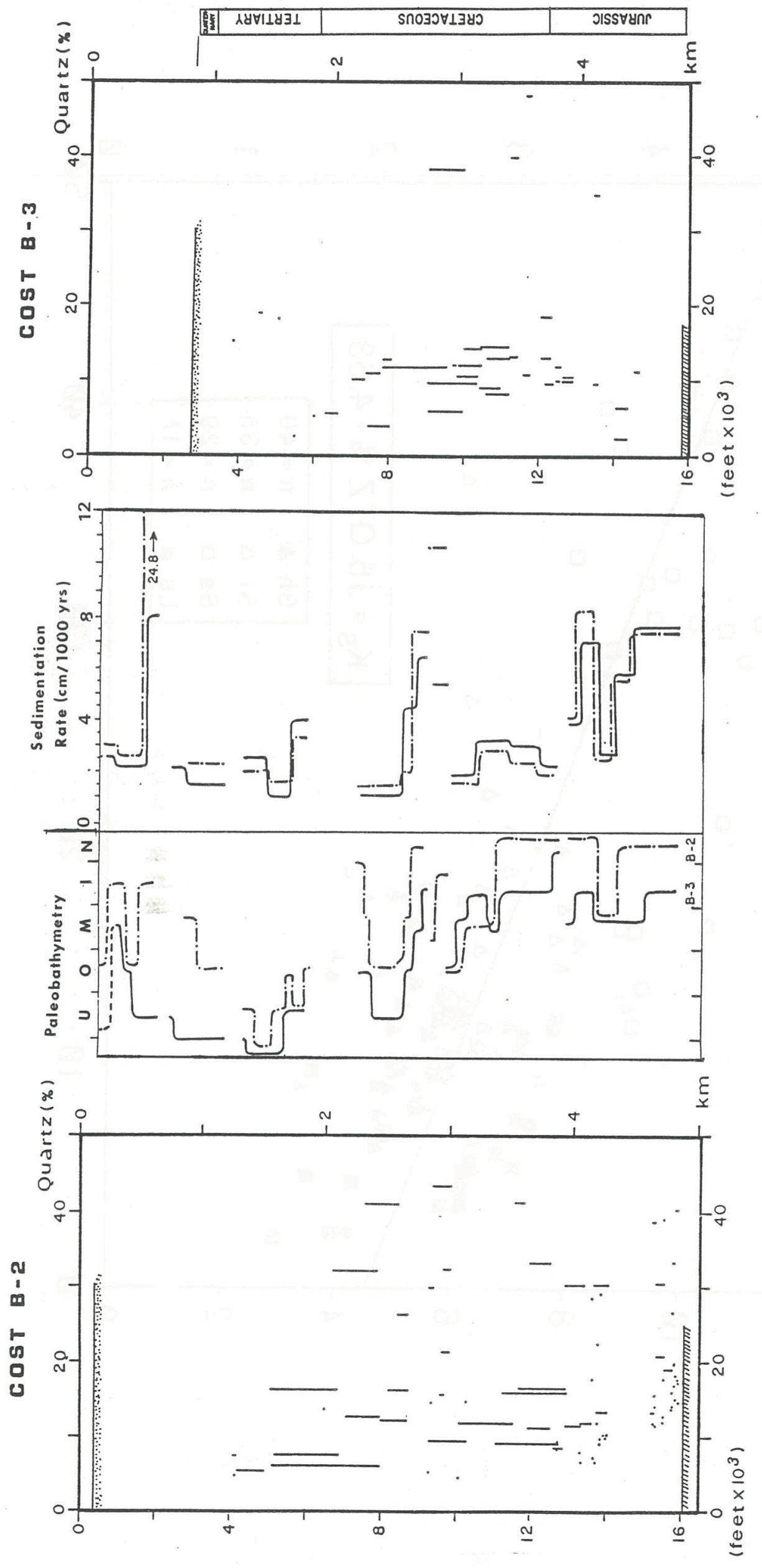

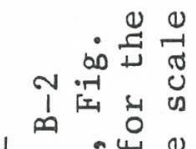

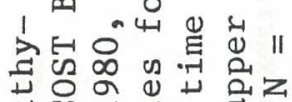

㟧 요요

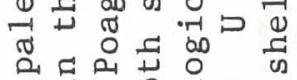
. न मे कि 范出

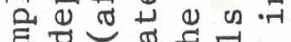

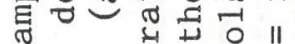
क 疍先 उ) की ने

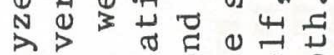

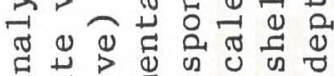
क

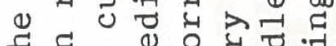

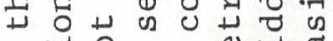

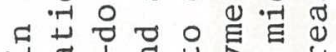
. 5 T

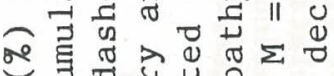

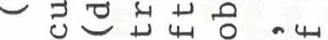
+ U ब थ 40 चี

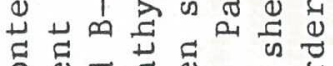
ปี

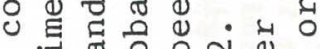

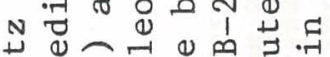

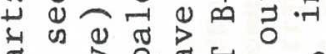

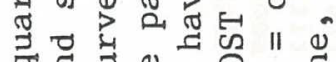

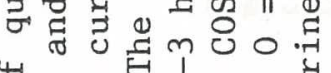

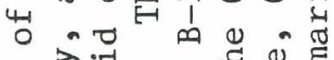

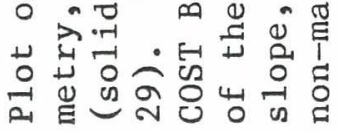
$\dot{0}$ $\underset{\substack{\infty \\ \dot{a n}}}{\dot{1}}$ 


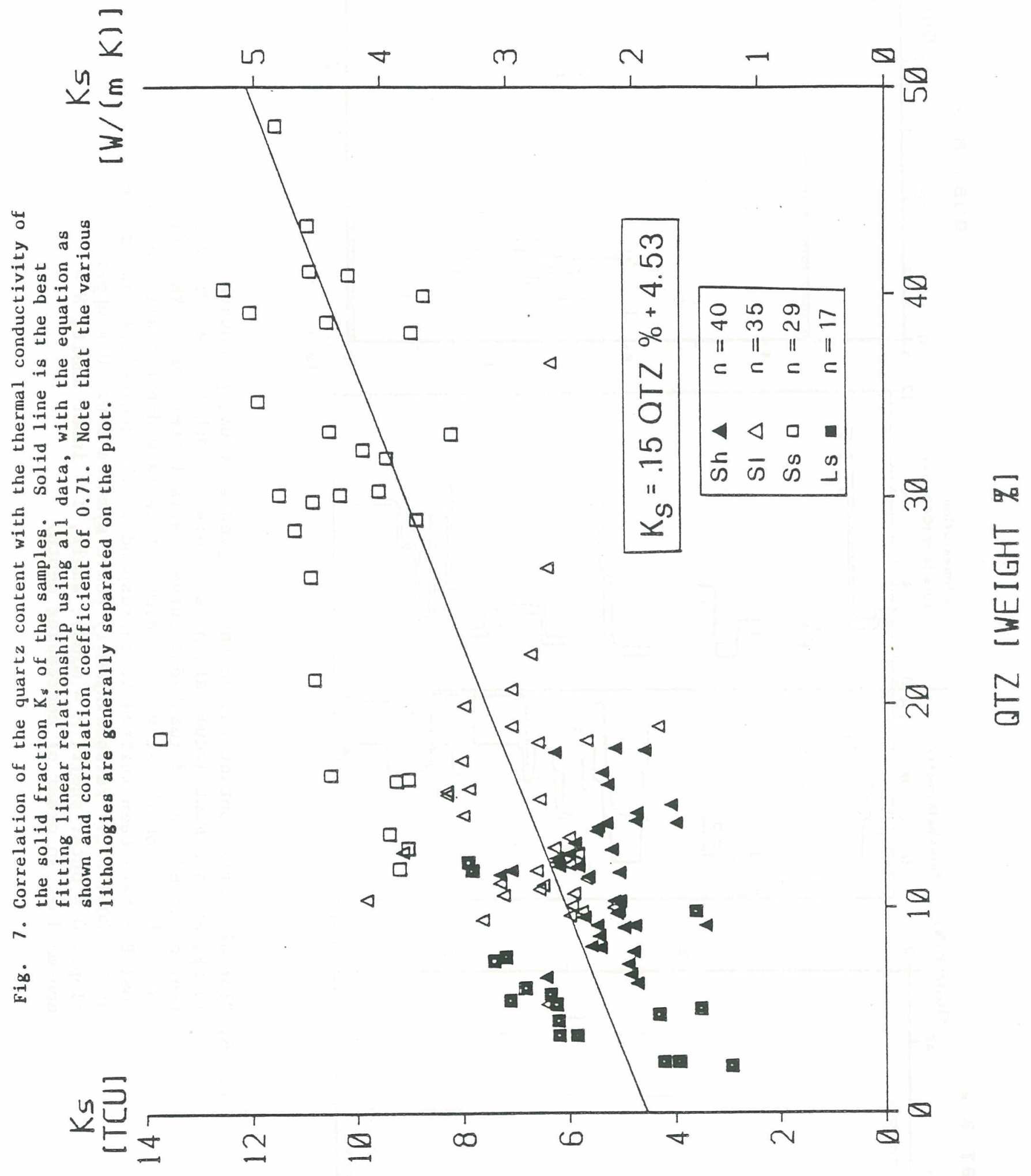


conductivities of randomly oriented quartz and free quartz matrix are known independently from the model. The plot of Fig. 8 illustrates the results of the comparison: 34 samples from COST B-2 and 40 from COST B-3 are shown with different symbols. Most of the calculated values are within \pm 0.3 T.C.U. $\left( \pm 0.13 \mathrm{Wm}^{-1} \mathrm{~K}^{-1}\right)$ of the measured ones. Thirteen samples have measured conductivities higher than calculated ones (11 sandstones, 1 limestone and 1 siltstone); these are probably caused by some other high conductivity minerals (perhaps calcite and/or dolomite) in the samples in addition to quartz, which increase the average thermal conductivity of the aggregate. Such minerals are more likely included in coarse sandstones or in limestones.

On the other hand there are 3 limestones, 1 sandstone and 1 siltstone with measured conductivities lower than calculated ones; this could be explained by the presence of significant amounts of low conductivity constituents such as amorphous material and non-crystalline carbonates. Errors, either in the measured or in the calculated conductivities (as a function of the quartz content) must also be considered. The general agreement of measured and calculated values appears to support the reliability of the approach.

\subsection{LITHOLOGY DISTRIBUTION AND IN SITU POROSITY ESTIMATE}

To obtain the mean in situ thermal conductivity over depth intervals, the volumetric fraction and the mean conductivity must be estimated for each 1ithology present. The mean conductivities for the various 1ithologies measured in our samples is given in Table 5. The lithology assignment for depth intervals of the COST B-2 well is based on Rhodehame1 (1977) and on a reevaluation of the 1ithologic log to distinguish between clays/shales and siltstones (Fig. 9). For the COST B-3 well it is based on a subjective interpretation of the lithologic log (Table 6) by assigning for each $25^{\prime}$ depth interval a certain proportion of each lithology.

Determination of the depth distribution of porosity is a major aim in explorative hydrocarbon drilling; it is measured directly on cores or estimated from well geophysical logs. The COST B-2 porosity data set is summarized over $1000 \mathrm{ft}$. depth intervals in Table 7. Sandstone porosities have been derived from density (FDC) and sonic (BHC) logs (Rhodehame1, 1977), measured on side wa11 cores (Smith et al., 1976; Core Laboratories, Inc., 1976), or evaluated from combinations of various well logs (Coriband, unpublished software by Schlumberger, Inc.). Shale porosities are estimated by the Coriband model or liquid pycnometry on chips. Siltstone and limestone porosities are derived from the Coriband model only. A few of these porosity distributions are shown in Fig. 10a-c.

Porosity data from the COST B-3 well were evaluated from Wu and Nichols (1980) LOGCALC models, utilizing the stratigraphic sequence of the lithologic log. The two we11-log-analysis models of Wu and Nichols (1980) which we used are:

1) a sand-shale log-analysis mode1 from 8200' to $12400^{\prime}$ depth.

2) a carbonate-sandstone model from 12688' to 15810' depth.

Outside these depth intervals they were estimated from the COST B-2 we11 porosity distribution and from core analyses (Core Laboratories, Inc., 1979). This causes the shale and siltstone porosities for the deeper intervals of the COST B-3 well (Table 9) to be relatively poorly constrained. 


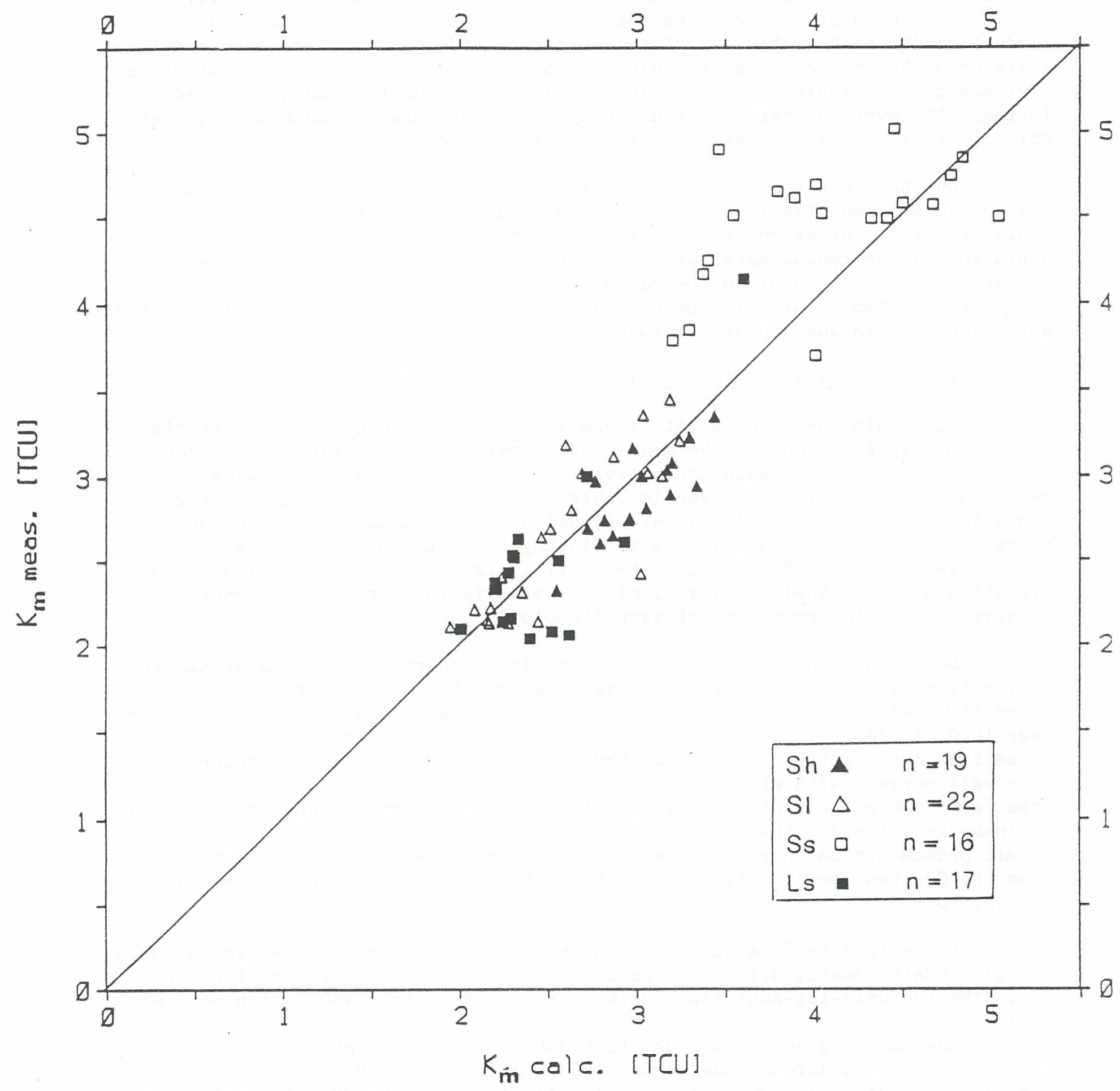

Fig. 8. Plot of the $K_{m}$ measured on the samples vs. $K_{m}$ calculated from equation (5). Line gives relationship for ratio of 1 between axis variables. 


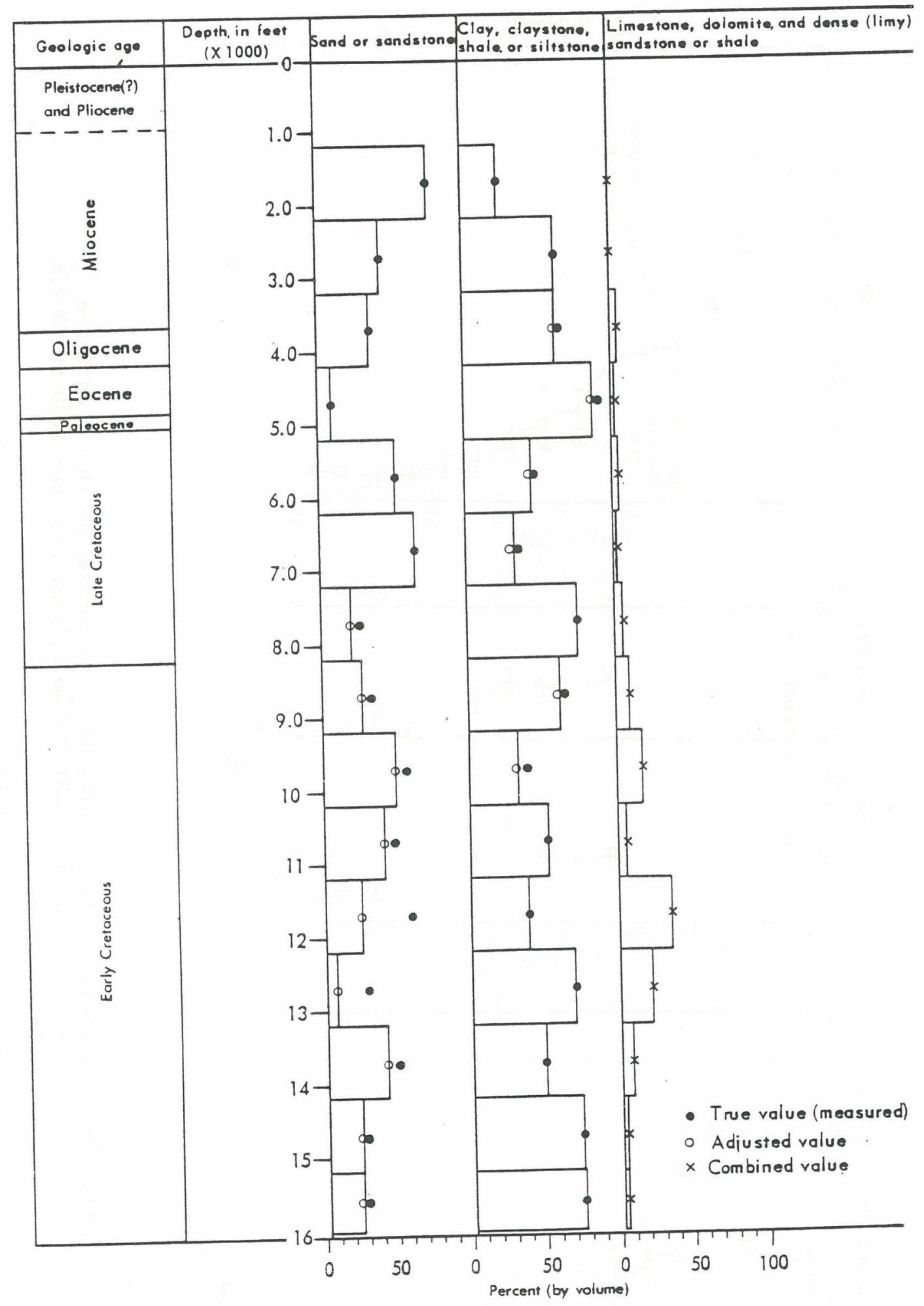

Fig. 9. Principal lithologies vs. depth in the COST B-2 well averaged over $1000 \mathrm{ft}(304.8 \mathrm{~m})$ intervals (from Rhodehame1, 1977, Fig. 7). 

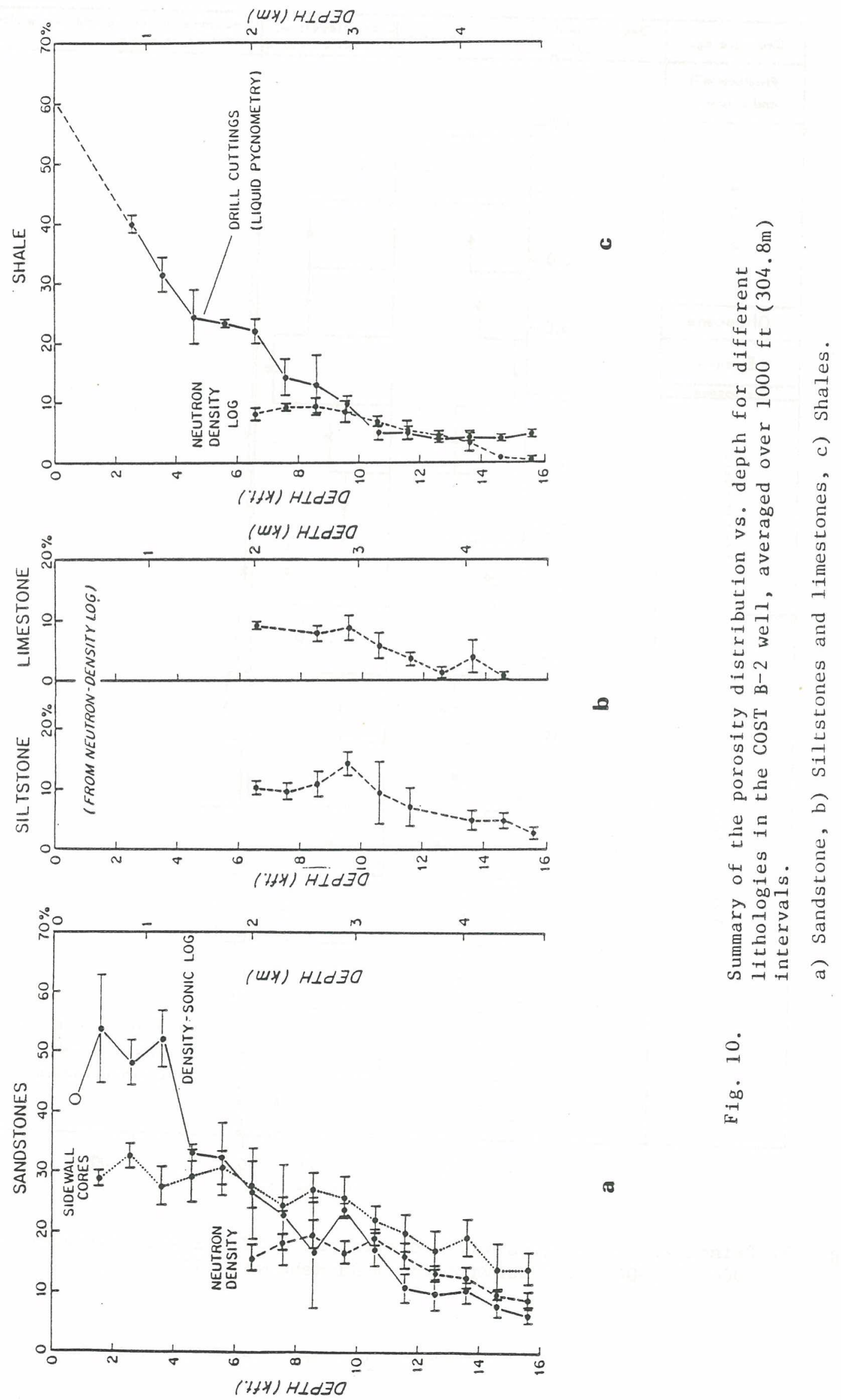

เ 
Table 6. COST B-3 Lithology in 1000-ft. (304.8 m) depth intervals

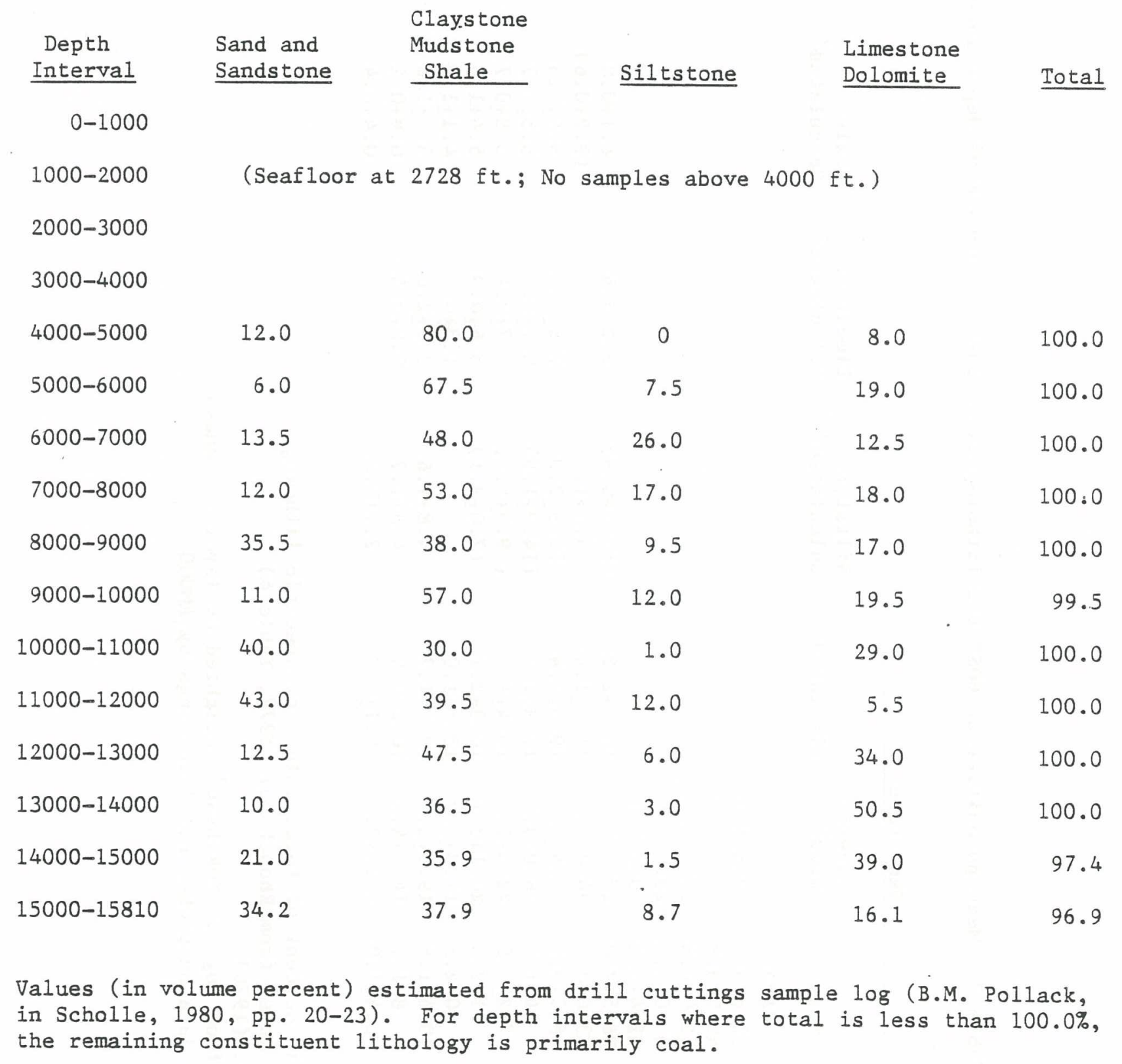




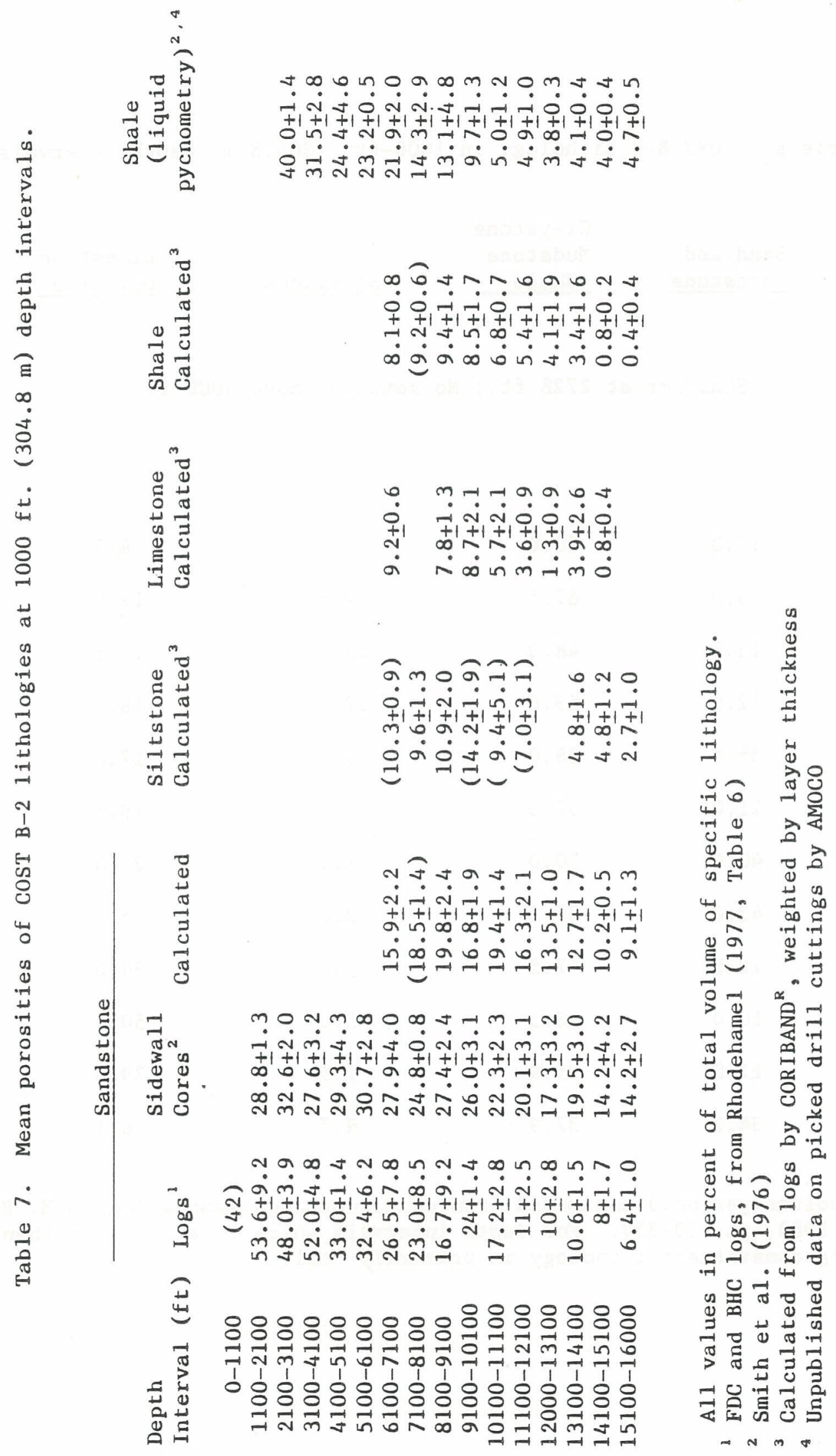




\subsection{MEAN IN SITU THERMAL CONDUCTIVITY AND ANISOTROPY CORRECTION}

According to our procedures (Figure 5) the mean thermal conductivity of the 1ithologies measured at laboratory conditions should be corrected for the in-situ pressures and temperatures before calculating the true $\mathrm{K}$ (with the formation porosities) by a second application of the Woodside and Messmer (1961a) geometric mean model (eqn. 3). The corrections for these in-situ conditions will be different for the solid matrix and fluid components of the lithologic types. The thermal conductivity of water increases directly with both pressure and temperature (Clark, 1966). Hydrostatic pressure and measured well temperature data (see below) were considered in correcting the pore water thermal conductivity as a function of depth on COST B-2 and COST B-3 we11s (Tables 8, 9).

The thermal conductivities of the solid phases generally increase with pressure (Kappelmeyer and Haene1, 1974; Lubimova et al., 1979); the increase in conductivity is around a few percent per $100 \mathrm{MPa}\left(1000 \mathrm{~kg} / \mathrm{cm}^{2}\right.$ ) for hard rocks or minerals, and may reach $10 \%$ or more for softer rocks such as claystone, siltstone and marlstone (Sekiguchi, 1984). This is related to the variation with pressure of the pore space more than variation in the conductivity of the grains, so that the effect of pressure for soft rocks is probably a function of the porosity.

On the other hand, the effect of temperature on thermal conductivity of rocks is significant and generally inversely correlated (Birch and Clark, 1940; Clark, 1966; Winkler, 1952; Schatz and Simmons, 1972; Kappelmeyer and Haene1, 1974; Lubimova et a1., 1979; Sekiguchi, 1984). On the basis of these studies, the following correction factors were chosen for the different 1ithologies:

\section{Lithologies Temp. coefficient}

$$
\begin{array}{ll}
\text { sands tone } & -1 \% / 5^{\circ} \mathrm{C} \\
\text { silts tone } & -1 \% / 10^{\circ} \mathrm{C} \\
\text { limestone } & -1 \% / 10^{\circ} \mathrm{C} \\
\text { shale } & -1 \% / 20^{\circ} \mathrm{C}
\end{array}
$$

The published data on shales are somewhat ambiguous. For example: Birch and Clark (1940) showed a slight decrease of conductivity with increasing temperature, whereas Winkler (1952) published an opposite trend. Sekiguchi (1984) suggests that the conductivity of poor conductors ( $4-5$ T.C.U.), such as shale with less than $25 \%$ porosity, and basalt, is nearly independent of temperature. These different results for shales are probably related to the porosity of the samples; at high porosities the pore fluid becomes relatively more important and the conductivity might increase with temperature (Winkler, 1952).

The pressure and temperature correction of $\mathrm{K}_{\mathrm{w}}$ and $\mathrm{K}_{\mathrm{s}}$ (for each lithology) were calculated for the mid-depth of the interval for which the porosity and volume fraction were available. Application of the WoodsideMessmer relation (eqn. 3) to the in-situ values of $\mathrm{Kw}$, Ks, and $\Phi$ gives the mean conductivity $\mathrm{K}$.

At this point we have reconstructed the mean random thermal conductivity $(K)$ of each lithology at depth without considering any anisotropy. 


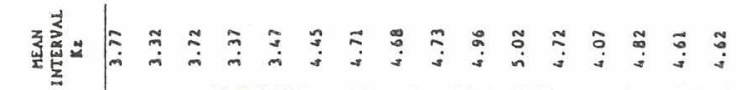

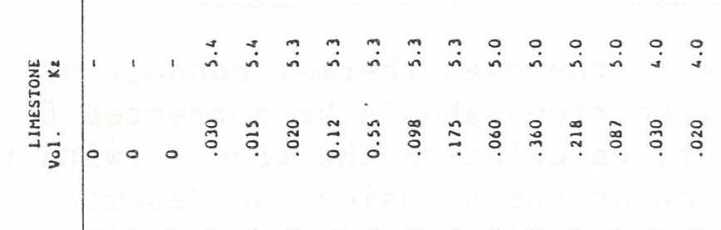

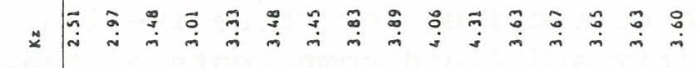
峌 崖艾

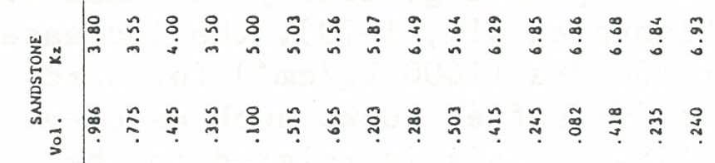

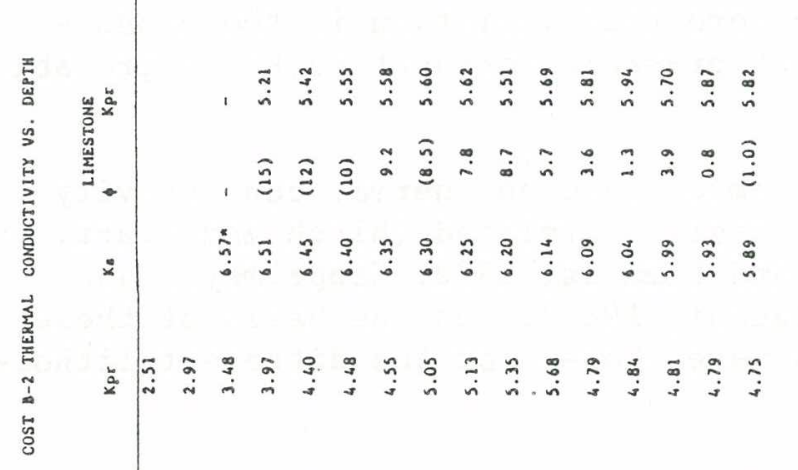

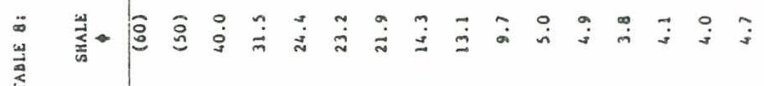

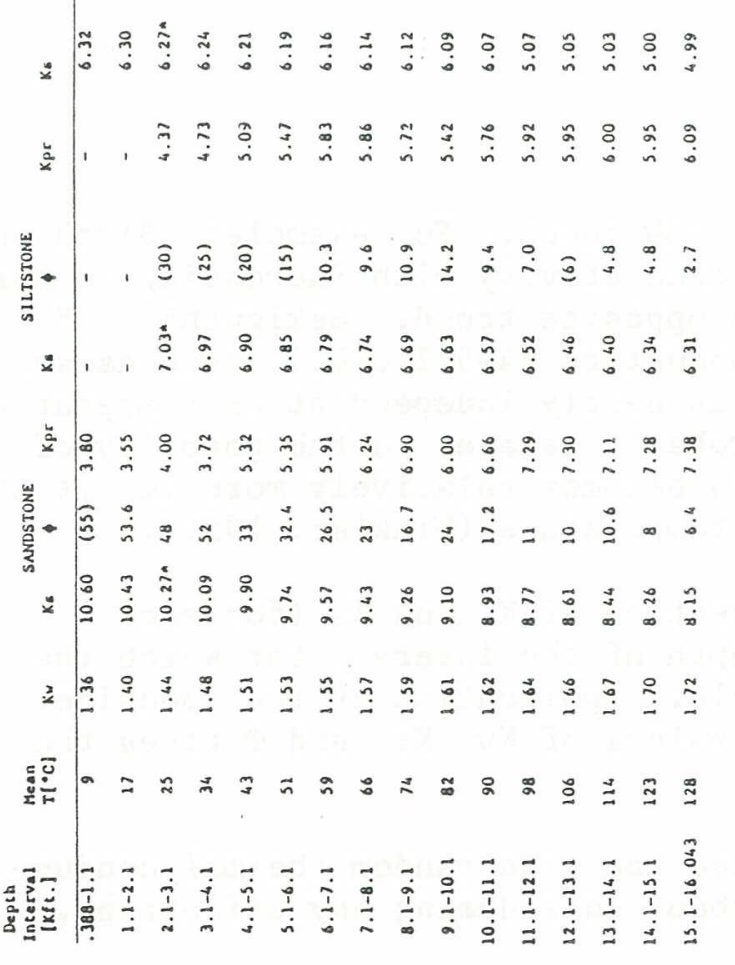

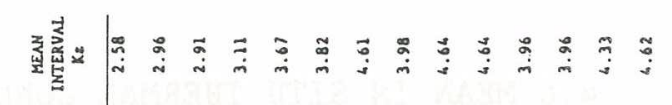

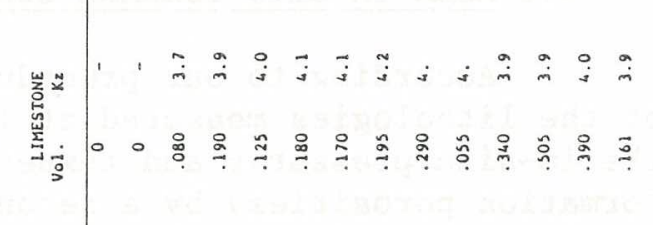

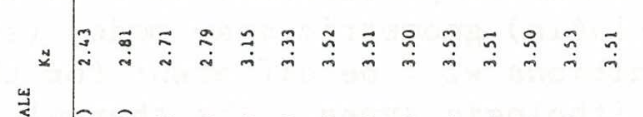

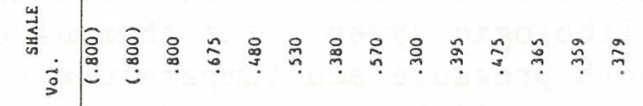

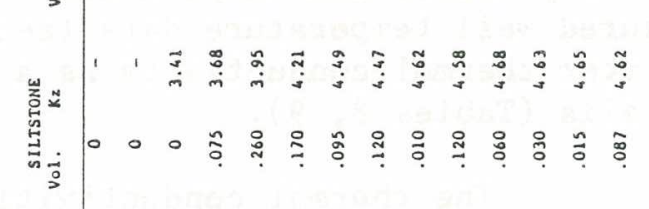

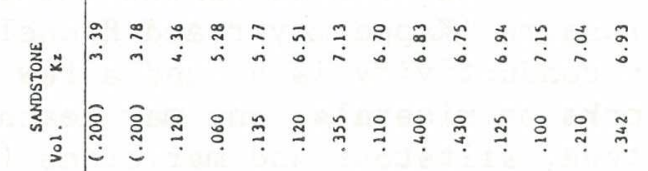

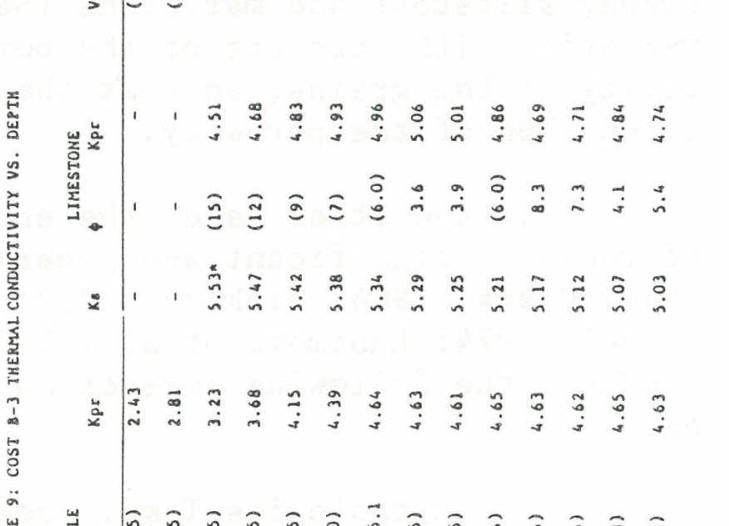

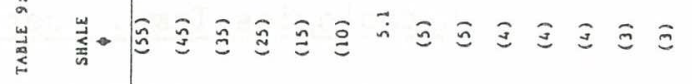

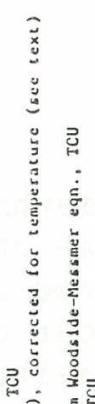

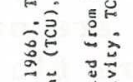

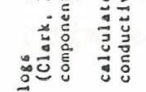

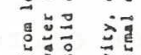

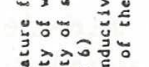

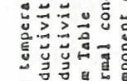

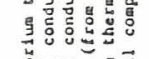

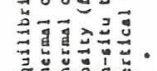

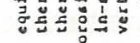
…… \&

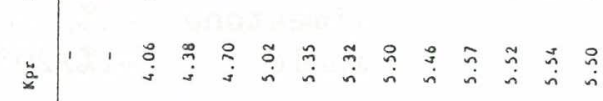

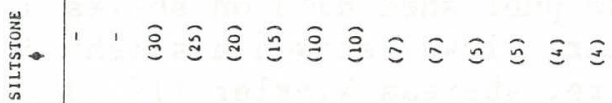

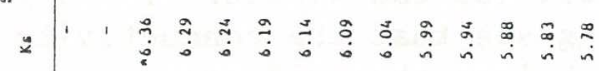
艾

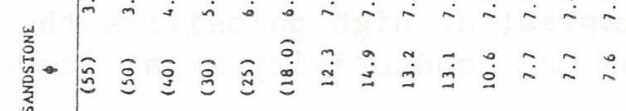

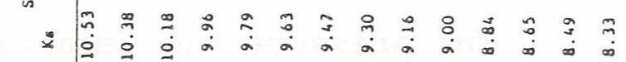

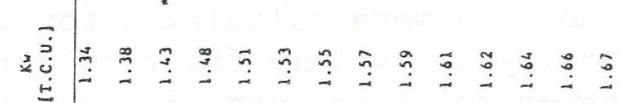

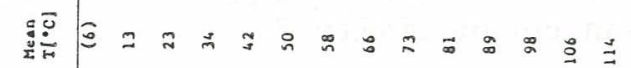
กำ

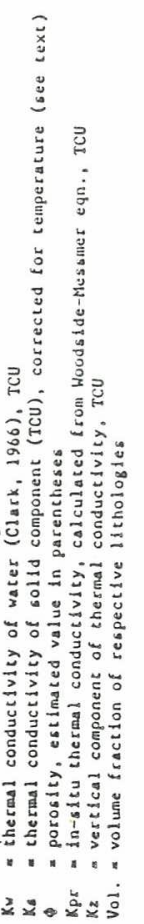


Sedimentary formations, such as those drilled at COST wells, show well defined bedding planes, layering, lamination, or foliation, particularly for shales and limestones. In many cases, the thermal conductivity is significantly less perpendicular to the bedding (vertical direction), than parallel to the bedding in the horizontal ( $\mathrm{x}-\mathrm{y}$ ) plane (Birch and Clark, 1940; Simmons, 1961; King and Simmons, 1972; Kappelmeyer and Haene1, 1974). The anisotropy effect may influence the final computation of heat flow by $30 \%$ or more (King and Simmons, 1972).

However, in pulverizing the samples any anisotropy due to bedding or texture was destroyed. Assuming a horizontal geometry of stratification (not exactly true in the case of COST B-3 well drilled on the slope) it is possible to calculate the vertical component of the thermal conductivity if the anisotropy factor $A(z)$ is known, where

$$
A=\frac{K_{x, y}}{K_{z}}
$$

and $\mathrm{K}_{\mathrm{x}, \mathrm{y}}$ is the conductivity parallel to bedding and $\mathrm{K}_{\mathrm{z}}$ is perpendicular to it. The conductivity in an arbitrary direction $\mathrm{K}_{\phi}$ is calculated (Kappelmeyer and Haene1, 1974, p. 57, eqn. 3.5) as

$$
K_{\phi}=K_{z} \cos ^{2} \phi+K_{x, y} \sin ^{2} \phi
$$

where $\phi$ is the angle between the direction and the perpendicular to bedding. Since the conductivity $\overline{\mathrm{K}}$ measured on pulverized rock is the result of random orientations of anisotropic material, we have

$$
\overline{\mathrm{K}}=\frac{\int_{0}^{\pi / 2} \mathrm{~K}_{\phi} \mathrm{d} \phi}{\int^{\pi / 2} \mathrm{~d} \phi}=\frac{\mathrm{K}_{\mathrm{z}}+\mathrm{K}_{\mathrm{x}, \mathrm{y}}}{2}=\frac{\mathrm{K}_{\mathrm{z}}(1+\mathrm{A})}{2}
$$

The anisotropy correction was applied below $3000 \mathrm{ft}$. K.B. (857 m below sea floor) for the COST B-2 and below $5000 \mathrm{ft}$. K.B. (693m below sea floor) for the COST B-3, considering that well-defined bedding and layering was significant at 1ithification depth (from lithologic logs) and below. Anisotropy is probably related to ambient pressure and temperature, as well as to diagenetic and metamorphic processes which occur over time, but with no further information we assumed a constant factor with depth.

Reasonable values of anisotrophy for each lithology have been assigned from the literature (previously cited papers), i.e., $A=1.1$ for sandstone, 1.3 for limestone, and 1.5 for shale. We have calculated the average conductivity $\mathrm{K}_{\mathrm{z}}$ in each depth interval bounded with in-situ temperature measurements by considering the volume-averaged fraction of all the contributing 1ithologies:

$$
\overline{\mathrm{K}}_{\mathrm{z}}=\mathrm{Z} /\left[\Delta \mathrm{Z}_{1} \mathrm{~V}_{1} / \mathrm{K}_{\mathrm{z} 1}+\cdots+\Delta \mathrm{Z}_{\mathrm{n}} \mathrm{V}_{\mathrm{n}} / \mathrm{K}_{\mathrm{zn}}\right]
$$

with: $\nabla_{1}, \ldots, V_{n}=$ volume fraction of each lithology in the interval $\Delta \mathrm{Z}_{\mathrm{n}}$ $\Delta \mathrm{Z}_{1}, \ldots, \Delta \mathrm{Z}_{\mathrm{n}}=$ thicknesses of units 1 through $\mathrm{n}$, $\mathrm{K}_{\mathrm{z} 1}, \ldots, \mathrm{K}_{\mathrm{zn}}=$ in situ $\mathrm{K}_{\mathrm{z}}$ for each 1ithology. 


\subsection{ESTIMATION OF THERMAL CONDUCTIVITY FROM WELL LOGS}

We tried to find a general and reliable relationship between thermal conductivity and some of the rock physical properties to estimate the thermal characteristics of sedimentary rocks from standard geophysical well logs. Several previous studies of this type have attempted to address the problem; however, the relations obtained are applicable only for particular lithologies, mainly sandstones (Zierfuss and Van der Vliet, 1956, Tikhomirov, 1968, Anand et a1., 1973; Goss et a1., 1975) or siliciclastic and carbonate rocks (Houbolt and Wells, 1980). An empirical linear relationship between the ratio of sound velocity $\left(V_{p}\right)$ to thermal conductivity $(K)$ and formation temperature $\left(\mathrm{T}_{z}\right)$ is deduced in the latter study. The relation obtained from 10 North Sea wells has the form:

$$
\mathrm{K}_{\mathrm{z}}=\frac{\mathrm{V}_{\mathrm{p}} \cdot 77}{1.039\left(80.31+\mathrm{T}_{\mathrm{z}}\right)}
$$

where $\mathrm{K}_{\mathrm{z}}$ = vertical component of in situ thermal conductivity, in $\mathrm{Wm}^{-1} \mathrm{~K}^{-1}$.

A comparison of the average interval $\mathrm{K}_{\mathrm{z}}$ with the model of Houbolt and Wells (1980) for the COST B-2 wel1 shows a reasonable agreement (Fig. 11). The values of the compressional velocity $V_{p}$ for each lithology and their variation with depth were estimated from the sonic logs.

\subsection{EQUILIBRIUM TEMPERATURES AND THERMAL GRADIENTS}

Multiple logging runs were made to several depths during drilling of the COST B-2 and COST B-3 wells, and temperature measurements were recorded on most of these logs. In the COST B-2 a High Resolution Temperature log (HRT) was run as well.

Therefore, near-bottom hole temperatures (BHT) measured several times after cessation of drilling and circulation are available. True formation temperatures can be estimated with good accuracy (within $1^{\circ} \mathrm{C}$ ) if the total perturbing time $\left(t_{1}\right)$ (time elapsed during drilling of last 30 feet of well and subsequent circulation), and the time elapsed between end of circulation and the temperature measurement $\left(t_{2}\right)$ are known (Dowdle and Cobb, 1975; Fert1 and Wichmann, 1977; Middleton, 1979):

$$
B H T=T-C \ln \left(1+t_{1} / t_{2}\right)
$$

where $\mathrm{T}$ is the true temperature and $\mathrm{C}$ is a constant determined by least squares fit of equation (11). It is assumed that the disturbance due to circulation is of constant magnitude over its duration, and eqn. (11) is a good approximation when the in-situ temperatures are measured over at least several thermal time constants of the hole $\left(\mathrm{a}^{2} / \mathrm{k}\right.$, where $\mathrm{a}$ is the hole radius and $\mathrm{k}$ is thermal diffusivity of surrounding material) after cessation of circulation (Bullard, 1947). The information contained in the well logs and daily drilling reports is not always sufficient to accurately determine $t_{1}$ and $t_{2}$, particularly when the logging operations are interrupted by mud conditioning intervals, fishing attempts, reaming, etc. 

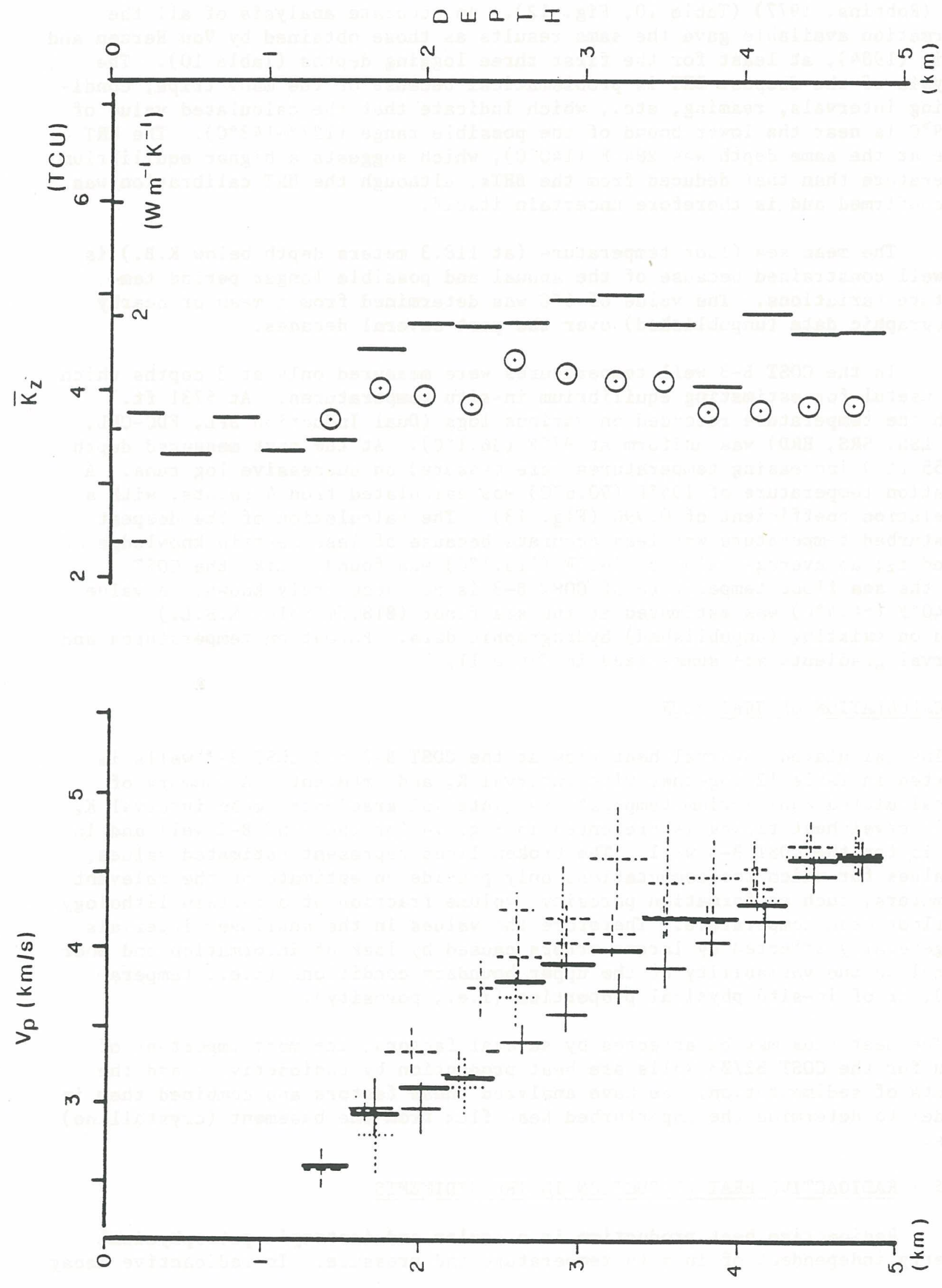

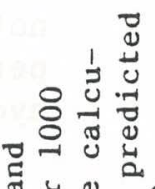

ธั

ये

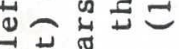

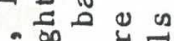

$\infty \begin{gathered}\infty \\ \infty\end{gathered}$

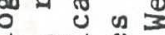

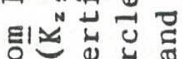

点 $>$

至

$\sum_{0 \rightarrow 1}^{-1}$ 을

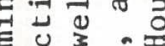

当

(1)

0 -1

구

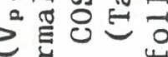

㟧 क

क స

击山先

两 $0>$

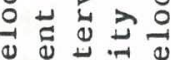

艺号

ט

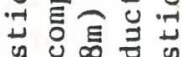

$\infty$.

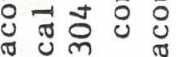

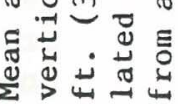

$\doteq$

$\underset{\substack{\infty \\ \text { in }}}{\infty}$ 
In the COST B-2 we11, 4 BHTs were measured at various depths in the hole (Robbins, 1977) (Table 10, Fig. 12). An accurate analysis of all the information available gave the same results as those obtained by Von Herzen and Helwig (1984), at least for the first three logging depths (Table 10). The analysis of the deepest BHT is problematical because of the many trips, conditioning intervals, reaming, etc., which indicate that the calculated value of $127.9^{\circ} \mathrm{C}$ is near the lower bound of the possible range $\left(127^{\circ}-143^{\circ} \mathrm{C}\right)$. The HRT value at the same depth was $284^{\circ} \mathrm{F}\left(140^{\circ} \mathrm{C}\right)$, which suggests a higher equilibrium temperature than that deduced from the BHTs, although the HRT calibration was not confirmed and is therefore uncertain itself.

The mean sea floor temperature (at 118.3 meters depth below K.B.) is not well constrained because of the annual and possible longer period temperature variations. The value of $6^{\circ} \mathrm{C}$ was determined from a mean of nearby hydrographic data (unpublished) over the past several decades.

In the $\operatorname{COST}$ B-3 well temperatures were measured only at 3 depths which were useful for estimating equilibrium in-situ temperatures. At $5731 \mathrm{ft}$. depth the temperature recorded on various logs (Dual Induction SFL, FDC-CNL, FDC, LSS, SRS, HRD) was uniform at $97^{\circ} \mathrm{F}\left(36.1^{\circ} \mathrm{C}\right)$. At the next measured depth (12655 ft.) increasing temperatures were measured on successive 1 og runs. A formation temperature of $195^{\circ} \mathrm{F}\left(90.6^{\circ} \mathrm{C}\right)$ was calculated fron 4 points, with a correlation coefficient of 0.996 (Fig. 13). The calculation of the deepest undisturbed temperature was less accurate because of less certain knowledge of $t_{1}$ and $t_{2}$; an average value of $241^{\circ} \mathrm{F}\left(116.1^{\circ} \mathrm{C}\right)$ was found. Like the COST $\mathrm{B}-2$, the sea floor temperature of $\operatorname{COST} \mathrm{B}-3$ is not accurately known. A value of $\sim 40^{\circ} \mathrm{F}\left(\sim 4.4^{\circ} \mathrm{C}\right)$ was estimated at the sea floor ( $818.7 \mathrm{~m}$ below M.S.L.) based on existing (unpublished) hydrographic data. Formation temperatures and interval gradients are summarized in Table 11.

\section{CALCULATION OF HEAT FLUX}

The calculated interval heat flow at the COST B-2 and COST B-3 wells is reported in Table 12 together with interval $\mathrm{K}_{\mathrm{z}}$ and gradient. A summary of the calculated equilibrium temperatures, interval gradients, mean interval $\mathrm{K}_{\mathrm{z}}$ and interval heat fluxes is presented in Fig. 14 for the COST B-2 well and in Fig. 15 for the COST B-3 well. The broken lines represent estimated values, or values for which the computations only provide an estimate of the relevant parameters, such as formation porosity, volume fraction of a certain lithology, sea floor mean temperature. Therefore the values in the shallower intervals are generally affected by larger errors caused by lack of information and poor control on the variability of the upper boundary conditions (i.e., temperature), or of in-situ physical properties (i.e., porosity).

The heat flux may be affected by several factors, the most important of which for the COST B2/B3 we11s are heat production by radioactivity and the effects of sedimentation. We have analyzed these factors and combined them in a model to determine the unperturbed heat flux from the basement (crystalline) rocks.

\subsection{RADIOACTIVE HEAT PRODUCTION IN THE SEDIMENTS}

Radioactive heat production is a scalar and isotropic petrophysical property independent of in situ temperature and pressure. In radioactive decay 


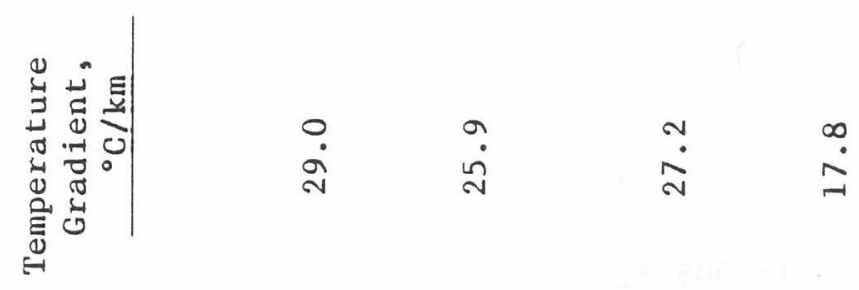

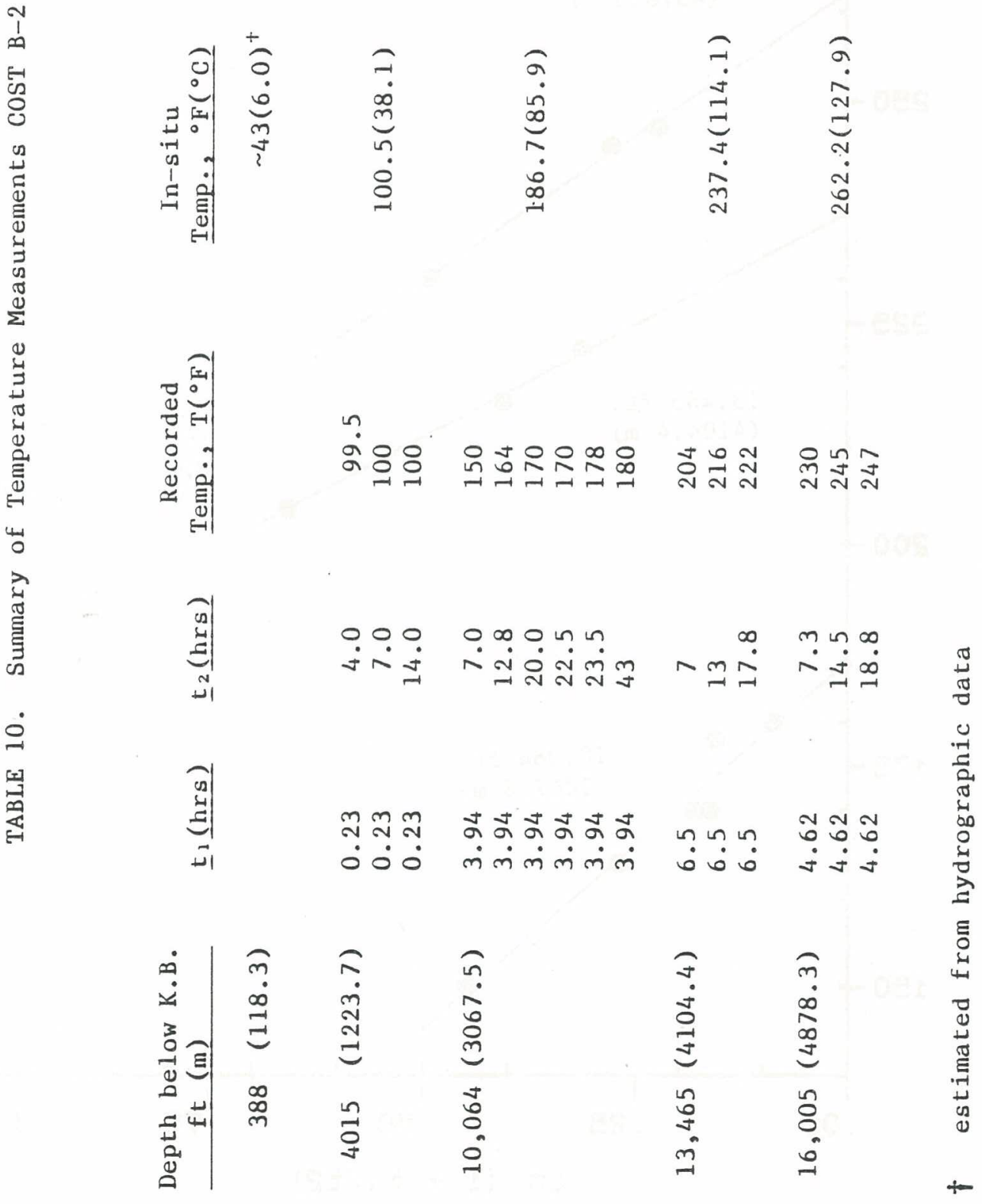




\section{COST B-2 DOWNHOLE TEMPERATURES}

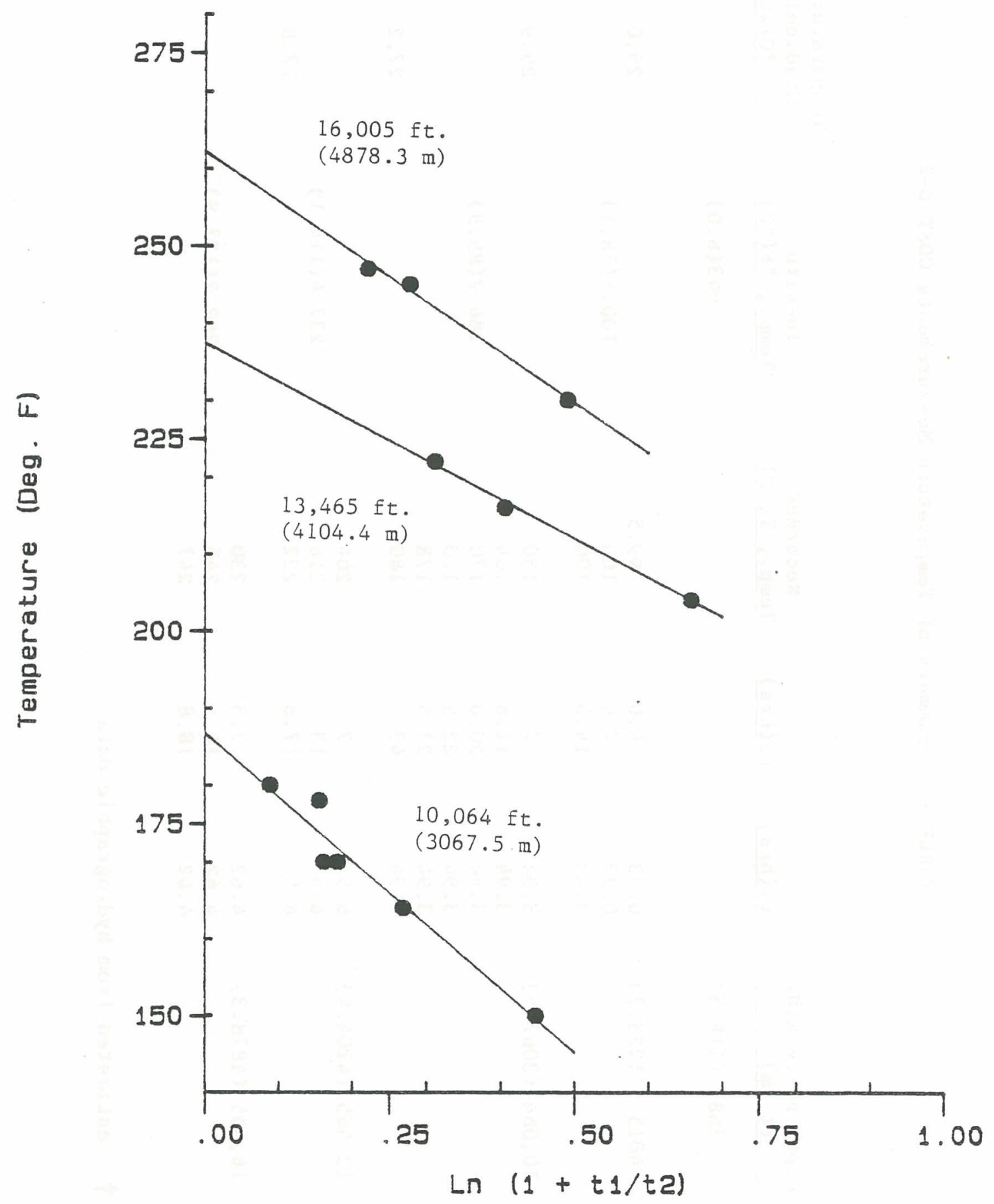

Fig. 12. Plot of recorded bottom hole temperatures vs. $\ln \left(1+t_{1} / t_{2}\right)$ for multiple $\log$ runs at three depths in the COST B-2 well. $t_{1}$ is total disturbance (circulation) time at each depth, and $t_{2}$ is the time since cessation of the disturbance. The temperature intercept is the undisturbed formation temperature (Table 10). 
TABLE 11. Summary of Temperature Measurements COST B-3

\begin{tabular}{|c|c|c|c|c|c|}
\hline $\begin{array}{l}\text { Depth below K.B. } \\
\text { ft (m) }\end{array}$ & $\underline{t_{1}(h r s)}$ & $\underline{t_{2}(h r s)}$ & $\begin{array}{c}\text { Recorded } \\
\text { Temp., } \mathrm{T}\left({ }^{\circ} \mathrm{F}\right) \\
\end{array}$ & $\begin{array}{l}\text { Calculated in-situ } \dagger \\
\text { Temp., To, }{ }^{\circ} \mathrm{F}\left({ }^{\circ} \mathrm{C}\right)\end{array}$ & $\begin{array}{c}\text { Temperature } \\
\text { Gradient, } \\
{ }^{\circ} \mathrm{C} / \mathrm{km} \\
\end{array}$ \\
\hline$(831.5)(\mathrm{SF})$ & --- & --- & $\sim 40$ & $\sim 40(4.4)$ & 34.6 \\
\hline $5731 \quad(1746.8)$ & $\begin{array}{l}0.365 \\
0.365 \\
0.365 \\
0.365\end{array}$ & $\begin{array}{r}9.0 \\
5.0 \\
11.0 \\
13.0\end{array}$ & $\begin{array}{l}96 \\
97 \\
97 \\
97\end{array}$ & $97(36.1)$ & 25.8 \\
\hline $12,655(3857.2)$ & $\begin{array}{r}6.57 \\
6.57 \\
15.5 ? \\
15.5 ? \\
15.5 ?\end{array}$ & $\begin{array}{c}7.75 \\
14.0 \\
80 \\
101.5 \\
103.5\end{array}$ & $\begin{array}{l}138 \\
156 \\
178 \\
(158) * \\
183\end{array}$ & $195(90.6)$ & 26.8 \\
\hline $15,779(4809.4)$ & $\begin{array}{l}5.4 \\
5.4 \\
5.4 \\
5.4 \\
5.4 \\
6.9\end{array}$ & $\begin{array}{r}11.25 \\
17.25 \\
24.75 \\
41.25 \\
51.75 \\
123.75\end{array}$ & $\begin{array}{l}210 \\
217 \\
225 \\
232 \\
239 \\
232\end{array}$ & $241(116.1)$ & \\
\hline
\end{tabular}

* Doubtful value, omitted from extrapolation to in-situ temperature

$\dagger$ Calculated by least-squares fitting of $T=T_{0}+A \cdot \ln \left(1+t_{1} / t_{2}\right)$

$t_{1}=$ total time of drilling/circulation disturbance at depth being considered.

$t_{2}=$ time from end of drilling/circulation disturbance to measurement. 


\section{COST B-3 DOWNHOLE TEMPERATURES}

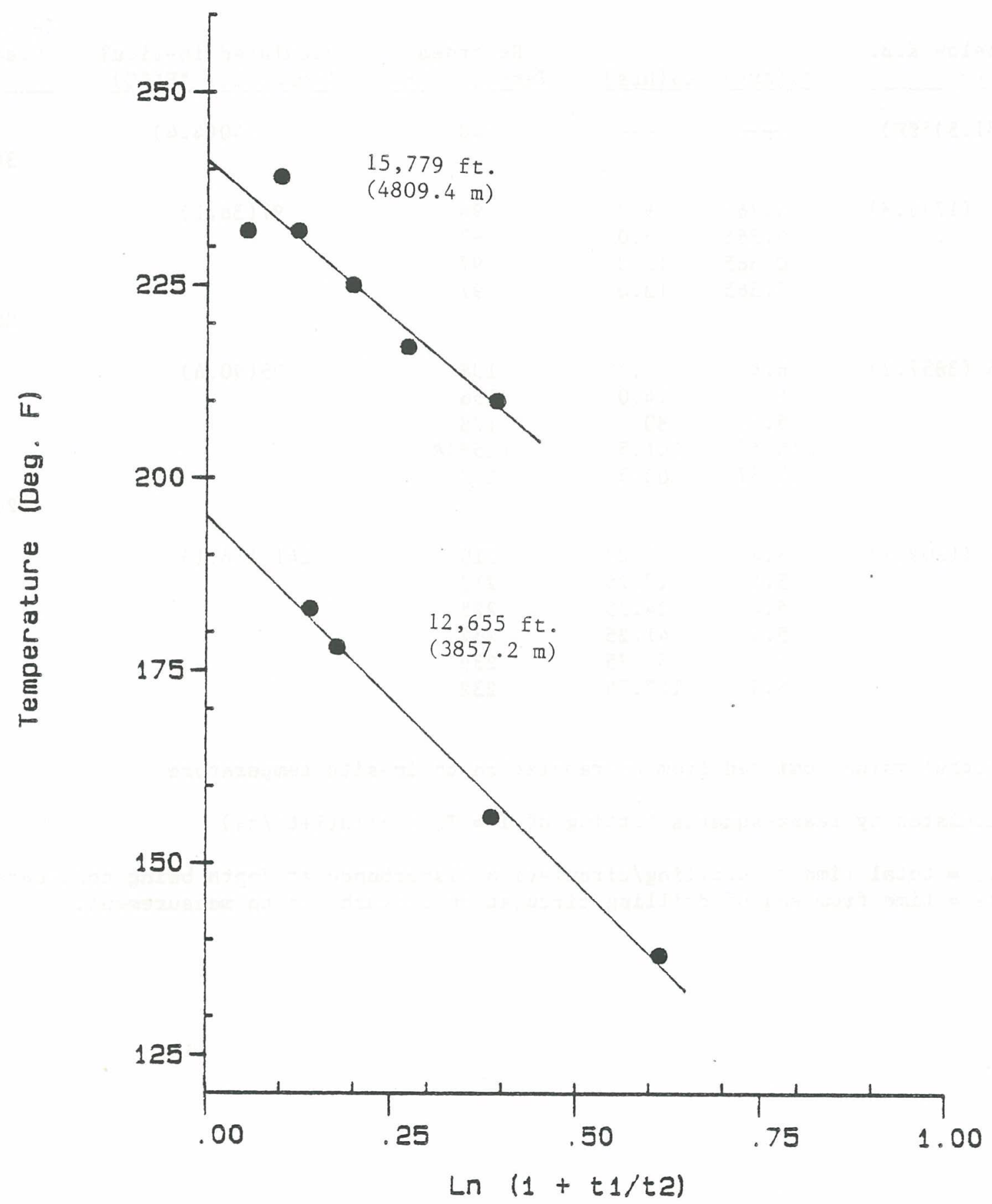

Fig. 13. Plot of recorded bottom hole temperatures vs. In $\left(1+t_{1} / t_{2}\right)$ for multiple log runs at two depths in the COST B-3 well. 


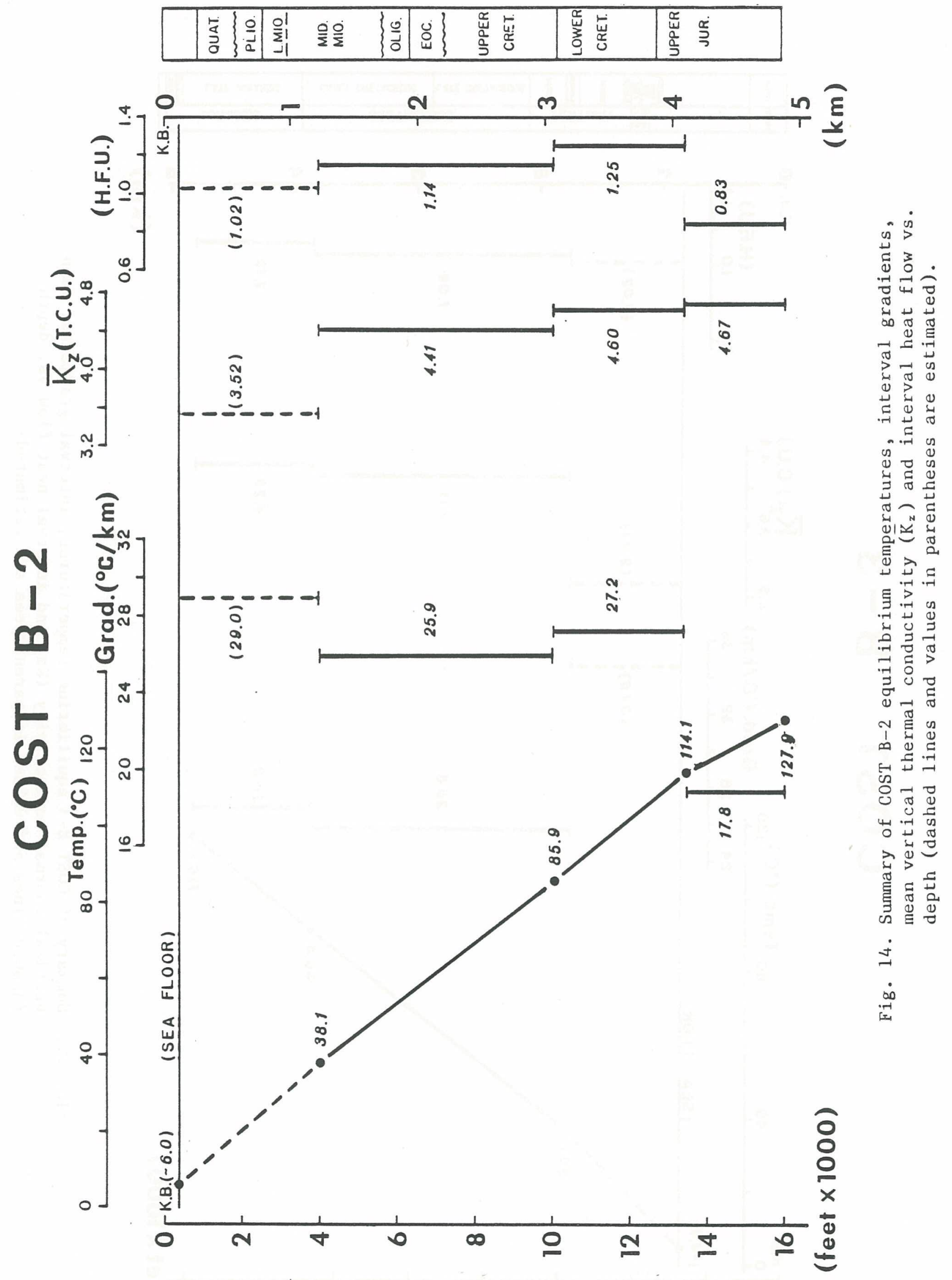




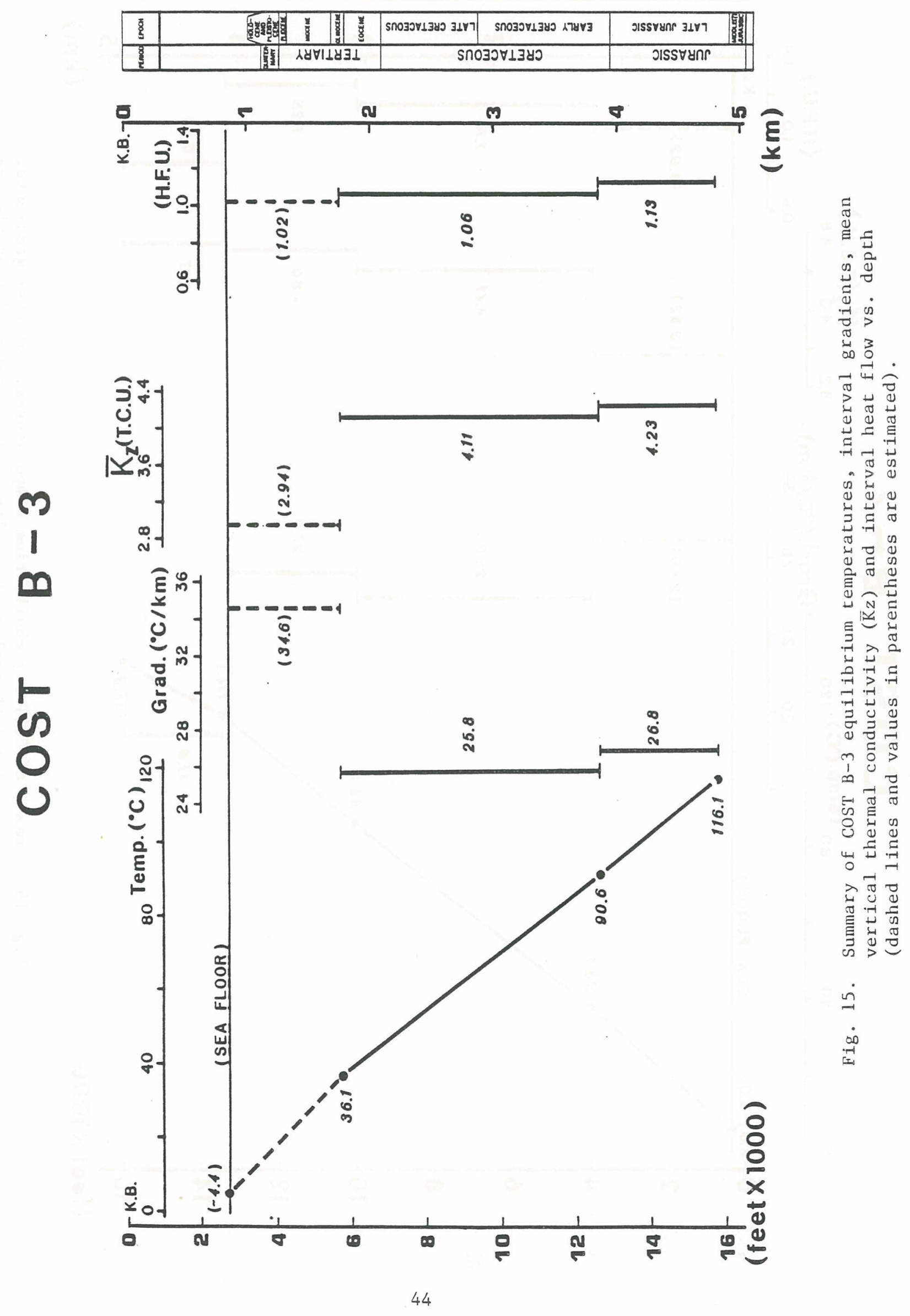




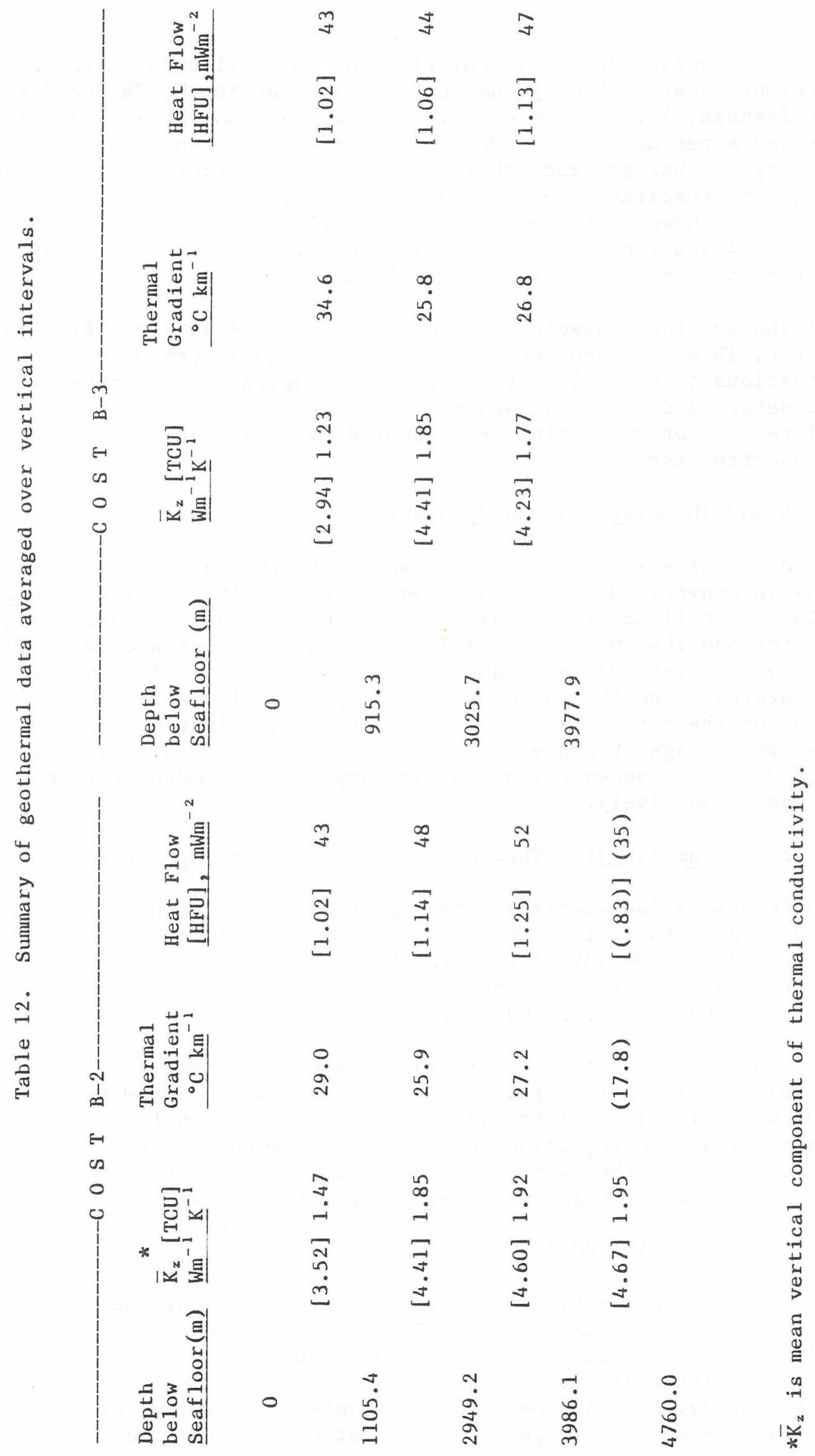


almost the entire decay energy is converted to heat. All natural radioactive isotopes generate heat, but only the contributions of the $U$, Th and ${ }^{40} \mathrm{~K}$ are significant (Rybach, 1976). Radioactive heat production is important in sedimentary sequences because it may provide an appreciable contribution to their thermal history (Richardson and Oxburgh, 1978). Its effect is to increase the heat flow and the temperature within the sediments. For example, Keen and Lewis (1982) have shown that the radiogenic heat production increases the heat flow by up to $15 \%$ and the present temperatures within the sediments by $17^{\circ} \mathrm{C}$ at $5 \mathrm{~km}$ depth for the continental margin off Nova Scotia.

Al1 the available samples ( 82 for COST B-2 plus 40 for COST B-3) were measured for $U$, Th and $K$ : neutron activation techniques were used to determine the concentrations of $U$ and Th for various 1ithologies. Total potassium content was determined by atomic absorption spectrophotometry (Appendix B). A more restricted set of 21 samples were counted for ${ }^{40} \mathrm{~K}$ peaks on a $\gamma$-ray spectrometer.

\section{a) $U$ and Th Determination By Neutron Activation}

$\mathrm{U}$ and Th analyses on the samples were performed at the U.S.G.S. Laboratories in Denver, C0, with a delayed neutron activation method (e.g., Amiel, 1962). A small amount of sample (less than $10 \mathrm{~g}$ ) is irradiated in a nuclear reactor and the induced $U$ and Th decay energy peaks are measured. The measuring time required for each sample is about 1 minute. A computerized routine calculates $U$ and Th concentration in ppm with the relative coefficient of variation and the ratio Th/U (Table 4). The coefficient of variation is expressed as percentage of concentration and is equal to 1 standard deviation. The range of $U$ and $T h$ concentration in our samples is bounded between $1-10 \mathrm{ppm}$ and 2.7-20 ppm respective1y.

\section{b) Potassium Analysis Through Atomic Absorption Spectrophotometry}

Atomic absorption spectrophotometry is an accurate analytical technique to measure the total potassium content of a sample (Appendix B). The potassium content in \% weight of each sample is reported on Table 4. The accuracy of the determinations is better than $0.1 \%$. The range of variability was found to fall between 0.06 and $3.53 \%$.

Since potassium in sedimentary rocks is mainly contained in potassiumrich feldspars, micas, illite, glauconite and other secondary minerals, its relative concentration is qualitatively related to the 1ithology of the sedimentary rocks. Thus a correlation should exist between potassium content and thermal conductivity of the solid fraction, $K_{s}$. A plot of $K_{s}$ as a function of the potassium content (Fig. 16) shows a significant inverse relationship:

$$
\mathrm{K}_{\mathrm{s}}=9.21-1.24 \cdot \mathrm{POT} \%
$$

The correlation coefficient is low, 0.48 , reflecting the data scatter particularly at low potassium content. This scatter appears to decrease as the potassium content increases. Similar to the plot of quartz content vs. $\mathrm{K}_{\mathbf{s}}$ (Fig. 7), the different 1ithologies are also separated on this plot of potassium content vs. $K_{s}$. At low potassium content two different coexisting lithologies cause a maximum range in $K_{s}$ : sandstones at the upper $K_{s}$ range 


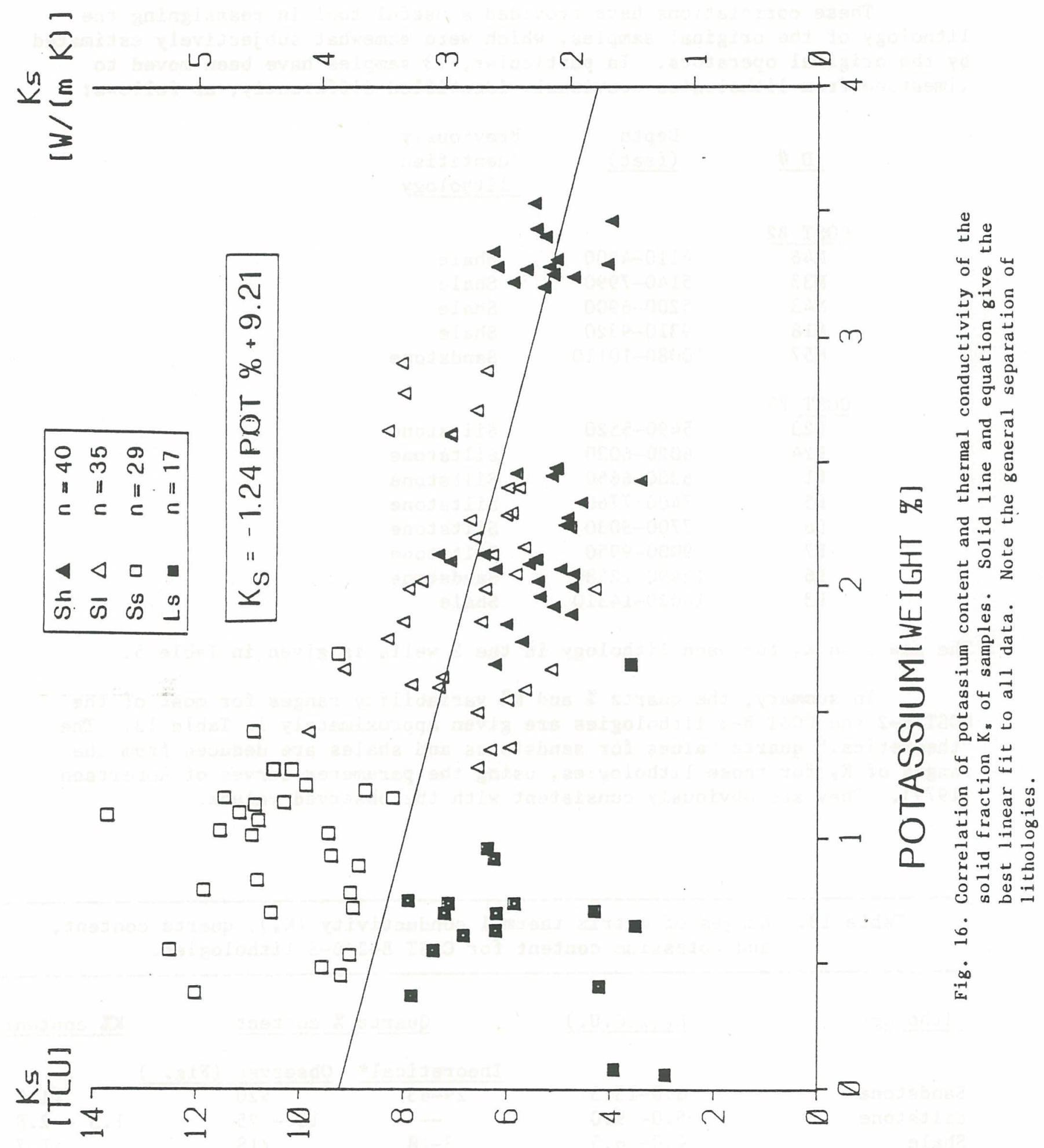


and limestones at the lower. Potassium concentrations higher than $3 \%$ are observed only in the deepest COST B-2 shales (from 15,000 to 16,000 feet).

These correlations have provided a useful tool in reassigning the lithology of the original samples, which were somewhat subjectively estimated by the original operators. In particular, 13 samples have been moved to limestone from 1ithologies previously identified differently, as follows:

\begin{tabular}{|c|c|c|}
\hline ID 非 & $\begin{array}{l}\text { Depth } \\
\text { (feet) }\end{array}$ & $\begin{array}{r}\text { Previous 1y } \\
\text { Identified } \\
\text { lithology }\end{array}$ \\
\hline \multicolumn{3}{|l|}{ COST B2 } \\
\hline M46 & $4110-4200$ & Shale \\
\hline M33 & $5140-7990$ & Shale \\
\hline M43 & $5200-6900$ & Shale \\
\hline M18 & $9310-9320$ & Shale \\
\hline M57 & $10080-10110$ & Sandstone \\
\hline \multicolumn{3}{|l|}{ COST B3 } \\
\hline B23 & $5490-5520$ & Siltstor \\
\hline B 24 & $6020-6030$ & Siltstone \\
\hline B1 & $6300-6650$ & Siltstone \\
\hline B5 & $7400-7760$ & Siltstone \\
\hline B6 & $7700-8030$ & Siltstone \\
\hline B7 & $9000-9950$ & Siltstone \\
\hline L6 & $12490-12580$ & Sands tone \\
\hline L3 & $14020-14310$ & Shale \\
\hline
\end{tabular}

The new mean $K_{s}$ for each lithology in the 2 wells is given in Table 5 .

In summary, the quartz $\%$ and $\mathrm{K} \%$ variability ranges for most of the COST B-2 and COST B-3 1ithologies are given approximately in Table 13. The "theoretical" quartz values for sandstones and shales are deduced from the ranges of $\mathrm{K}_{\mathrm{s}}$ for those lithologies, using the parameter curves of Robertson (1979). They are obviously consistent with the observed values.

Table 13. Ranges of matrix thermal conductivity $\left(K_{s}\right)$, quartz content, and potassium content for COST B-2/B-3 lithologies.

Lithology

Sandstone

Siltstone

Shale

Limestone
$\underline{K_{S}(T . C . U .)}$

$8 \cdot 0-13.5$

$5.0-9.0$

$4.0-6.5$

$3.5-8.0$
Quartz \% content

$\mathrm{K} \%$ content

Theoretica1* Observed (Fig.)

$\begin{array}{rrr}29-63 & >20 & <1.5 \\ -- & 10- & 25 \\ 3-18 & <18 & 1.3-2.8 \\ -- & <10 & >1.7 \\ & & <1.0\end{array}$

*from Robertson, 1979 


\section{c) ${ }^{40} \mathrm{~K} \gamma$-Ray Spectrometer Analysis}

The direct determination of ${ }^{40} \mathrm{~K}$ concentration through natural $y$-ray spectrometry is a relatively time consuming technique and has only moderate sensitivity (Lewis, 1974; Rybach, 1976). The natural $\gamma$-radiation intensities are low; therefore sample size and weight should be at least a few hundred grams (Rybach, 1976; Keen and Lewis, 1982). Since the COST B-2/B-3 samples were not more than 40-50 g each, only a limited set of samples was measured to check the results obtained with two independent methods.

Twenty-one samples were analyzed at the W.H.O.I. Y-spectrometer (Redfield laboratory, H. Livingston and D. Schneider). The mean detecting time was 14 hours each sample. Two Ge-Li detectors were used alternatively. The output counts per sec. were corrected for the background level, and the net signal was ratioed to the NBS SRM $4350{ }^{40} \mathrm{~K}$ standard of 0.54 disintegrations per second per gram. Calculating the number of ${ }^{40} \mathrm{~K}$ atoms and knowing the weight of a mole of ${ }^{40} \mathrm{~K}$, the weight in $\mathrm{g}$ of ${ }^{40} \mathrm{~K}$ per gram of sample can be obtained.

The ${ }^{40} \mathrm{~K}$ concentration in $\mathrm{ppm}$ is shown in Table 4. The total $\mathrm{K}$ concentratration was calculated, assuming a ratio ${ }^{40} \mathrm{~K} / \mathrm{K}$ equal to $1.167 \mathrm{x}$ $10^{-4}$ (Dohrenwend, et a1., 1984). The comparison of these results with the corresponding atomic absorption values gives an acceptable agreement (Fig. 17). A systematic enhancement of the potassium content of about $17 \%$ determined by the $\gamma$-spectrometer vs. the absorption spectrophotometric technique is attributed to an absolute calibration problem of the $\gamma$-spectrometer.

The $U$, Th and $K$ contents of $\operatorname{COST} B-2$ and COST B-3 samples, summarized on Tables 4 and 14, show that a significant correlation exists between their concentration and lithologies. The U (ppm) vs Th (ppm) plot (Fig. 18a)

TABLE 14. U, Th and Potassium Content and Heat Production of primary lithologies

\begin{tabular}{|c|c|c|c|c|c|}
\hline Lithology & $\begin{array}{l}\mathrm{K}(\%) \\
\text { Content } \\
\end{array}$ & $\begin{array}{l}\mathrm{U}(\mathrm{ppm}) \\
\text { Content }\end{array}$ & $\begin{array}{l}\text { Th (ppm) } \\
\text { Content }\end{array}$ & $\begin{array}{l}\text { Heat Production } \\
\text { COST B-2 }\end{array}$ & $\begin{array}{l}\left(\mu \mathrm{Wm}^{-3}\right) * \\
\operatorname{COST} B-3\end{array}$ \\
\hline Limes tone & $<1.0$ & $<5$ & $3-6(?)$ & $1.15 \pm .21(8)$ & $0.81 \pm .11(9)$ \\
\hline Sands tone & $<1.5$ & $<5$ & $3-20$ & $1.53 \pm .10(22)$ & $1.26 \pm .20(7)$ \\
\hline Siltstone & $1.3-2.8$ & $2-10$ & $4-18$ & $2.34 \pm .03(16)$ & $1.80 \pm .12(19)$ \\
\hline Shale & $>1.7$ & $3-6$ & $11-20$ & $2.37 \pm .03(36)$ & $2.15+.13(5)$ \\
\hline
\end{tabular}

* Values of heat production given are mean \pm standard error, number of measurements in parentheses.

shows different relationships for each 1ithology. Shales exhibit a nearly constant high $U$ (3-6 ppm) and high Th (11-20 ppm) content, siltstones show a more scattered distribution with $U$ between 2 and 10 ppm and Th between 4 and 


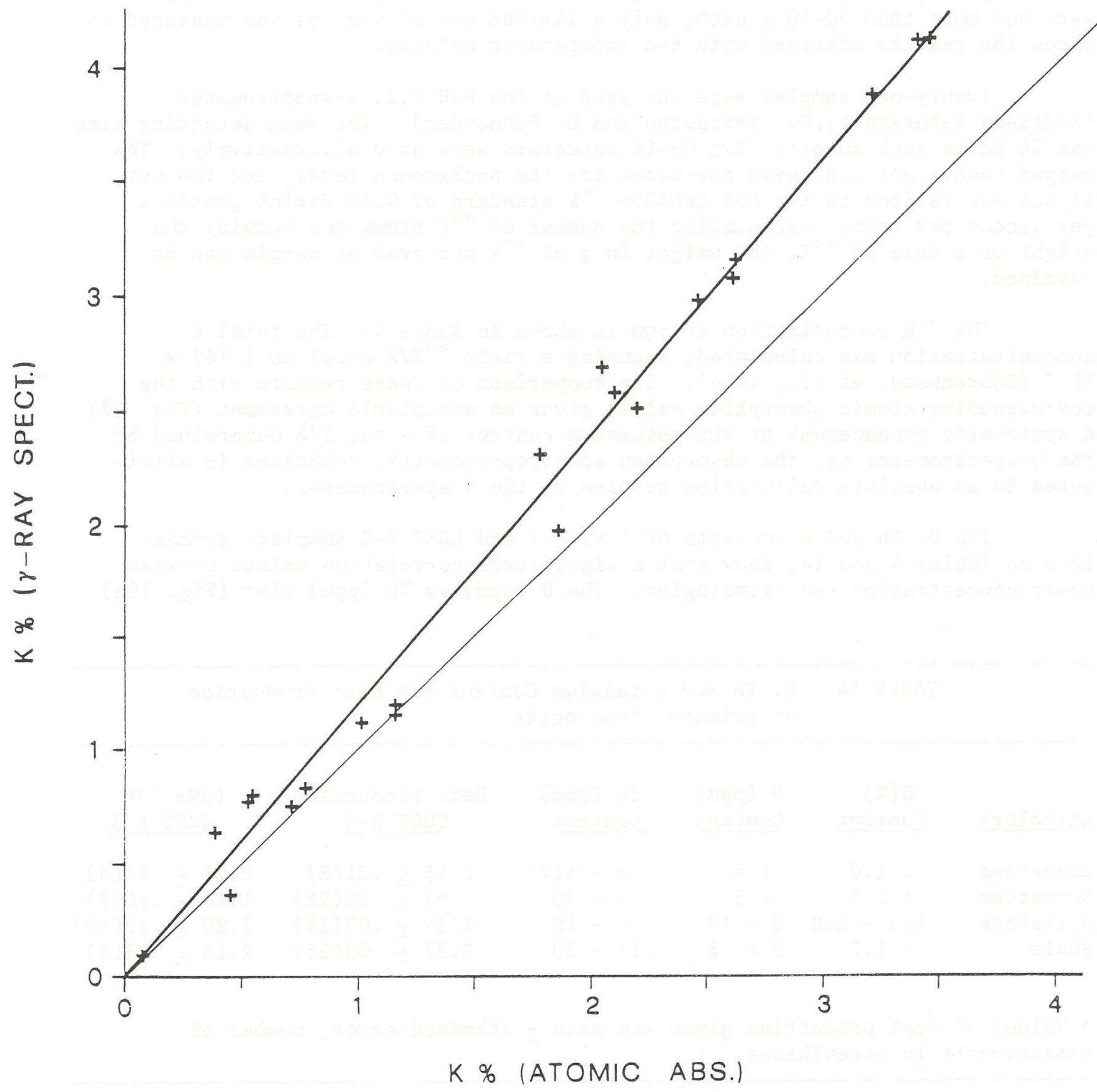

Fig. 17. P1ot of the 21 samples analyzed for potassium (K) with two techniques: $\gamma$-ray spectrometry and atomic absorption spectrophotometry. The heavy solid line is the best fit, and the thin line is the relationship of equivalence between both methods. 

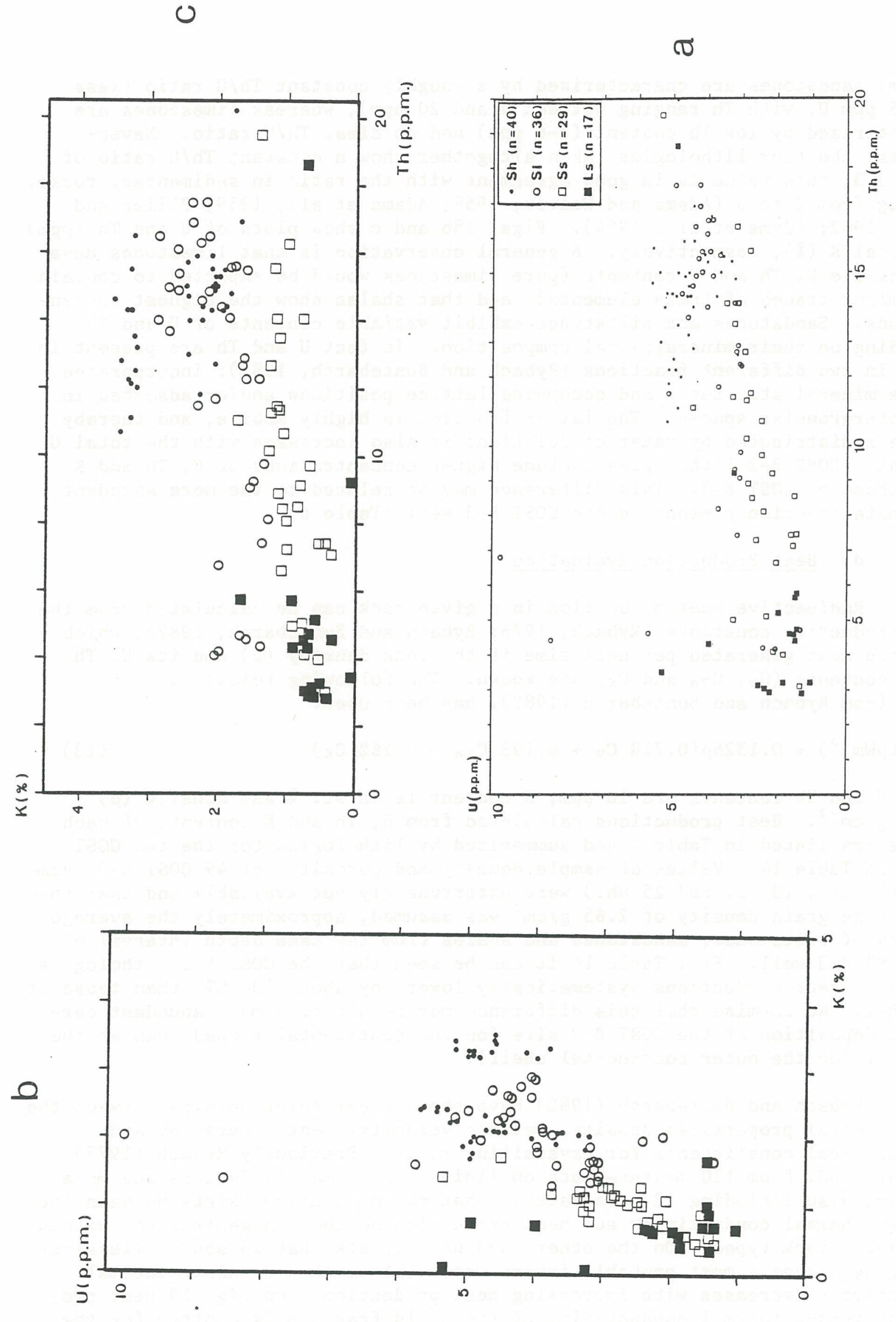

ลิ

$\checkmark$.

in

$>\rightarrow$

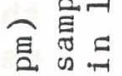

舟

$\ddots 1$
0

วิ

. ठ

ถิ चี

蚛

독

$\exists$.

동

붕

i

$>$

จำ

竞

ㄴ.

寻穴的

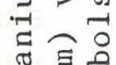

嵒言节

ज्ञ

ฮี

茨于

草导出 
$18 \mathrm{ppm}$, sandstones are characterized by a roughly constant Th/U ratio (1ess than 5 ppm U, with Th ranging between 4 and $20 \mathrm{ppm}$ ), whereas limestones are characterized by low Th content (3-6 ppm) and no clear Th/U ratio. Nevertheless, the four lithologies taken altogether show a constant Th/U ratio of about 3.3; this value is in good agreement with the ratio in sedimentary rocks, ranging from 2 to 5 (Adams and Weaver, 1958; Adams et a1., 1959; P1iler and Adams, 1962; Adams et a1., 1964). Figs. 18b and $c$ show plots of $U$ and Th (ppm) vs. total $\mathrm{K}(\%)$, respectively. A general observation is that limestones have appreciable $U$, Th and $K$ contents (pure limestones would be expected to contain only minor traces of these elements), and that shales show the highest concentrations. Sandstones and siltstones exhibit variable contents of $U$ and $T h$ depending on their mineralogical composition. In fact $U$ and Th are present in rocks in two different fractions (Rybach and Buntebarth, 1982): incorporated in the mineral structures and occupying lattice positions and/or adsorbed in the intergranular spaces. The latter fraction is highly mobile, and thereby may be redistributed by water circulation; it also increases with the total $U$ content. COST B-2 lithologies include higher concentrations of $U$, Th and $K$ than those of COST B-3. This difference may be related to the more abundant carbonate fraction present in the COST B-3 well (Table 6).

\section{d) Heat Production Evaluation}

Radioactive heat production in a given rock can be calculated from the heat production constants (Rybach, 1976; Rybach and Buntebarth, 1982), which give the heat generated per unit time if the rock density $(p)$ and its $U$, Th and $\mathrm{K}$ contents $\left(\mathrm{C}_{U}, \mathrm{C}_{\mathrm{Th}}\right.$ and $\mathrm{C}_{\mathrm{K}}$ ) are known. The following relation, taken from Rybach and Buntebarth (1982), has been used:

$$
A\left(\mu \mathrm{Wm}^{-3}\right)=0.1325 \rho\left(0.718 \mathrm{C}_{U}+0.193 \mathrm{C}_{\mathrm{Th}}+0.262 \mathrm{C}_{K}\right)
$$

where $U$ and Th contents are in ppm, K content is in wt. \% and density ( $\rho)$ is in $\mathrm{g} \mathrm{cm}^{-3}$. Heat productions calculated from $\mathrm{U}$, Th and $\mathrm{K}$ contents of each sample are listed in Table 4 and summarized by lithologies for the two COST wells in Table 14. Values of sample density and porosity for 49 COST B-2 samples (11 Ss., $13 \mathrm{~S} 1$. and $25 \mathrm{Sh}$.) were unfortunately not available and therefore an average grain density of $2.65 \mathrm{~g} / \mathrm{cm}^{3}$ was assumed, approximately the average density of siltstones, sandstones and shales from the same depth interval of the COST B-3 we11. From Table 14 it can be seen that the COST B-3 1ithologies have mean heat productions systematically lower (by about 10-30\%) than those of COST B-2. We surmise that this difference may result from more abundant carbonate deposition at the COST B-3 site (on the continental slope) than at the COST B-2 (on the outer continental shelf).

Rybach and Buntebarth (1982) have shown clear relationships between the petrophysical properties: density, seismic velocity, heat generation and mineralogical constituents for crystalline rocks. Previously Rybach (1975) demonstrated, from 110 measurements on Alpine rocks (mainly igneous and metamorphic, also including 12 carbonates), that no correlation exists between the average thermal conductivity and heat production neither in general nor within individual rock types. On the other hand he suggests that in sand-shale alternating sequences a most probable inverse correlation should exist: thermal conductivity decreases with increasing heat production. On Fig. 19 heat production versus thermal conductivity of the solid fraction is plotted for the 


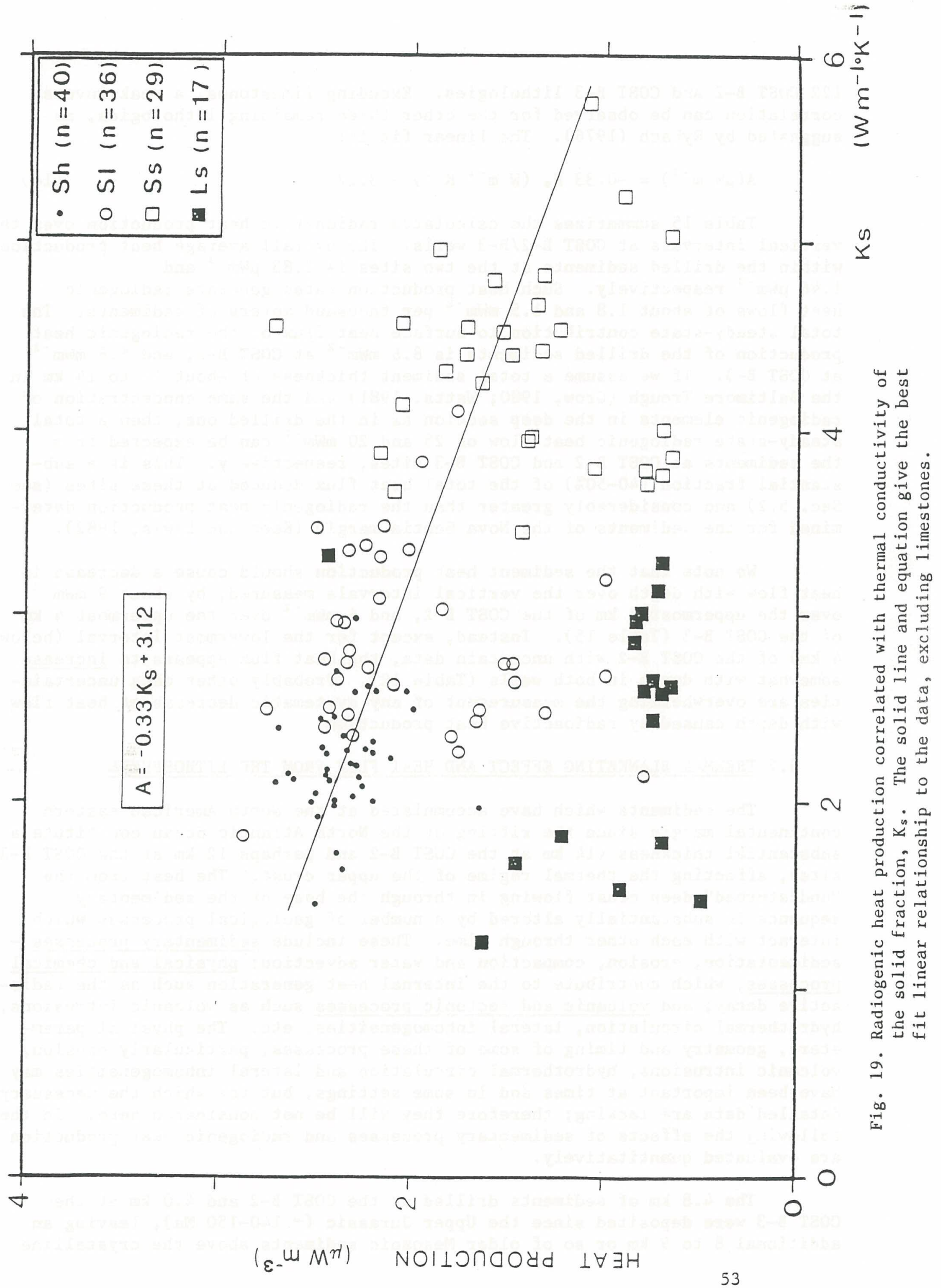


$122 \operatorname{COST}$ B-2 and COST B-3 1ithologies. Excuding limestones, a weak inverse correlation can be observed for the other three remaining lithologies, as suggested by Rybach (1976). The linear fit is:

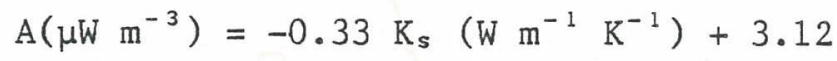

Table 15 summarizes the calculated radioactive heat production over the vertical intervals at COST $B-2 / B-3$ wells. The overall average heat production

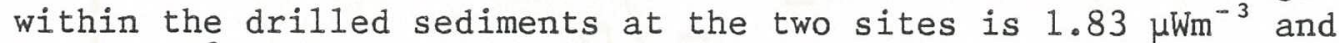
$1.46 \mathrm{NWm}^{-3}$ respectively. Such heat production rates generate radiogenic heat flows of about 1.8 and $1.5 \mathrm{mWm}^{-2}$ per thousand meters of sediments. The total steady-state contribution to surface heat flux of the radiogenic heat production of the drilled sediments is $8.6 \mathrm{mWm}^{-2}$ at COST $\mathrm{B}-2$, and $5.8 \mathrm{mWm}^{-2}$ at COST B-3. If we assume a total sediment thickness of about 12 to $14 \mathrm{~km}$ in the Baltimore Trough (Grow, 1980; Watts, 1981) and the same concentration of radiogenic elements in the deep section as in the drilled one, then a total steady-state radiogenic heat flow of 25 and $20 \mathrm{mWm}^{-2}$ can be expected from the sediments at COST B-2 and COST B-3 sites, respectively. This is a substantial fraction (40-50\%) of the total heat flux deduced at these sites (see Sec. 5.2) and considerably greater than the radiogenic heat production determined for the sediments of the Nova Scotia margin (Keen and Lewis, 1982).

We note that the sediment heat production should cause a decrease in heat flow with depth over the vertical intervals measured, by about $9 \mathrm{mWm}^{-2}$ over the uppermost $5 \mathrm{~km}$ of the COST B-2, and $6 \mathrm{mWm}^{-2}$ over the uppermost $4 \mathrm{~km}$ of the COST B-3 (Table 15). Instead, except for the lowermost interva1 (below $4 \mathrm{~km}$ ) of the COST B-2 with uncertain data, the heat flux appears to increase somewhat with depth in both wells (Table 12). Probably other data uncertainties are overwhelming the measurement of any systematic decrease of heat flow with depth caused by radioactive heat production.

\subsection{THERMAL BLANKETING EFFECT AND HEAT FLUX FROM THE LITHOSPHERE}

The sediments which have accumulated at the North American eastern continental margin since the rifting of the North Atlantic Ocean constitute a substantial thickness ( $14 \mathrm{~km}$ at the COST B-2 and perhaps $12 \mathrm{~km}$ at the COST B-3 site), affecting the thermal regime of the upper crust. The heat from the "undisturbed" deep crust flowing in through the base of the sedimentary sequence is substantially altered by a number of geological processes which interact with each other through time. These include sedimentary processes sedimentation, erosion, compaction and water advection; physical and chemical processes, which contribute to the internal heat generation such as the radioactive decay; and volcanic and tectonic processes such as volcanic intrusions, hydrothermal circulation, lateral inhomogeneities, etc. The physical parameters, geometry and timing of some of these processes, particularly erosion, volcanic intrusions, hydrothermal circulation and lateral inhomogeneities may have been important at times and in some settings, but for which the necessary detailed data are lacking; therefore they will be not considered here. In the following the effects of sedimentary processes and radiogenic heat production are evaluated quantitatively.

The $4.8 \mathrm{~km}$ of sediments drilled at the COST B-2 and $4.0 \mathrm{~km}$ at the COST B-3 were deposited since the Upper Jurassic ( 140-150 Ma), leaving an additional 8 to $9 \mathrm{~km}$ or so of older Mesozoic sediments above the crystalline 
TABLE 15. Calculated Radioactive Heat Production over vertical intervals.

Depth Interval

below K.B. (m)

$118.2(\mathrm{SF})-1223.7$

$1223.7-3067.5$

$3067.5-4104.4$

$4104 \cdot 4-4878.3$

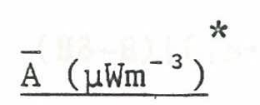

$\underline{\operatorname{cosT} B-2}$
Interval heat flow

Contribution $\left(\mathrm{mWm}^{-2}\right)$

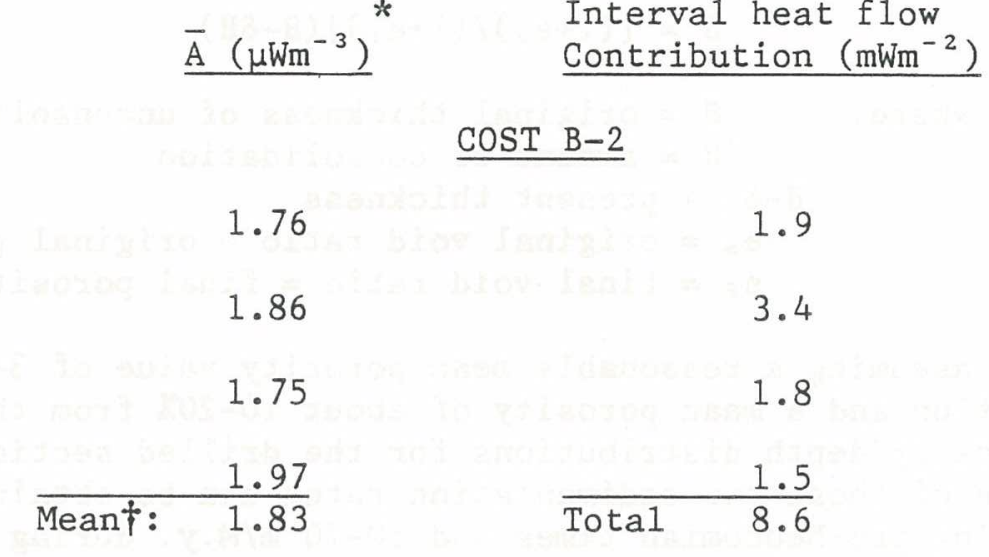

\section{$\underline{\operatorname{COST} B-3}$}

$831.5(\mathrm{SF})-1746.8$

1.76

1.6

$1746.8-3857.2$

1.43

3.0

$3857.2-4809 \cdot 4$

1.2
Total 5.8

* Calculated as $\overline{\mathrm{A}}=0.1325 \rho\left(0.718 \mathrm{C}_{u}+0.193 \mathrm{C}_{\mathrm{th}}+0.262 \mathrm{C}_{K}\right)$, from Rybach and Buntebarth (1982)

where $\mathrm{C}_{\mathrm{u}}, \mathrm{C}_{\mathrm{th}}$, and $\mathrm{C}_{\mathrm{K}}$ are respective concentrations of $U$, Th (both in $\mathrm{ppm}$ ), and $\mathrm{K}(\%)$, using the values measured in Table 14 considering the relative amounts of lithologies over depth intervals in Tables 8 and 9.

$\dagger$ Mean value weighted according to vertical intervals. 
basement. The total sediment accumulation in the Baltimore Trough (Fig. 20), mainly taken from Watts and Thorne (1984), shows two major distinct patterns: a very high deposition rate from the beginning of the rifting (some $190 \mathrm{Ma}$ ) until Neocomian times (about $130 \mathrm{Ma}$ ), followed by a much slower deposition up to the present; in this latter interval a significant increase in sedimentation during the Serravallian (15-11 Ma) can be observed (COST B-2). Applying the simple Hamilton (1959) formula:

$$
\mathrm{H}=\left[\left(1+\mathrm{e}_{\circ}\right) /\left(1+\mathrm{e}_{\mathrm{f}}\right)\right](\mathrm{H}-\delta \mathrm{H})
$$

where: $\quad H=$ original thickness of unconsolidated sediments $\delta \mathrm{H}=$ amount of consolidation

$\mathrm{H}-\delta \mathrm{H}=$ present thickness

$e_{\circ}=$ original void ratio = original porosity/(1-porosity)

$e_{\mathrm{f}}=\mathrm{final}$ void ratio $=$ final porosity/(1-porosity)

and assuming a reasonable mean porosity value of $3-5 \%$ for the older undrilled section and a mean porosity of about $10-20 \%$ from the COST B-2 and B-3

porosity/depth distributions for the drilled section (Fig. 10), a rough estimate of these two sedimentation rates can be obtained: about 300-350 m/M.y. during pre-Neocomian times and 50-70 m/M.y. during the last $130 \mathrm{M} . \mathrm{y}$. This latter value is in good agreement with Poag's (1980) estimate (Fig.6).

Assuming an average constant sedimentation of $150 \mathrm{~m} / \mathrm{M} . \mathrm{y}$. over $190 \mathrm{M} . \mathrm{y}$. and using Von Herzen and Uyeda's (1963) mode1, the surface non-radiogenic heat flow will be about the $70-75 \%$ of the value if no sedimentation would have taken place. The $\sim 45 \mathrm{mWm}^{-2}$ measured, reduced by the radiogenic contribution of 20-25 $\mathrm{mWm}^{-2}$, will result in a deep undisturbed heat flow of only 25-35 $\mathrm{mWm}^{-2}$ for a constant sedimentation rate of $150 \mathrm{~m} / \mathrm{M} \cdot \mathrm{y}$. for $190 \mathrm{M} \cdot \mathrm{y}$.

Recently, more realistic numerical models of the sedimentation processes, accounting for compaction, pore water movement and surface temperature changes have been developed (Hutchison, 1985). The physical onedimensional model consists of 2 main layers: the lower one is assumed to be non-porous basement, whereas in the upper layer the proportions of sediment grains and pore water change as the sediment column compacts. As the deposition proceeds and compaction take place, pore water is assumed to move upward (one-dimensionally) as a function of depth with respect to the subsiding basement surface. Radiogenic heat production within the sediments is also included in the model.

Appropriate physical and thermal constants for the sediments and interstitial water have been assumed in the model, and the heat flux at the basement interface is assumed constant. The mean matrix density, specific heat, and thermal conductivity of sediment grains are taken as $2650 \mathrm{~kg} \mathrm{~m}^{-3}$, $1045 \mathrm{~J} \mathrm{Kg}^{-1} \mathrm{~K}^{-1}$, and $2.5 \mathrm{~W} \mathrm{~m}^{-1} \mathrm{~K}^{-1}$, respectively; the same parameters for water are $1020 \mathrm{~kg} \mathrm{~m}^{-3}, 4180 \mathrm{~J} \mathrm{Kg}^{-1} \mathrm{~K}^{-1}$, and $0.67 \mathrm{~W} \mathrm{~m}^{-1} \mathrm{~K}^{-1}$. The dependence of these on temperature and pressure was not included. Compaction of sediments is assumed to have an exponential dependence with depth(z), so that porosity $(\Phi)$ is given by

$$
\Phi(z)=\Phi_{\circ} e^{-z / \lambda}
$$




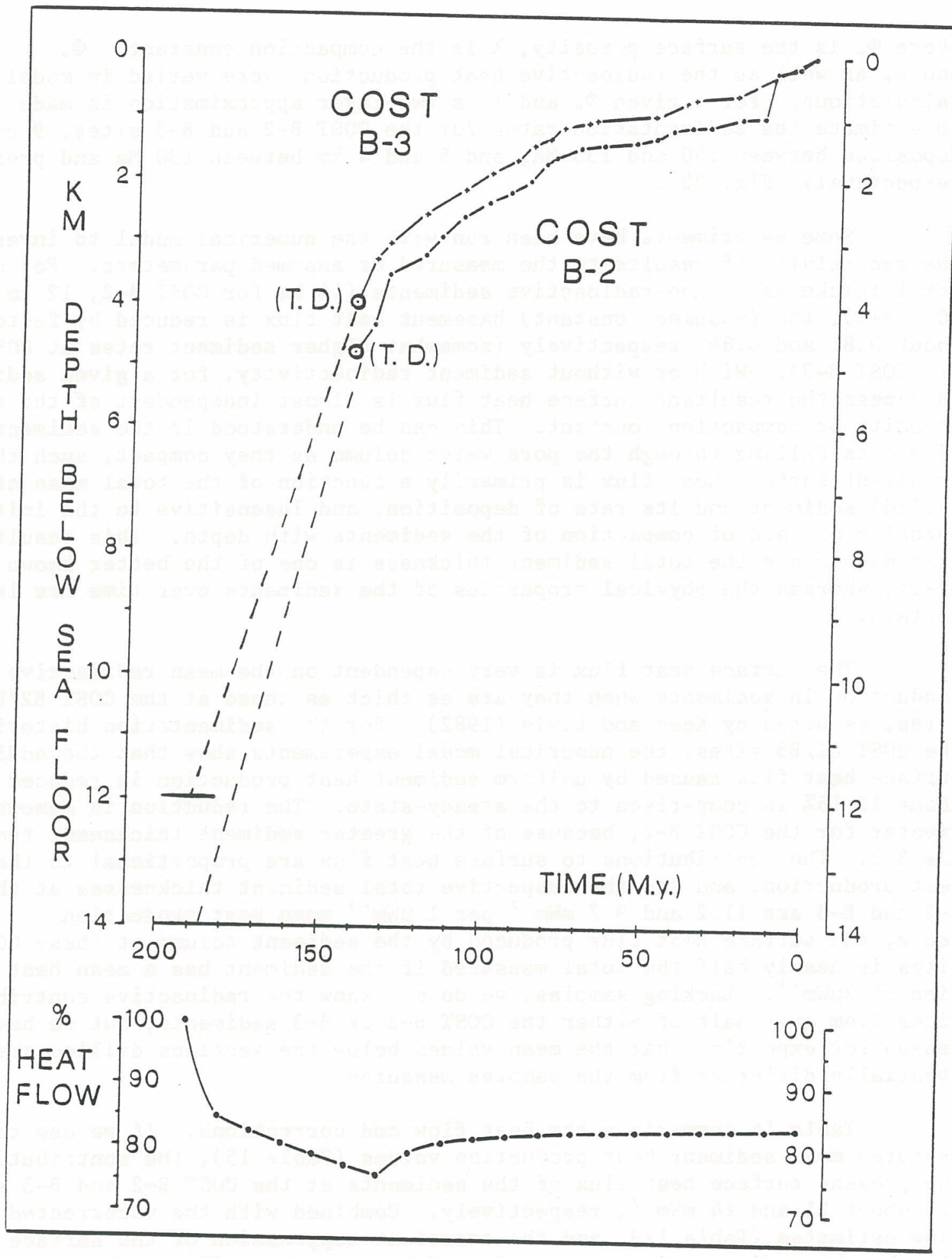

Fig. 20. Estimated sediment accumulation over time at the COST B-2 and COST B-3 wells (top), taken mainly from Watts and Thorne (1984). Dashed lines represent the earliest (constant) deposition, beginning about $190 \mathrm{Ma}$. The relative heat flow over time (bottom) gives the effect calculations assume not including internal heat production. Model earliest $60 \mathrm{M} . \mathrm{y}$. earliest $60 \mathrm{M} . \mathrm{y}$. and another for the remaining $130 \mathrm{M} . \mathrm{y}$. (see text). 
where $\Phi_{\circ}$ is the surface porosity, $\lambda$ is the compaction constant. $\Phi_{0}$ and $\lambda$, as well as the radioactive heat production, were varied in model calculations. For a given $\Phi_{\circ}$ and $\lambda$, a two-layer approximation is made to estimate the sedimentation rates for the COST B-2 and B-3 sites: 9 and $8 \mathrm{~km}$ deposited between 190 and $130 \mathrm{Ma}$, and 5 and $4 \mathrm{~km}$ between $130 \mathrm{Ma}$ and present, respectively (Fig. 20).

Some experiments have been run with the numerical model to investigate the sensitivity of results to the measured or assumed parameters. For a given total thickness of non-radioactive sediments (14 km for COST B-2, $12 \mathrm{~km}$ for $\operatorname{COST} B-3$ ), the (assumed constant) basement heat flux is reduced by factors of about 0.81 and 0.84 , respectively (somewhat higher sediment rates at COST B-2 vs. COST B-3). With or without sediment radioactivity, for a given sediment thickness the resultant surface heat flux is almost independent of the surface porosity or compaction constant. This can be understood if the sediments are viewed as falling through the pore water column as they compact, such that the transient surface heat flux is primarily a function of the total mass of (solid) sediment and its rate of deposition, and insensitive to the initial porosity or rate of compaction of the sediments with depth. This result is fortunate since the total sediment thickness is one of the better known parameters, whereas the physical properties of the sediments over time are less certain.

The surface heat flux is very dependent on the mean radioactive heat production in sediments when they are as thick as those at the COST B2/B3 sites, as noted by Keen and Lewis (1982). For the sedimentation histories at the COST B2/B3 sites, the numerical model experiments show that the additional surface heat flux caused by uniform sediment heat production is reduced by about $12-15 \%$ in comparison to the steady-state. The reduction is somewhat greater for the COST B-2, because of the greater sediment thickness, than for the B-3. The contributions to surface heat flux are proportional to the mean heat production, and for the respective total sediment thicknesses at the COST $\mathrm{B}-2$ and $\mathrm{B}-3$ are 11.2 and $9.7 \mathrm{mWm}^{-2}$ per $1 \mu \mathrm{Wm}^{-3}$ mean heat production. Hence, the surface heat flux produced by the sediment column at these COST sites is nearly half the total measured if the sediment has a mean heat generation of $2 \mu \mathrm{Wm}^{-3}$. Lacking samples, we do not know the radioactive contributions from over half of either the COST B-2 or B-3 sediments, but we have no reason for expecting that the mean values below the sections drilled are substantially different from the samples measured.

Table 16 summarizes the heat flow and corrections. If we use the measured mean sediment heat production values (Table 15), the contributions to the present surface heat flux of the sediments at the COST B-2 and B-3 sites are about 21 and $14 \mathrm{mWm}^{-2}$, respectively. Combined with the uncorrected heat flow estimates (Table 12), and the transient suppression of the surface heat flux by the sedimentation, the estimated basement heat flux at both the COST $\mathrm{B}-2$ and $\mathrm{B}-3$ wells is in the range of $33-39 \mathrm{mWm}^{-2}$. The basement flux does not appear significantly different at the two sites within the uncertainties of the measurements and assumptions.

\section{DISCUSSION AND CONCLUSIONS}

Heat flow measurements at the Earth surface are particularly meaningful in geological and geophysical interpretation if they are accurately 
Table 16. Heat Flow Summary

\begin{tabular}{|c|c|c|c|c|c|c|}
\hline Site & $\begin{array}{l}\text { Uncorrected* } \\
\text { Heat F1ow } \\
\qquad\left(\mathrm{mWm}^{2}\right)\end{array}$ & $\begin{array}{l}\text { Mean } \\
\text { Heat }\end{array}$ & $\begin{array}{l}\text { radioactive } \dagger \\
\text { production } \\
\underline{\left(\mu \mathrm{Wm}^{-3}\right)}\end{array}$ & $\begin{array}{l}\text { Sediment } \\
\text { Radioactive } \\
\text { Correction } \\
\underline{\left(\mathrm{mWm}^{-2}\right)}\end{array}$ & $\begin{array}{c}\text { Transient } \\
\text { Sedimentation } \\
\text { Factor }\end{array}$ & $\begin{array}{c}\text { Estimated } \\
\text { Basement } \\
\text { Flux } \\
\left(\mathrm{mWm}^{-2}\right) \\
\end{array}$ \\
\hline $\operatorname{cosT} B-2$ & $48-52$ & & 1.83 & 21 & 0.81 & $33-38$ \\
\hline $\operatorname{cosT} B-3$ & $44-47$ & & 1.46 & 14 & 0.84 & $36-39$ \\
\hline $\begin{array}{c}\text { trom } \\
\dagger \quad " \quad\end{array}$ & $\begin{array}{ll}\text { Table } & 12 \\
\text { Table } & 15\end{array}$ & & & & & \\
\hline
\end{tabular}

estimated in deep we11s. In most cases, thermal gradients estimated from logs in oil and gas wells are accurate, on average, within about $\pm 10-15 \%$ (Reiter and Jessop, 1985). These accuracies can be improved to perhaps $\pm 4-5 \%$ if multiple temperature measurements are available at the same depth at different times and if the errors produced by instrumental and environmental disturbances are known.

On the other hand, thermal conductivity evaluation is generally more elusive and difficult to calculate in situ within known bounds. This parameter depends on the mineral constituency of the geological materials (Horai and Simmons, 1969; Horai, 1971; Horai and Baldridge, 1972), geometry of mineral grains (King and Simmons, 1972; Kappelmeyer and Haene1, 1974), and in situ conditions (Birch and Clark, 1940; Kappelmeyer and Haene1,1974; Sekiguchi, 1984). In Section 4.6 we have shown that temperature, together with the porosity and anisotropy of minerals, all generally a function of depth, substantially influence the in situ thermal conductivity of the sedimentary formations.

Thermal conductivity measurements on well samples are scarce; their dependencies on temperature, pressure-porosity and direction are not always adequately constrained. More of ten, thermal conductivity values are estimated from lithological composition, assuming mean values of the thermal conductivity of constituents from the literature. In this case any rock type has a spread of values that can exceed a factor of 2 (Kappelmeyer and Haene1, 1974; Reiter and Jessop, 1985). The total uncertainty introduced by these errors and/or assumptions on thermal conductivity evaluation could be reasonably estimated as $\pm 30-50 \%$. Thus in estimating the heat flow from deep wells, the thermal conductivity is at least 2-5 times more uncertain than the respective thermal gradient.

Five out of the twelve data groups identified by Reiter and Jessop (1985) along offshore eastern Canada show a mean thermal gradient almost coincident with those of COST B-2 and COST B-3 wells. However estimated mean thermal conductivities are substantially higher (about 50\%) in the Canadian province, even though age, nature and evolution of the sedimentary sequences are comparable. Rather than there being real differences in the thermal conductivity of the rocks in the two provinces of this order, it seems likely that the methods of estimation used are responsible for much of the discrepancy. 
Although direct measurements of thermal conductivity are tedious, they may be required whenever the most accurate heat flow values are desired.

\subsection{SAMPLES TREATMENT AND LABORATORY MEASUREMENTS}

Sorting of the original samples by 1ithology was somewhat subjective, but it was significantly improved by a posteriori quartz and potassium content determinations. Density and porosity determinations on pulverized samples are probably the most uncertain among all the laboratory measurements (Table 4) mainly because of the difficulty in saturation of the samples (air bubbles included in the mixture) and thereby in weighing the pore water. This quantity is directly proportional to grain density and porosity of the sample, therefore an eventual underestimate of pore water content leads to an underestimate of matrix conductivity $\left(\mathrm{K}_{\mathrm{s}}\right)$ when the Woodside and Messmer (1961a) geometric mean mode1 (eqn. 3) is applied to conductivity measured $\left(\mathrm{K}_{\mathrm{m}}\right)$ on saturated laboratory samples. In the same way an underestimate of the density lowers the radioactive heat production of a rock with fixed $U$, Th and potassium contents. of course these errors propagate into the final heat flow evaluation. The porosities and densities of many COST B-2 and a few COST B-3 samples (Table 4) are quite approximate (values in parentheses). The mean $\mathrm{K}_{\mathrm{s}}$ for each 1ithology (Table 5) was calculated on a selected set of values measured on samples with both reliable porosities and $\mathrm{K}_{\mathrm{m}}$. For the determination of radioactive heat production (Tables 4 and 14) we used all the reliable density estimates, assigning values from nearby samples for unreliable determinations or assuming a mean density of $2.65 \mathrm{~g} / \mathrm{cm}^{3}$ for missing values. Uncertainties in porosity and density of the samples are probably about $\pm 10 \%$ and $\pm 5 \%$ respectively.

The thermal conductivity of the saturated sample $\left(\mathrm{K}_{\mathrm{m}}\right)$ has been measured with the needle probe technique (Von Herzen and Maxwe11, 1959) within about $\pm 1-2 \%$ uncertainty (Goldberg et al., 1980). The uncertainty in thermal conductivity of the matrix $\left(\mathrm{K}_{\mathrm{s}}\right)$ is obtained by combining those associated with porosity and $\mathrm{K}_{\mathrm{m}}$. At low porosity $(0-10 \%)$ the uncertainity is between $\pm 2 \%$ and $\pm 5 \%$, whereas at high porosity (40-50\%) it ranges around $\pm 15-18 \%$. Averaging all the $\mathrm{K}_{s}$ determinations by lithology (Table 6) decreases the total uncertainty. A mean uncertainty of $\pm 8-10 \%$ can reasonably be estimated for the $K_{s}$ of each lithology. The uncertainty of quartz content determined by $x$-ray powder diffraction has been estimated as $\pm 5 \%$. A moderate but significant correlation between quartz content and thermal conductivity of the solid fraction has been observed (Fig. 7). A plot of measured vs. calculated thermal conductivities based on quartz content (Fig. 8) shows that quartz is the most abundant high conductivity mineral in the samples, followed by a subordinate percentage of probable dolomite and calcite.

Potassium analysis has been done mainly to evaluate the amount of ${ }^{40} \mathrm{~K}$ of the samples (Table 4). An interesting correlation was found to exist beteen potassium content and thermal conductivity of the matrix $\mathrm{K}_{\mathbf{s}}$ (Fig. 16); this observation proved to be useful in lithological assignments and as an indicator of shale content of the samples. The accuracy of the atomic absorption spectrophotometry technique is better than $0.1 \%$. 
Uranium and thorium contents in the samples were measured by neutron activation methodology. These measurements constitute a substantial data set (122 samples) for sedimentary rocks. The accuracy of these determinations is estimated to average \pm 5 to $\pm 10 \%$ for $\mathrm{U}$, depending on the concentration, and $\pm 2-3 \%$ for $\mathrm{Th}$.

\subsection{WELL LOG ANALYSIS}

The volumetric fraction of each lithology vs. depth was averaged over 1000 feet $(304.8 \mathrm{~m}$ ) intervals (Fig. 9 for COST B-2 and Table 6 for COST B-3); this estimate is a subjective interpretation of the lithological $10 \mathrm{~g}$ and therefore a $\pm 10 \%$ uncertainty is reasonable.

Porosities were estimated from: sidewall cores, drill cuttings (1iquid pycnometry) and well geophysical and lithological logs. COST B-2 porosities (Table 7) are based on more data than those of the COST B-3 (Table 9). The porosity of sandstones shows a large scatter and an appreciable difference for the various methods used (Fig. 10a), whereas siltstones, limestones and shales (Fig. 10b,c) seem to have less variability. The uncertainties of situ porosities should be within the variability for a lithology at a given depth interval, and generally is of the order of $\pm 10-20 \%$.

Sonic and lithological logs of $\operatorname{COST} B-2$ were analyzed to verify the relationship between sound velocity $\left(V_{p}\right)$, thermal conductivity $\left(K_{z}\right)$ and formation temperature (Houbolt and We11s, 1980). The agreement between average interval $\mathrm{K}_{\mathrm{z}}$ and the values predicted independently by the model (Fig. 11) is reasonable. A systematic bias of about $20 \%$ which seems to increase with depth, could be explained by an underestimate of the anisotropy factor, which also probably increases with depth, and/or from the temperature effect.

The anisotropy of the thermal conductivity is more prominent for layered formations such as shales limestones and siltstones (King and Simmons, 1972; Kappelmeyer and Haene1, 1974). Insufficient work has been done to fully understand the behaviour of thermal anisotropy of rocks under varying conditions of temperature, pressure and diagenetic processes. Anisotropy must be considered when thermal conductivity measurements on oriented and sufficiently large samples are not possible.

The final evaluation of the average in situ vertical component of the thermal conductivity $\mathrm{K}_{\mathrm{z}}$ (Figs. 14, 15), (with $\pm 15 \%$ uncertainty estimated for in situ porosity, $\pm 10 \%$ for matrix thermal conductivity, $\pm 10 \%$ for the anisotropy factor, and $\pm 10 \%$ for the volume fraction estimate) has an accuracy of the order of $\pm 20 \%$.

The calculation of equilibrium temperatures at logging depth for the two sites was determined from extrapolation of temperatures measured on multiple logging runs at certain depths (Eqn. 11). A well-established extrapolation procedure (Bullard, 1947; Middleton, 1979) allowed us to estimate the true formation temperature within an accuracy of about $\pm 1-2 \%$ (Fig. 12 and 13) when reliable notes on operations during logging were available. The deepest COST B-2 and COST B-3 temperatures were less accurate and problematic. The estimate of the appropriate sea floor temperatures has a much larger uncertainty (perhaps $\pm 10-20 \%$ ) and therefore is only approximate. The mean 
deep thermal gradients obtained at the two sites are, on average, accurate to $\pm 5-8 \%$.

\subsection{HEAT FLOW ESTIMATE}

Temperatures, thermal gradients, conductivities and heat flows of COST B-2 and COST B-3 wells are summarized on Figs. 14 and 15. The most reliable COST B-2 thermal gradient should range between the mean value calculated from the two intermediate intervals $\left(26.3{ }^{\circ} \mathrm{C} \mathrm{km}^{-1}\right.$ ) and the mean of a11 the intervals excluding the uppermost $\left(23.0^{\circ} \mathrm{C} \mathrm{km}^{-1}\right)$. The deepest COST $\mathrm{B}-2$ interval gradient is anomalous with respect to the other interval gradients; it is probably caused by a poor estimate of the deepest temperature. The COST B-3 average thermal gradient of $26.1{ }^{\circ} \mathrm{C} \mathrm{km}^{-1}$ is better constrained and agrees with the value for the intermediate depth intervals of COST B-2. The gradients may increase slightly with depth in both the COST B-2 and B-3, although the increase in both cases is probably not significant nor does it correlate with decreased thermal conductivity with depth, as would be expected if heat flow were constant with depth. The gradients are much more uniform than found for boreholes in offshore eastern Canada by Reiter and Jessop (1985).

Thermal conductivities from the two sites are comparable; the mean values for the COST B-2 are systematically higher than those for the COST B-3 by about $10 \%$. This is caused mainly by the different fraction of the various lithologies present in the wells; sandstones are more abundant in COST B-2, whereas more limestones occur in COST B-3. Excluding the uppermost interva1, the average values are $1.89 \mathrm{~W} \mathrm{~m}^{-1} \mathrm{~K}^{-1}$ (4.52 T.C.U.) for COST B-2 and 1.82 $\mathrm{W} \mathrm{m}^{-1} \mathrm{~K}^{-1}$ (4.35 T.C.U.) for COST B-3.

The average heat flow caluclated at the two sites is $45 \mathrm{~mW} \mathrm{~m}^{-2}(1.07$ $\mathrm{HFU}$ ) for the COST B-2 and $44 \mathrm{~mW} \mathrm{~m}^{-2}$ (1.06 HFU) for the COST B-3. Excluding the poorly controlled top intervals from both wells does not significantly change these estimates. If the bottom interval gradient is also excluded, the COST B-2 value would be about $49 \mathrm{~mW} \mathrm{~m}^{-2}$ (1.18 HFU). The total uncertainty on these estimates is probably of the order of $20-25 \%$.

\subsection{INTERNAL HEAT PRODUCTION AND THERMAL BLANKETING EFFECT}

Uranium, thorium and ${ }^{40} \mathrm{~K}$ concentrations in COST B-2 and B-3 samples are within normal ranges for sediments and sedimentary rocks (Adams and Weaver, 1958; Adams et a1., 1964; Rybach, 1976). Significant amounts of radioactive isotopes are found in limestones, indicating most likely the presence of other 1ithologies or possibly a redistribution of the isotopes by interstitial water circulation.

A weak inverse correlation has been observed between internal heat production of sandstones, siltstones and shales and their matrix thermal conductivity $\mathrm{K}_{\mathrm{s}}$ (Fig. $19 \mathrm{~b}$ ), whereas limestones show nearly a constant heat production rate independent of $\mathrm{K}_{\mathrm{s}}$ (Fig. 19a).

A significant difference in mean radiogenic heat production is found between COST B-2 and COST B-3 vertical intervals (Table 15); on average the COST B-3 values are about $20 \%$ less than those of the COST B-2. Moreover, in the COST B-3 well the heat production rate decreases with depth as the limestone content increases, i.e., approaching the prograding carbonate bank or 
reef (Grow, 1980; 1981). Extrapolating the overal1 average heat production rate (Table 15) over the 14- to 12 - km-thick sedimentary sequence at the COST B-2 and B-3 sites, gives an estimated total contribution from the sediments to the surface heat flow of about 25 and $20 \mathrm{mWm}^{-2}$, respectively.

In evaluating the sedimentation rates on the margin since the early rifting, formation thicknesses and ages are needed. For the undrilled section no data are available, and therefore the sedimentary interval of about 8 to $9 \mathrm{~km}$ between the basement and the bottom of the wells was considered produced by uniform sedimentation over $60 \mathrm{M} . \mathrm{y}$. time span. For the COST we11s we used the chronostratigraphic table of Watts and Thorne (1984) even though the age of the deepest drilled horizon in the two wells is somewhat uncertain between Early Cretaceous and Late Jurassic times (some 130-150 Ma). The total sediment thickness (Fig. 20) is to a good approximation the result of sedimentation (combined with compaction) at two substantially different rates.

The sedimentation correction program of Hutchison (1985) includes radiogenic heat production in the sediments. Considering the effect of sedimentation only (with no internal heat production), the constant sedimentation model (Von Herzen and Uyeda, 1963) indicates a reduction of the original heat flow to a value (70-75\%) which is comparable with that (83\%) obtained by Hutchison's (1985) model. The estimated deep undisturbed heat flow through the basement is 33 to $39 \mathrm{mWm}^{-2}$. The quite surprising result of a surface heat flow higher than that flowing through the basement, primarily because of the radioactivity in the $12-14 \mathrm{~km}$ thick sediment column, should be investigated and verified elsewhere.

The slight increase (5-10\%) of het flow with depth over the most reliable intervals of the COST $B-2$ and $B-3$ wells is probably not significant since the uncertainties of the data, especially thermal conductivity estimates, are much larger. However, we note that a majority (41 of 71) of the offshore Canadian wells studied by Reiter and Jessop (1985) also show this type of variation, frequently of larger magnitude. Factors which may cause such effects include rapid (transient) sedimentation or water circulation within the measurement intervals. A transient pulse of sedimentation would cause a difference in heat flow between the surface and depth $z$ which would substantially decay over a time given by $z^{2} / \kappa$ ( $\kappa=$ sediment thermal diffusivity $\sim 6 \times 10^{-3} \mathrm{~cm}^{2} \mathrm{~s}^{-1}$ ), which is about 1 million years for a depth of $5 \mathrm{~km}$. Although there may have been a higher sedimentation rate for the COST B-2 (not B-3) about 10-15 Ma (Fig. 20), its effects on heat flow variation with depth would have dissipated long ago, and apparently there are no more recent significant perturbations. A steady sedimentation rate could also create a decrease of heat flow with depth. Numerical model results show that the decrease could have been marginally significant during the time of initial high sedimentation rate at the COST $\mathrm{B}-2 / \mathrm{B}-3$ sites (130-150 Ma, $\sim 4 \%$ increase between the surface and $5 \mathrm{~km}$ depth), but that the present difference due to this effect over the same depth range is insignificant ( $<1 \%)$.

Reiter and Jessop (1985) suggested that slow water circulation, at rates between 2 to $13 \mathrm{~mm} /$ year, could explain heat flow variations vertically at any site as well as laterally between sites, on the Canadian Atlantic margin. Similarly it is possible that a very slow downward component of water movement ( $1 \mathrm{~mm} /$ year) could account for the vertical differences in heat flux at the COST B-2/B-3 sites. Like Reiter and Jessop, we have no independent evidence 
to establish the existence of such water circulation, and it seems probable that other sources of data error are responsible. The uniformity of heat flow between the COST B-2 and B-3 sites, about $60 \mathrm{~km}$ apart, argues against any significant water circulation patterns on this scale which could affect the heat flow measurements. 


\section{REFERENCES}

Adams, J. and C. Weaver, 1958, Thorium-to-uranium ratios as indicators of sedimentary processes: example of concept of geochemical facies, Amer. Assoc. Petrol. Geol. Bul1., 42, 387-430.

Adams, J., J. Osmond and J. Rogers, 1959, The geochemistry of thorium and uranium, In Physics and Chemistry of the Earth, Pergamon, 3, 298-348, London.

Adams, J., A. Mahdavi and J. Rogers, 1964, Thorium, uranium and potassium in Gulf and Atlantic Coast beach sand, Geol. Soc. Amer. Spec. Paper, 76, 2.

Adler, D., L.P. Flora and S.D. Senturia, 1973, Electrical conductivity in disordered systems, So1id State Commun., 12, 9-12.

Amato, R.V. and J.W. Bebout, 1978, Geographical and operational summary, CoST No. GE-1 wel1, Southeast Georgia embayment area, South Atlantic oCS, U.S.G.S. Open File Report 78-668, 122 pp.

Amiel, S., 1962, Analytical applications of delayed neutron emission in fissionable elements, Ana1. Chem., 34, 1683-1692.

Anand, J., W.H. Somerton and E. Gomaa, 1973, Predicting the thermal conductivities of formation from other known properties, Society of Petroleum Engineers Journal, 13, 267-273.

Bader, R.G., et al., 1970, Initial Reports DSDP, vo1. IV; Appendix III: Shore based laboratory procedures, Washington, D.C. (U.S. Government Printing Office) 745-753.

Birch, F. and H. Clark, 1940, The thermal conductivity of rocks and its dependence on temperature and composition, Am. J. Sci., 238, 529-558 and 613-635.

Borga, P., 1981, Heat conductivity measurements of sediment samples from the COST B-3 we11, 21 p. (unpublished).

Brailsford, A.D. and K.G. Major, 1964, The thermal conductivity of aggregates of several phases, including porous materials, Brit. J. App1. Phys., 15, 313-319.

Budiansky, B., 1970, Thermal and thermoelastic properties of isotropic composites, J. Composite Materials, 4, 286-295.

Buffler, R.T., J.S. Watkins and W.P. Dillon, 1979, Geology of the offshore southeast Georgia embayment, U.S. Atlantic continental margin, based on multichannel seismic reflection profiles, in J.S. Watkins, L. Montadert, P.W. Dickerson (Eds.), Geological and Geophysical Investigations of Continental Margins, Amer. Assoc. Petro1. Geol. Bul1. Memoir 29, 11-16.

Bullard, E.C., 1947, The time necessary for a borehole to attain temperature equilibrium, Mon. Not. Roy. Astr. Soc., Geoph. Supp1., 5, 127-130. 
Clark, S.P., 1966, Thermal conductivity, In: Clark, S.P., ed., Handbook of Physica1 Constants, Geo1. Soc. Am. Mem. 97, 461-482.

Core Laboratories, Inc., 1976, Core studies, C.O.S.T. Atlantic we11 B-2, Baltimore Canyon: Dallas, TX, 168p.

Core Laboratories, Inc., 1979, Geochemical service report -- Atlantic COST B-3, Baltimore Canyon: Dallas, Texas, 200 p.

Dohrenwend, J.C., L.D. McFadden, B.D. Turrin, and S.G. We11s, 1984, K-Ar dating of the Cima volcanic field, eastern Mojave desert, California: 1ate Cenozoic volcanic history and landscape evolution, Geology, 12, 163-167.

Dowdle, W.L., W.M. Cobb, 1975, Static formation temperature from well logs an empirical method, J. Petrol. Tech., 27, 1326-1330.

Drury, M.J. and A.M. Jessop, 1983, The estimation of rock thermal conductivity from mineral content - an assessment of techniques, Zb1. Geol. Paleont. Teil I, H1/2 Stuttgart, 35-48.

Evans, T.R., 1977, Thermal properties of North Sea rocks, The Log Analyst (Mar-Apr 1977), 3-12.

Fert1, W.H. and P.A. Wichmann, 1977, How to determine static BHT from we11 1 og data, World 0i1, 184, 105-106.

Fry, M:, 1982, Use of sediment physical properties to estimate thermal conductivity, WHOI summer fellowship project, unpublished internal report, 26 p. and 5 appendices.

Goldberg, D., R.P. Von Herzen and J. Sclater, 1980, Thermal conductivity measurement of fused silica glass, WHOI Technical Report, WHOI-80-34, 19 p.

Goss, G., J. Combs and A. Timer, 1975, Prediction of thermal conductivity in rocks from other physical parameters and from standard geophysical well logs, SPWLA Annual Meeting, New Orleans.

Grow, J.A., 1980, Deep structure and evolution of the Baltimore Canyon Trough in the vicinity of the COST No. B-3 well, In: Scholle, P.A., ed., Geological Studies on the COST No. B-3 We11, U.S. Mid-Atlantic Outer Continental Shelf Area, U.S. Geological Survey Circular No.833, 117-126.

Grow, J.A. and K. Klitgord, 1980, Structural framework, in Matick, R.E. and Hennesy, J.L. (Ed.), Structural Framework, Stratigraphy, and Petroleum Geology of the Area of Oil and Gas Lease Sale No. 49 on the U.S. Atlantic Continental Shelf and Slope, Geological Survey Circular 812, 8-35.

Grow, J.A. and R.G. Mark1, 1977, IPOD-USGS multichannel seismic reflection profile from Cape Hatteras to the Mid-Atlantic Ridge, Geology, 5, 625-630.

Grow, J.A.. R.E. Mattick and J.S. Schlee, 1979, Multichannel seismic depth sections and interval velocities over outer continental shelf and upper slope between Cape Hatteras and Cape Cod, in Geological investigations of continental margins, J.S. Watkins, L. Montadert, and P.W. Dickerson (Eds.), Amer. Assoc. Petro1. Geo1. Bul1., Memoir 29, 65-83. 
Hamilton, E.L., 1959, Thickness and consolidation of deep sea sediments, Bu11. Geo1. Soc. Amer., 70, 1399-1424

Hellinger, S.J. and J.G. Sclater, 1983, Some comments on two layer extensional models for the evolution of sedimentary basins, J. Geophys. Res., vo1. 88, 8251-8269.

Hobbie, L., 1980, Preparation procedures for thermal conductivity measurements, unpublished internal report, WHOI, 9 p.

Horai, K. and G. Simmons, 1969, Thermal conductivity of rock-forming minerals, Earth Plan. Sci. Lett., 6, 359-368.

Horai, K., 1971, Thermal conductivity of rock forming minerals, J. Geophys . Res., 76, 1278-1308.

Horai, K. and S. Baldridge, 1972, Thermal conductivity of 19 igneous rocks, II Estimation of the thermal conductivity of rocks from the mineral and chemical compositions, Phys. Earth Planet. Inter., 5, 157-166.

Houbolt, J.J.H.C. and P.R.A. Wells, 1980, Estimation of heat flow in oil wells based on a relation between heat conductivity and sound velocity, Geologie en Mijnbouw, 59 (3), 215-224.

Hutchison, I., 1985, The effects of sedimentation and compaction on oceanic heat flow, Geophys. J.R. astr. Soc., 82, 439-459.

Jansa, L.F. and J.A. Wade, 1975, Geology of the continental margin off Nova Scotia and Newfoundland, in: Offshore Geology of Eastern Canada, Canada Geo1. Survey, Paper 74-30, 2, 51-105.

Kappelmeyer, 0. and R. Haenel, 1974, Geothermics with special reference to applications, Geoexploration Monographs, Gebruder Borntrager, Stuttgart, $240 \mathrm{pp}$.

Keen, C.E. and T. Lewis, 1982, Measured radiogenic heat production in sediments from continental margin of eastern North America: implications for petroleum generation, Amer. Assoc. Petrol. Geol. Bull., 66, No. 9, 1402-1407.

King, W. and G. Simmons, 1972, Heat flow near Orlando, Florida and Uvalde, Texas determined from well cuttings, Geothermics, 1, No. 4, 133-139.

K1itgord, K.D. and J.C. Behrendt, 1979, Basin structure of the U.S. Atlantic margin, in J.S. Watkins et a1. (eds). Geological and geophysical investigations of continental margins, Amer. Assoc. Petro1. Geol. Memoir $29,85-112$.

Lange, K., 1982, Unpublished notebook of thermal conductivity measurements on COST B-3 samples.

Lewis, T., 1974, Heat production measurement on rocks using a gamma ray spectrometer with a solid state detector, Can. J. Earth Sci., 11, 526-532. 
Lubimova, E.A., A.I. Maslennikov and Yu.A. Ganiev, 1979, On the thermal conductivity of rocks saturated with water or oil at a state with increasing temperatures and pressures, Fiz. Zemli, 5, 87-93 (in Russian).

McKenzie, D.P., 1978, Some remarks on the development of sedimentary basins, Earth Planet. Sci. Lett., 40, 25-32.

Middleton, M.F., 1979, A model for bottom-hole temperature stabilization, Geophysics, 44, 1458-1462.

Morin, R. and A.J. Silva, 1984, The effects of high temperature on some physical properties of ocean sediments, J. Geophys. Res., 89, 511-526.

Moritz, G., 1979, Thermal conductivity in the B-2 we11, Unpublished notebook.

Parsons, B. and J.G. Sclater, 1977, An analysis of the variation of ocean floor bathymetry and heat flow with age, J. Geophys. Res., 82, 803-827.

Pliler, R. and J. Adams, 1962, The distribution of thorium, uranium and potassium in the Mancos shale, Geochim. Cosmochim. Acta, 26, 1115-1135.

Poag, C.W., 1980, Foraminiferal stratigraphy, paleoenvironments, and depositional cycles in the outer Baltimore Canyon Trough, In: Scholle, P.A., ed., Geological Studies of the COST B-3 We11, United States Mid-Atlantic Continental Slope Area, U.S. Geological Survey Circular No. $833,44-65$.

Rabinowitz, P.D., 1974, The boundary between oceanic and continental crust in the western North Atlantic. in The Geology of continental margins, C.A. Burk and C.L. Drake, (Eds.), Springer-Verlag, New York, 67-84.

Rabinowitz, P.D., 1982, Gravity measurements bordering passive continental margins, In: Scrutton, R.A., (ed.), Dynamics of passive margins, Geodynamics series, vo1. 6, Am. Geophys. Union, 91-115.

Reiter, M. and A.M. Jessop, 1985, Estimates of terrestrial heat flow in offshore eastern Canada, Can. J. Earth Sci., 22, 1503-1517.

Rhodehame1, E.C., 1977, Lithologic descriptions, In: Scholle, P.A., ed., Geological Studies on the COST No. B-2 We11, U.S. Mid-Atlantic Outer Continental Shelf Area, U.S. Geological Survey Circular No. 750, 15-22.

Rhodehame1, E.C., 1977, Sandstone Porosities, In: Scholle, P.A., ed., Geological Studies on the COST No. B-2 Well, U.S. Mid-Atlantic Outer Continental Shelf Area, U.S. Geological Survey Circular No. 750, 23-31.

Richardson, S.W. and E.R. Oxburgh, 1978, Heat flow, radiogenic-heat production and crustal temperatures in England and Wales, J. Geol. Soc., 135, 323-337.

Robbins, E.I., 1977, Geotherma1 Gradients, In: Scholle, P.A., ed., Geologica1 Studies on the COST No. B-2 Well, U.S. Mid-Atlantic Outer Continenta1 Shelf Area, U.S. Geological Survey Circular No. 750, 44-45. 
Robertson, E.C., 1979, Thermal conductivities of rocks, Open File Report 79-356, U.S. Geological Survey, 31 p.

Robertson, E.C. and D.L. Peck, 1974, Thermal conductivity of vesicular basalt from Hawaii, J. Geophys. Res., 79, 4875-4888.

Royden, L., J.G. Sclater and R.P. Von Herzen, 1980, Continenta1 margin subsidence and heat flow, important parameters in formation of petroleum hydrocarbons, Am. Assoc. Petro1. Geo1. Bul1., 64, 173-187.

Rybach, L., 1976, Radioactive heat production in rocks and its relation to other petrophysical parameters, Pure App1. Geophysics, 114, 309-318.

Rybach, L. and G. Buntebarth, 1982, Relationships between the petrophysical properties density, seismic velocity, heat generation, and mineralogical constitution, Earth P1an. Sci. Lett., 57, 367-376.

Sass, J.H., A.H. Lachenbruch and R.J. Munroe, 1971, Thermal conductivity of rocks from measurements on fragments and its application to heat-flow determinations, J. Geophys. Res., 76, 3391-3401.

Schatz, J.F. and G. Simmons, 1972, Therma1 conductivity of earth materials at high temperatures, J. Geoph. Res., 77, 6966-6983.

Schlee, J.S., 1981, Seismic stratigraphy of Baltimore Canyon Trough, Amer. Assoc. Petro1. Geo1. Bull., 65, 26-53.

Schlee, J., J.C. Behrendt, J.A. Grow, J.M. Robb, R.E. Mattick, P.T. Taylor and B.A. Lawson, 1976. Regional geologic framework off northeastern United States, Amer. Assoc. Petro1. Geo1. Bul1., 60, 926-951, 1976.

Schlee, J.S. and Grow, J.A., 1980, Seismic stratigraphy in the vicinity of the COST B-3, In: Scholle, P.A., ed., Geological Studies of the COST No. B-3 We11, U.S. Mid-Atlantic Outer Continental Shelf Area, U.S. Geological Survey Circular No. 833, 111-116.

Scholle, P.A., 1977, Data summary and petroleum potential, In: Scholle, P.A., ed., Geological studies on the COST No. B-2 we11, U.S. Mid-Atlantic outer continental shelf area, U.S. Geological Survey Circular No. 750, 8-14.

Scholle, P.A., 1977, Sandstone Petrography, In: Scholle, P.A., ed., Geological studies on the COST No. B-2 we11, U.S. Mid-Atlantic outer continental shelf area, U.S. Geological Survey Circular No. 750, 32-34.

Scholle, P.A., et al. 1977, Geological studies on the COST No. B-2 we11, U.S. Mid-Atlantic outer continental shelf area, U.S. Geological Survey Circular No. $750,71 \mathrm{pp}$.

Scholle, P.A., et a1., 1980, Geological studies of the COST No. B-3 we11, United States Mid-Atlantic continental slope area, U.S. Geological Survey Circular 833, 132 pp.

Schouten, H. and K.D. Klitgord, 1977, Map showing Mesozoic magnetic anomalies; western North Atlantic, U.S. Geo1. Survey Misc. Field Studies Map MF-915, scale $1: 2,000,000$. 
Sekiguchi, K., 1984, A method for determining terrestrial heat flow in oil basins areas, Tectonophysics, 103, 67-79.

Sheridan, R.E., 1976, Sedimentary basins of the Atlantic margin of North America, Tectonophysics, 36, 113-132.

Simmons, G., 1961, Anisotropic thermal conductivity, J. Geophys. Res., 66 , No. $7,2269-2270$.

Smith, M.A., R.V. Amato, M.A. Furbush, D.M. Pert, M.E. Nelson, J.S.Hendrix, L.C. Tamm, G. Wood, Jr. and D.R. Shaw, 1976, Geological and operational summary, COST No. B-2 we11, Baltimore Canyon Trough area, Mid-Atlantic outer continental shelf (OCS): U.S. Geol. Survey, open-file rept. 76-744, 79 pp.

Steckler, M.S., 1981, The thermal and mechanical evolution of Atlantic-type continental margins, Ph.D. Thesis, Columbia University, 261 p.

Steckler, M.S. and A.B. Watts, 1982, Subsidence history and tectonic evolution of Atlantic-type continental margins, Amer. Geophys. Union, Geodynamics Series, 6, 184-196.

Taylor, P.T., I. Zietz, and L.S. Dennis, 1968, Geological implications of aeromagnetic data for the eastern continental margin of the United States, Geophysics, 33, 755-780.

Tikhomirov, V.M., 1968, Conductivity of rocks and their relationship with density, saturation, and temperature, Neftianoe Khoziaistro, 46, 36-40.

Von Herzen, R.P. and S. Uyeda, 1963, Heat flow through the eastern Pacific ocean floor, J. Geophys. Res., 68, 4219-4250.

Von Herzen, R.P. and J.A. Helwig, 1984, Geothermal heat flux determined from COST wells on the Atlantic continental margin, in Thermal Phenomena in Sedimentary Basins, Collections Colloques et Seminaires 41, Edition's Technip, Paris (ed. B. Durand), 21-26.

Von Herzen, R. and A.E. Maxwe11, 1959, Measurements of thermal conductivity of deep-sea sediments by a needle-probe method, J. Geophys. Res., 64, 1557-1563.

Watts, A.B., 1981, The U.S. Atlantic continental margin: Subsidence history, crustal structure and thermal evolution, Amer. Assoc. Pet. Geologist Educ. Course Note Ser. 非19, 75 p.

Watts, A.B. and J. Thorne, 1984, Tectonics, global changes in sea-level and their relationship to stratigraphic sequences at the U.S. Atlantic continental margin, Marine and Petroleum Geology, 1, 319-339, 1984.

Winkler, H.G., 1952, IN: Lando1t-Bornstein. Zahlenwerte und Funktionen. Bd. III, Astronomie und Geophysik, 324, Springer.

Woodside, W. and J.H. Messmer, 1961a, Thermal conductivity of porous media, I. Unconsolidated sands, J. App1. Phys., 32, 1688-1699. 
Woodside, W. and J.H. Messmer, 1961b, Thermal conductivity of porous media, II. Consolidated rocks, Journal of Applied Physics, 32, 1699-1706.

Wu, Ching H. and R. Nichols, 1980, Computer we11-1og analysis, In: Scho1le, P.A., ed., Geological studies of the COST No. B-3 well, United States Mid-Atlantic continental slope area, U.S. Geologica1 Survey Circular 833, 26-43.

Zierfuss, H. and G. van der Vliet, 1956, Laboratory measurements of heat conductivity of sedimentary rocks, Amer. Assoc. Petrol. Geol. Bul1., 40, 2475-2488. 


\section{ACKNOWLEDGMENTS}

We are grateful to the detailed and tedious sorting of sediment samples and measurements of thermal conductivity and other physical parameters on them by the summer students involved: Gail Moritz, Lawrence Hobbie, Patricia Borga, and Kevin Lange. The drill cutting samples were generously provided by Phillips Petroleum (G. Erdman) and ARCO (J. Helwig). J. Helwig also provided an initial analysis of the temperatures logged in the COST B-2 we11. D. McKown (USGS, Denver) provided the measurements of $U$ and Th contents of samples by neutron activation analysis, and $F$. Wooding help us with the quartz content determinations by x-ray diffraction.

B. Della Vedova acknowledges support from the Italian National Research Council (CNR) which allowed his visit to Woods Hole and additional support from the U.S. Geological Survey. The summer students were supported either by the WHOI summer student fellowship program or the USGS, and R. Von Herzen is grateful to the USGS and WHOI support which allowed completion of this project. Manuscript preparation was ably assisted by Pam Foster, Alice Tricca, Annie Kauffman, and Janet Johnson. 


\title{
Appendix A. ANALYSIS OF SAMPLES QUARTZ CONTENT
}

\author{
Quartz standards preparation.
}

Since the amount of quartz requested for the standards preparation and that of $\alpha-\mathrm{Al}_{2} \mathrm{O}_{3}$, necessary for both standards and samples, was significant, second order standards have been acquired.

Selected pure quartz from COST B-2 samples was ground and its $x$-ray pattern compared with the standard $\alpha$-quartz furnished from the manufacturer of the x-ray machine; $\alpha-\mathrm{Al}_{2} \mathrm{O}_{3} 99 \%$ (非23,474-5) was acquired from Aldrich Chemical Co. and compared with the NBS $\alpha$-alumina standard 非674. Both the standard sets have been run 3 times on two different machines (USGS and McLean); the secondary standards were found coherent with the first order standards.

The quartz standards and all the samples were $\mathrm{x}$-rayed using a Phillips Norelco $x$-ray diffraction unit with monochrometer and under the following specifications:

- Radiation - CuKa monochrometized by means of a curved graphite crystal diffracted-beam monochrometer

- Tube voltage $=45 \mathrm{Kv}$

- Tube current $=25 \mathrm{~mA}$

- Divergence slit $=1^{\circ}$

- Receiving slit $=0.1 \mathrm{~mm}$

- Scintillation voltage $=.8716 \mathrm{Kv}$

- Gain = 128

- Baseline $=202$

- Window $=913$

- Mode = Differential

- Time constant $=2$

- \% signal suppression $=0$

- Goniometer speed $=1 \% / \mathrm{min}$.

- Chart speed = 1 inch $/ \mathrm{min}$.

The grain size to which standards and later samples have been reduced by hand grinding was checked on a few samples, but not always controlled. On average, it was that material which would pass through a 100 mesh sieve (1ess than $149 \mu)$. The background sediment chosen to constitute the matrix of the standards and close enough to the real samples matrix was a marine sediment from Panama Basin (obtained from G. Jones, WHOI). This material was not completely quartz free as we would have preferred, but in any case the small amount present (about 2-3\%) was taken into account in the standards.

Four samples with a mean range quartz content: $40 \%$ quartz, $60 \%$ Panama Basin sediment and different amounts of internal standard mixed (i.e. $5 \%, 10 \%$, $20 \%, 30 \% \alpha$-alumina) were run to select the best combination in comparing quartz peaks and $\alpha$-alumina peaks. The $30 \%$ internal standard mixture was adopted (E1lis, 1972, chose $33.33 \%$ in practice because it is equivalent to half of the sample weight).

Mixtures of standard quartz and Panama Basin sediment were $x$-rayed with $\alpha$-alumina as an internal standard. The 3.343 Angstrom quartz peak (101) was ratioed to the 3.479 Angstrom $\alpha-\mathrm{Al}_{2} \mathrm{O}_{3}$ peak (012) after subtraction of background noise. 
A preliminary attempt was made to use the peak height ratio; but since the height, width and shape of the peaks is a function of the abundance as wel1 as grain size uniformity and distribution, the peak does not give by itself as good a fit as shown in Fig. A-1. Therefore the areas under the peaks were measured three times each to smooth the reading errors. The results show that the scatter is significantly reduced (Fig. A-2).

The best fitting straight line equation is:

$$
\mathrm{R}=-.4098+.2433 \mathrm{Qtz} \%
$$

where $\mathrm{R}=$ Quartz peak area/interna1 standard peak area.

The correlation coefficient is $.996, N=21$. The fit is not signifigantly improved by imposing a quadratic relationship. We find that the quartz content can be estimated to an accuracy of $\pm 5 \%$ in absolute amount at the $99 \%$ confidence level from the area ratio (quartz peak area/ $\alpha$-alumina peak area), over the range from $0-50 \%$ quartz content.

\section{Quartz content evaluation in the samples.}

In analyzing the 82 COST B-2 and 40 COST B-3 samples a problem arose of interference of the quartz peak (101) with a small illite (003) peak $(A=3.33)$ and/or mica. In 31 cases the quartz peak was uncontaminated (Fig. A-3, parts A and B), in 63 cases it showed a "shoulder" on one side close to the base of the peak (Fig. A-3, parts C and D), and in the remainder 28 cases a distinct small peak was located on the basal area of the quartz peak (Fig. A-3, part E). In a few samples the $\alpha$-alumina peak also interfered with distinct clay minerals peaks, but in these cases it was usually quite easy to separate the respective contributions to the patterns (Fig. A-3, part D).

For deep-sea sediments, Heath and Pisias (1979) suggested solving the overlapping of quartz (101) and illite (003) by measuring the main illite peak (001) (shown on the right side of each diffractogram in Fig. 8) and subtract from the total quartz peak area $12.5 \%$ of the main illite peak. This percentage was experimentally determined for their samples. This technique was not adopted for the following reasons:

- The COST B-2/B-3 samples are not deep-ocean sediments.

- The overlapping illite peak in the deep-ocean sediments sits just on top of the quartz peak and therefore is not seen.

- Since the continental margin sedimentary sequence underwent diagenetic processes with some of the clay minerals altered to micas, it is not reliable to assume the experimental percentage found by Heath and Pisias (1979) for deep-ocean sediment.

- A comparison of the illite (001) peak with the supposed interfering illite (003) where both are clearly visible (Fig. A-3, part E) indicates that the proportion found by Heath and Pisias (1979) does not apply to our samples.

The interference was graphically eliminated by assuming symmetry of the quartz peak area (Fig. A-3). 


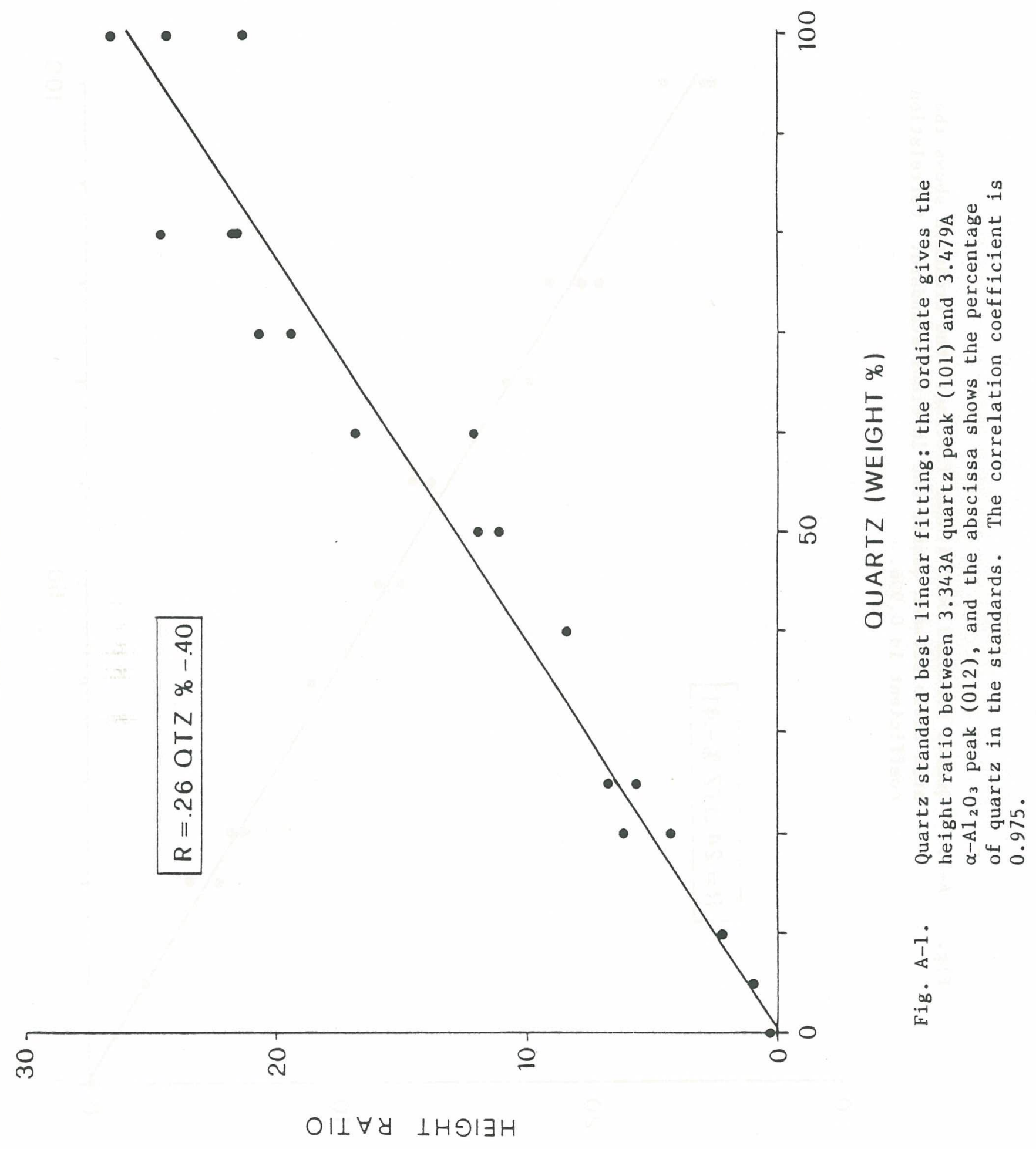



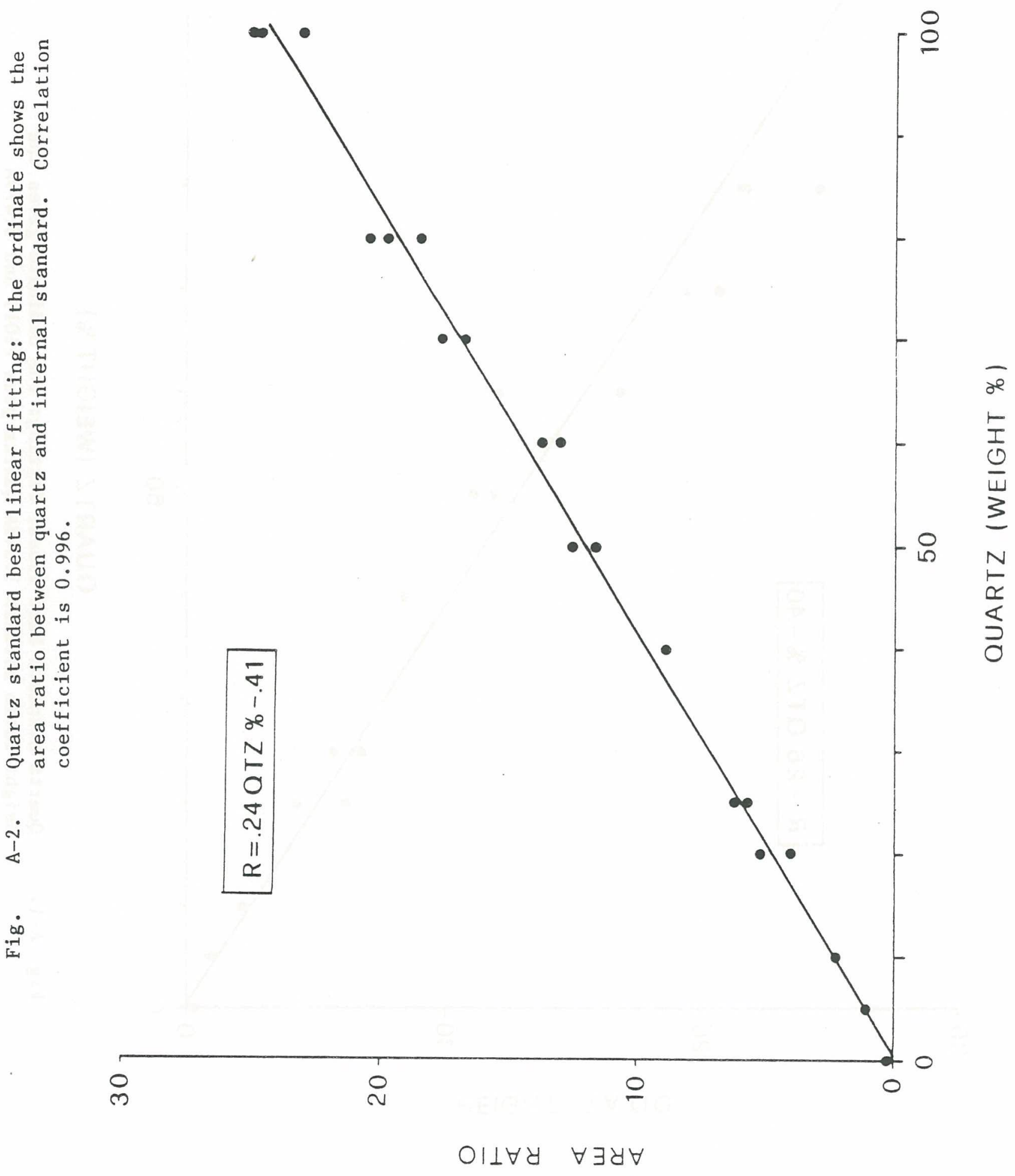


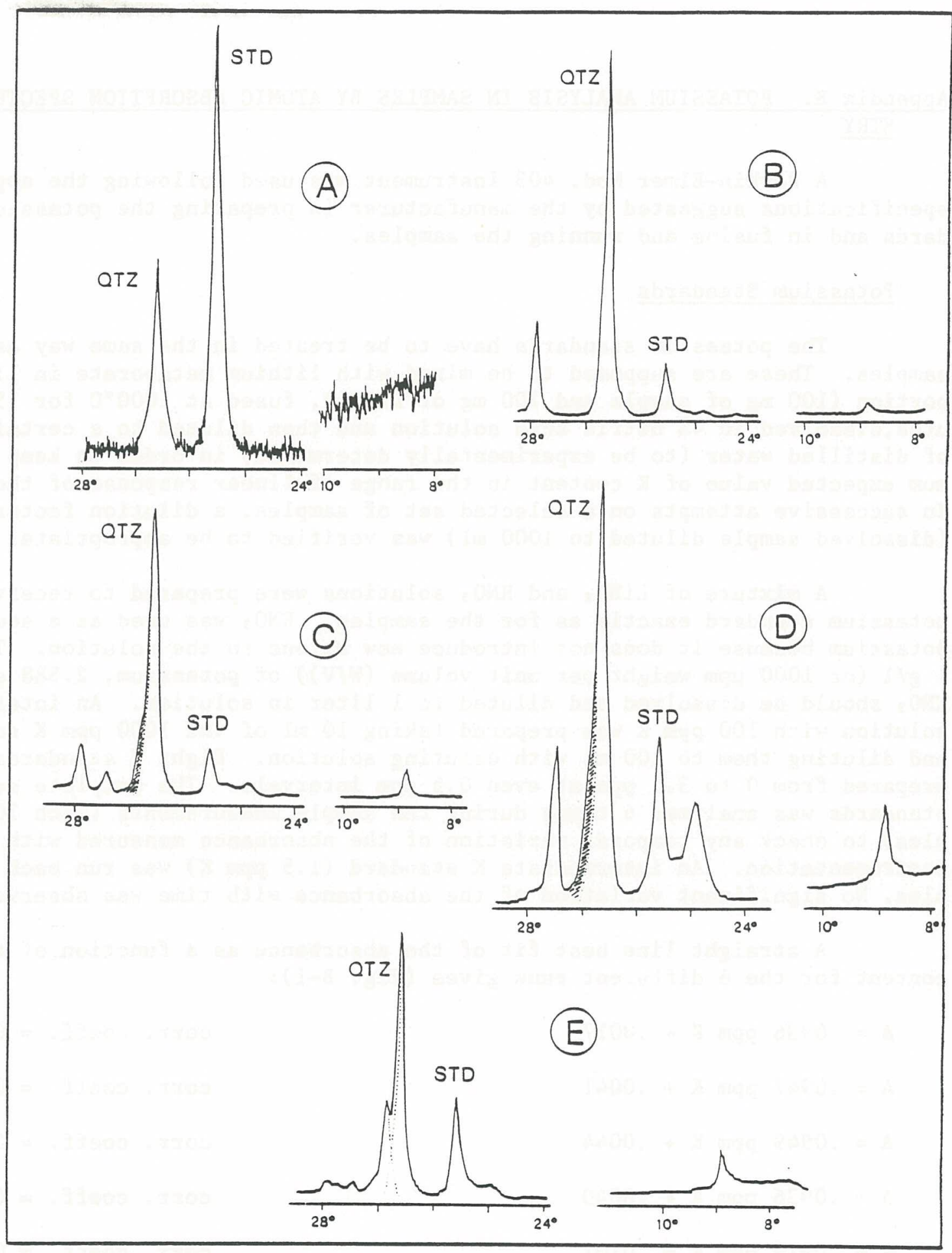

Fig. A-3. X-ray diffractograms showing the main different kinds of patterns observed on various 1ithologies:

A) COST B-3 1imestone (3.8\% quartz). Clear pattern; the major illite peak occurring at about $9^{\circ}$, where present, is shown on the right of each pattern.

B) COST B-3 sandstone ( $34.7 \%$ quartz). Clear pattern, a feldspar peak is observed on the left of quartz peak.

C) COST B-2 sandstone ( $30.1 \%$ quartz). The "shoulder" (shaded) at the base of the quartz peak is produced by a small interfering peak of illite and/or mica.

D) COST B-2 siltstone ( $11.1 \%$ quartz). The same interference as in C) is observed on the quartz peak and a kaolinite peak falls nearby the $\alpha$-alumina peak at $24.9^{\circ}$.

E) CosT B-2 shale ( $14.1 \%$ quartz). A distinct illite and/or mica peak is obvious near the base of the quartz peak pattern. 
Appendix B. POTASSIUM ANALYSIS IN SAMPLES BY ATOMIC ABSORPTION SPECTROPHOTOMETRY

A Perkin-Elmer Mod. 403 instrument was used following the appropriate specifications suggested by the manufacturer in preparing the potassium standards and in fusing and running the samples.

\section{Potassium Standards}

The potassium standards have to be treated in the same way as the samples. These are supposed to be mixed with lithium metaborate in 1:7 proportion ( $100 \mathrm{mg}$ of sample and $700 \mathrm{mg}$ of $\mathrm{LiBO}_{2}$ ), fused at $1000^{\circ} \mathrm{C}$ for $15 \mathrm{~min}-$ utes,dissolved in $4 \%$ nitric acid solution and then diluted to a certain volume of distilled water (to be experimentally determined) in order to keep the maximum expected value of $\mathrm{K}$ content in the range of linear response of the machine. In successive attempts on a selected set of samples, a dilution factor of 1,000 (dissolved sample diluted to $1000 \mathrm{ml}$ ) was verified to be appropriate.

A mixture of $\mathrm{LiBO}_{2}$ and $\mathrm{HNO}_{3}$ solutions were prepared to receive the potassium standard exactly as for the samples. $\mathrm{KNO}_{3}$ was used as a source of potassium because it does not introduce new anions in the solution. To have $1 \mathrm{~g} / 1$ (or $1000 \mathrm{ppm}$ weight per unit volume (W/V)) of potassium, $2.588 \mathrm{~g}$ of $\mathrm{KNO}_{3}$ should be dissolved and diluted to 1 liter in solution. An intermediate solution with $100 \mathrm{ppm} \mathrm{K}$ was prepared taking $10 \mathrm{ml}$ of the $1000 \mathrm{ppm} \mathrm{K}$ solution and diluting them to $100 \mathrm{ml}$ with diluting solution. Eight $\mathrm{K}$ standards were prepared from 0 to $3.5 \mathrm{ppm}$ at even $0.5 \mathrm{ppm}$ intervals. The complete set of standards was analyzed 6 times during the sample measurements (each 30-40 samples) to check any temporal variation of the absorbance measured with the instrumentation. An intermediate $\mathrm{K}$ standard ( $1.5 \mathrm{ppm} \mathrm{K}$ ) was run each 5 samples. No significant variation of the absorbance with time was observed.

A straight line best fit of the absorbance as a function of the $\mathrm{K}$ content for the 6 different runs gives (Fig. B-1):

$$
\begin{aligned}
& \mathrm{A}=.0936 \mathrm{ppm} \mathrm{K}+.0037 \\
& \text { corr. coeff. }=0.9977 \\
& \mathrm{~A}=.0947 \mathrm{ppm} \mathrm{K}+.0041 \\
& \text { corr. coeff. }=0.9976 \\
& \mathrm{~A}=.0949 \mathrm{ppm} \mathrm{K}+.0044 \\
& \text { corr. coeff. }=0.9976 \\
& \mathrm{~A}=.0936 \mathrm{ppm} \mathrm{K}+.0040 \\
& \text { corr. coeff. }=0.9982 \\
& \mathrm{~A}=.0914 \mathrm{ppm} \mathrm{K}+.0101 \\
& \text { corr. coeff. }=0.9974 \\
& \mathrm{~A}=.0884 \mathrm{ppm} \mathrm{K}+.0085 \\
& \text { corr. coeff. }=0.9979
\end{aligned}
$$

\section{Samples Treatment}

Pulverized samples and $\mathrm{LiBO}_{2}$ were dried in an oven at $60^{\circ} \mathrm{C}$ for 6-8 hrs., put in a drier to cool down for 2 hrs. and carefully weighed: $100 \mathrm{mg}$ 


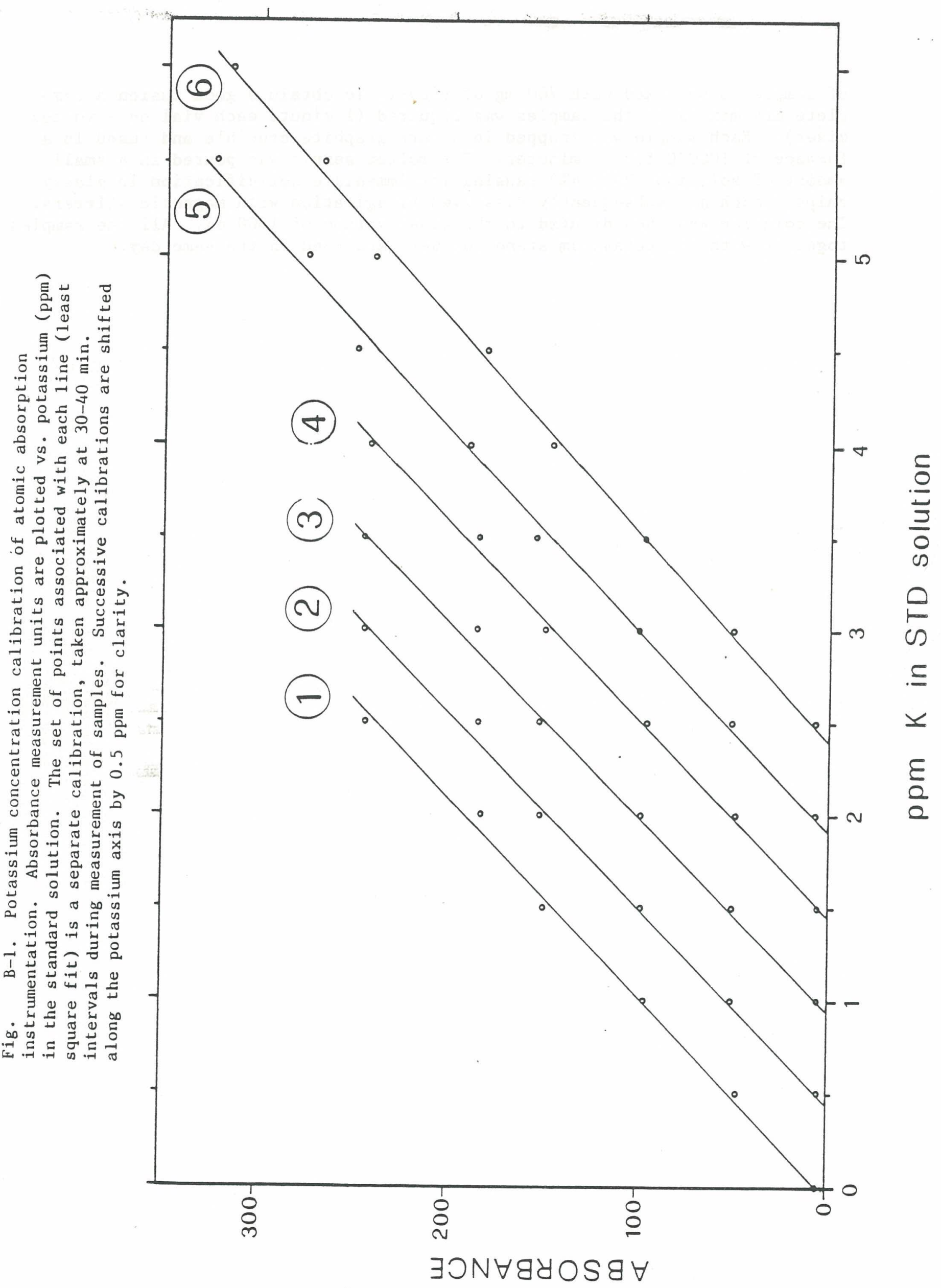


of sample to be mixed with $700 \mathrm{mg}$ of $\mathrm{LiBO}_{2}$. To obtain a good fusion a complete dry mixing of the samples was required ( 1 minute each vial on a vortex mixer). Each sample was dropped in a pure graphite crucible and fused in a furnace at $1000^{\circ} \mathrm{C}$ for 15 minutes. The molten sample was poured in a small amount of solution $\left(\mathrm{HNO}_{3} 4 \%\right)$ causing its immediate solidification in glassy chips, which are subsequently dissolved by agitation with magnetic stirrers. The solution was then diluted to the final volume of $1000 \mathrm{ml}$. All the samples together with the potassium standards were analyzed in the same day. 


\section{\begin{tabular}{|l|l|}
\hline REPORT DOCUMENTATION & 1. REPORT NO. \\
\hline
\end{tabular} \\ PAGE \\ 4. Title and Subtitle \\ Geothermal Heat Flux at the COST B-2 and B-3 Wells, U.S. Atlantic Continental Margin}

7. Author(s)

B. Della Vedova and R.P. Von Herzen

9. Performing Organization Name and Address

Woods Hole Oceanographic Institution

Woods Hole, Massachusetts 02543 3ocipient's Accession No

5. Report Date

July 1987

6.

8. Performing Organization Rept. No WHOI-87-28

10. Project/Task/Work Unit No.

11. Contract(C) or Grant(G) No

(C)

(G)

13. Type of Report \& Period Covered

Technical

14.

15. Supplementary Notes

This report should be cited as: Woods Hole Oceanog. Inst. Tech. Rept., WHOI-87-28.

16. Abstract (Limit: 200 words)

The heat flux from the earth's interior is estimated at two nearby locations on the U.S. Atlantic continental margin off New Jersey from well logs and measurements on drill cuttings samples. Vertical temperature gradients resulting from the heat flux are calculated from equilibrium temperatures deduced from repeated bottom hole temperatures measured during drilling of the holes to sub-bottom depths over $4 \mathrm{~km}$. Thermal conductivity is determined from needle-probe measurements on 128 ground samples, adjusted for the in-situ lithologies, temperatures, and porosities deduced from well logs and for lithologic anisotropy estimated from the literature.

The best estimates of temperature gradients are about $26^{\circ} \mathrm{C} \mathrm{km}-1$ at both sites below $1 \mathrm{~km}$ sub-bottom depths. Mean thermal conductivities range from about 1.8 to $1.9 \mathrm{Wm}^{-1} \mathrm{~K}^{-1}$, so that the average heat flux at both sites is about $45 \mathrm{~m} \mathrm{Wm}^{-2}$. The $12-14 \mathrm{~km}$ thick sedimentary sequences at these sites may contribute $20-25 \mathrm{mWm}^{-2}$ to the heat flux from radioactive decay. A numerical model incorporating the radioactive contribution and the transient effects of sedimentation gives a basement heat flux of about $33-39 \mathrm{mWm}^{-2}$, a relatively low value, with an overall uncertainty of $20-25 \%$.

\section{Document Analysis a. Descriptors}

1.. heat flow

2. passive continental margins

3. tectonics

b. Identifiers/Open-Ended Terms

c. COSATI Field/Group

18. Availability Statemen:

Approved for publication; distribution unlimited.

\begin{tabular}{|c|c|c|}
\hline $\begin{array}{l}\text { 19. Security Class (This Report) } \\
\text { UNCLASSIFIED }\end{array}$ & $=$ & $\begin{array}{l}\text { 21. No. of Pages } \\
80\end{array}$ \\
\hline 20. Security Class (This Page) & & 22. Price \\
\hline
\end{tabular}




\section{DOCUMENT LIBRARY}

August 21, 1987

\section{Distribution List for Technical Report Exchange}

Attn: Stella Sanchez-Wade

Documents Section

Scripps Institution of Oceanography

Library, Mail Code C-075C

La Jolla, CA 92093

Hancock Library of Biology \& Oceanography

Alan Hancock Laboratory

University of Southern California

University Park

Los Angelos, CA 90089-0371

Gifts \& Exchanges

Library

Bedford Institute of Oceanography

P.O. Box 1006

Dartmouth, NS, B2Y 4A2, CANADA

Office of the International Ice Patrol

c/o Coast Guard R \& D Center

Avery Point

Groton, CT 06340

Library

Physical Oceanographic Laboratory

Nova University

8000 N. Ocean Drive

Dania, FL 33304

NOAA/EDIS Miami Library Center 4301 Rickenbacker Causeway

Miami, FL 33149

Library

Skidaway Institute of Oceanography

P.O. Box 13687

Savannah, GA 31416

Institute of Geophysics

University of Hawaii

Library Room 252

2525 Correa Road

Honolulu, HI 96822

Library

Chesapeake Bay Institute

4800 Atwell Road

Shady Side, MD 20876

MIT Libraries

Serial Journal Room 14E-210

Cambridge, MA 02139
Director, Ralph M. Parsons Laboratory

Room 48-311

MIT

Cambridge, MA 02139

Marine Resources Information Center

Building E38-320

MIT

Cambridge, MA 02139

Library

Lamont-Doherty Geological Observatory

Colombia University

Palisades, NY 10964

Library

Serials Department

Oregon State University

Corvallis, OR 97331

Pell Marine Science Library

University of Rhode Island

Narragansett Bay Campus

Narragansett, RI 02882

Working Collection

Texas A\&M University

Dept. of Oceanography

College Station, TX 77843

Library

Virginia Institute of Marine Science

Gloucester Point, VA 23062

Fisheries-Oceanography Library

151 Oceanography Teaching Bldg.

University of Washington

Seattle, WA 98195

Library

R.S.M.A.S.

University of Miami

4600 Rickenbacker Causeway

Miami, FL 33149

Maury Oceanographic Library

Naval Oceanographic Office

Bay St. Louis

NSTL, MS 39522-5001 
